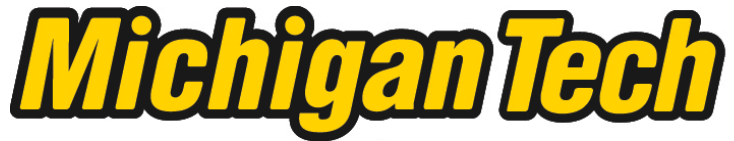 \\ Michigan Technological University Create the Future Digital Commons @ Michigan Tech
}

2014

\section{MORPHOLOGY AND MIXING STATE OF ATMOSPHERIC PARTICLES: LINKS TO OPTICAL PROPERTIES AND CLOUD PROCESSING}

Swarup China

Michigan Technological University

Follow this and additional works at: https://digitalcommons.mtu.edu/etds

Part of the Atmospheric Sciences Commons, and the Civil and Environmental Engineering Commons Copyright 2014 Swarup China

\section{Recommended Citation}

China, Swarup, "MORPHOLOGY AND MIXING STATE OF ATMOSPHERIC PARTICLES: LINKS TO OPTICAL PROPERTIES AND CLOUD PROCESSING", Dissertation, Michigan Technological University, 2014.

https://doi.org/10.37099/mtu.dc.etds/791

Follow this and additional works at: https://digitalcommons.mtu.edu/etds

Part of the Atmospheric Sciences Commons, and the Civil and Environmental Engineering Commons 


\title{
MORPHOLOGY AND MIXING STATE OF ATMOSPHERIC PARTICLES: LINKS TO OPTICAL PROPERTIES AND CLOUD PROCESSING
}

\author{
By \\ Swarup China
}

\begin{abstract}
A DISSERTATION
Submitted in partial fulfillment of the requirements for the degree of DOCTOR OF PHILOSOPHY

In Atmospheric Sciences
\end{abstract}

MICHIGAN TECHNOLOGICAL UNIVERSITY

2014

(C) 2014 Swarup China 
This dissertation has been approved in partial fulfillment of the requirements for the Degree of DOCTOR OF PHILOSOPHY in Atmospheric Sciences.

Department of Physics

Dissertation Advisor: Dr. Claudio Mazzoleni

Committee Member: Dr. Will Cantrell

Committee Member: Dr. Raymond Shaw

Committee Member: $\quad$ Dr. Alex Mayer

Department Chair: Dr. Ravi Pandey 
to my Choto Didi,

with love 


\section{Table of Contents}

List of Figures .............................................................................................................................. viii

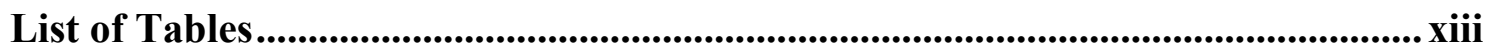

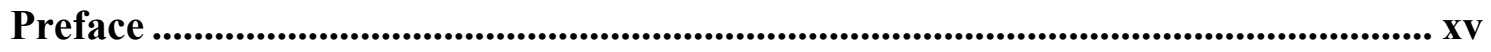

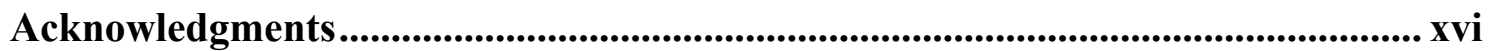

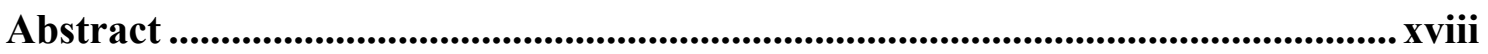

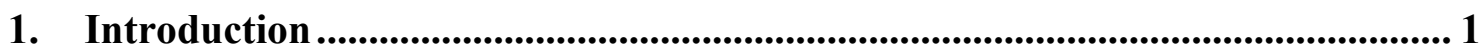

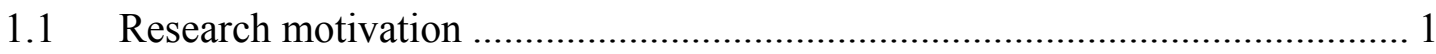

1.1.1 Effect of morphology and mixing state on optical properties ..................... 2

1.1.2 Effect of morphology and mixing state on microphysical process ............ 4

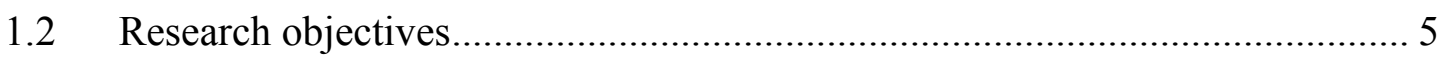

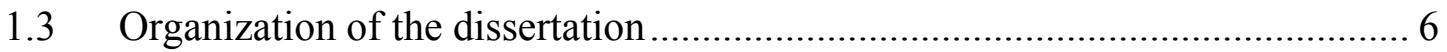

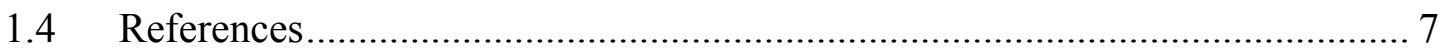

2. Morphology of Freshly Emitted Soot Particles ....................................................... 12

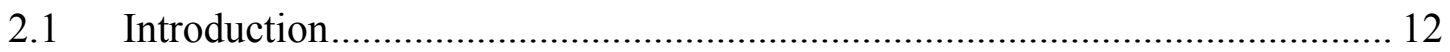

2.2 Experimental section and methods ……………...................................... 15

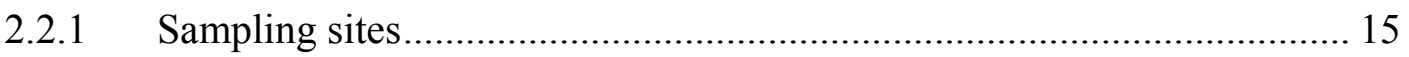

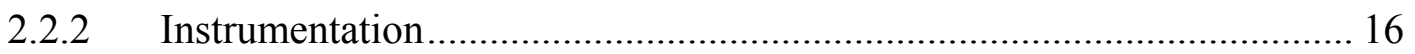

2.2.3 Particle Types and Classification ............................................................ 17

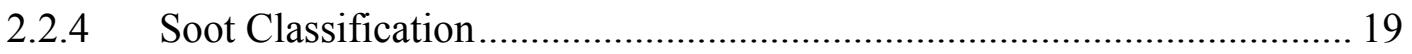

2.2.5 Area Equivalent Diameter and Shape Descriptors .................................. 19

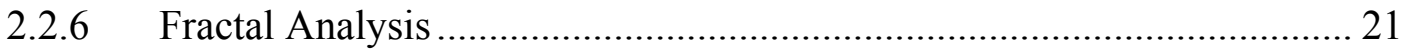

2.2.7 Vehicle Specific Power ......................................................................... 24

2.3 Results and discussions.......................................................................... 25

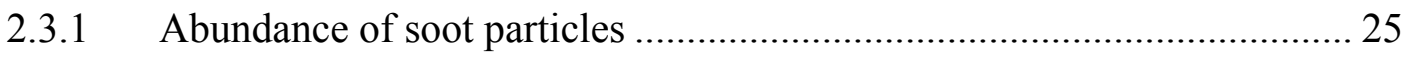




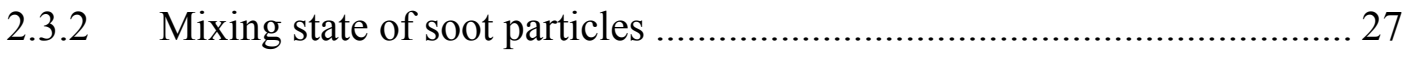

2.3.3 Monomer size distribution of soot......................................................... 28

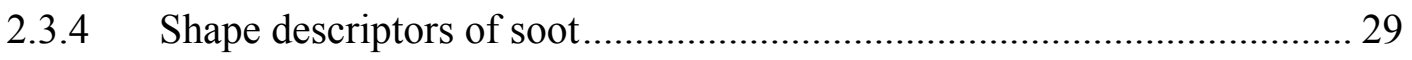

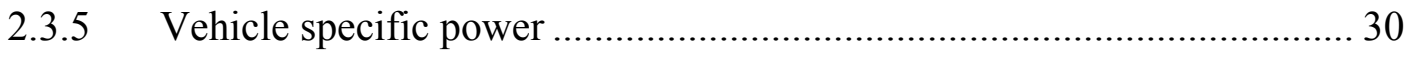

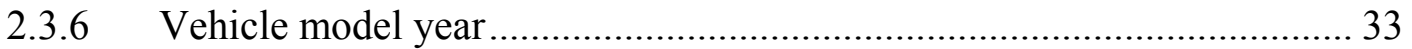

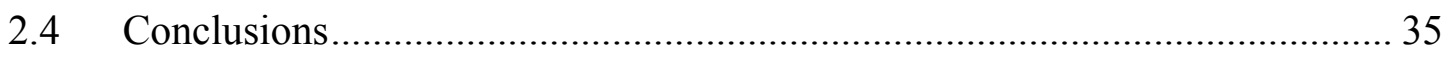

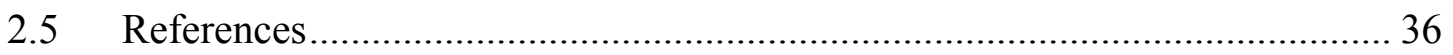

\section{Morphology and Mixing State of Freshly Emitted Wildfire Carbonaceous}

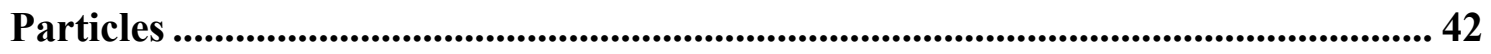

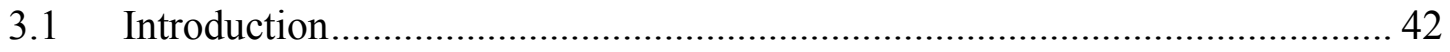

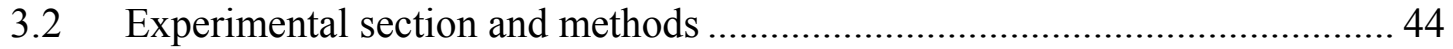

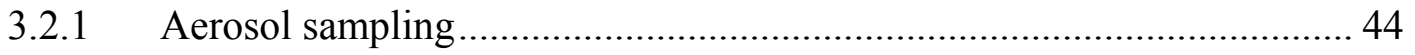

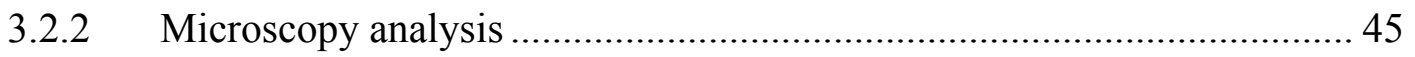

3.2.3 Fractal dimension analysis of soot particles ...................................... 46

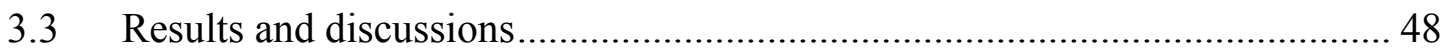

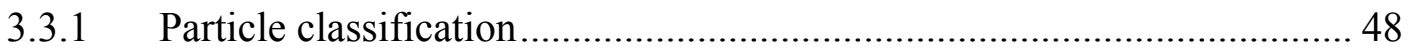

3.3.2 Identification of two kinds of TBs....................................................... 49

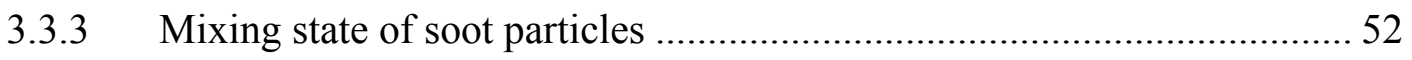

3.3.4 Morphology of ambient and denuded soot particles ........................... 53

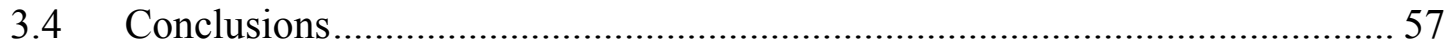

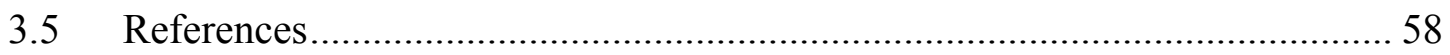

4. Evolution of Soot Morphology and Mixing State in the Atmosphere .............. 64

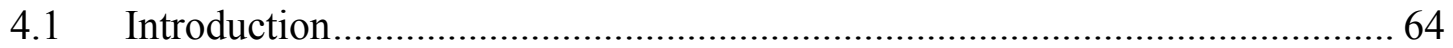

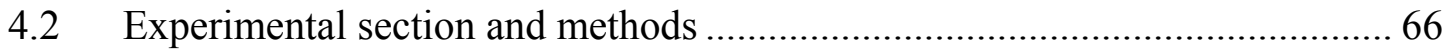

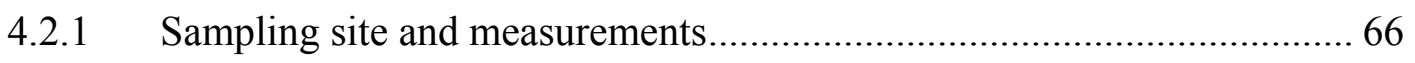

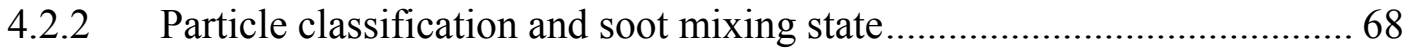

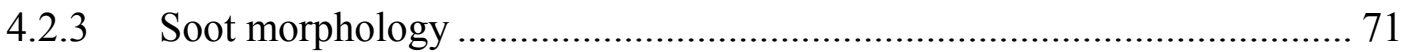

4.2.4 Optical properties of soot with different compaction............................ 72

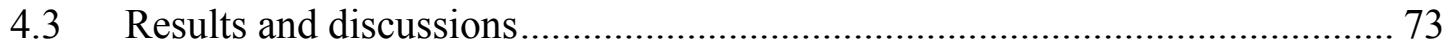


4.3.1 Abundance of soot particles ............................................................. 73

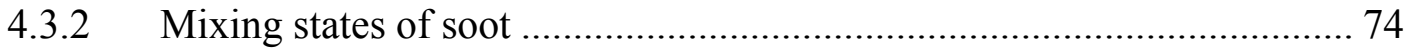

4.3.3 Morphology of soot particles........................................................... 75

4.3.4 Optical properties of soot particles.................................................. 79

4.3.5 Evolution of soot morphology and mixing state .................................. 83

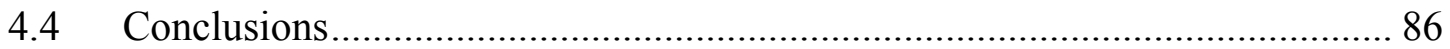

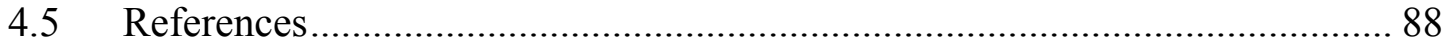

5. Morphology and Optical Properties of Soot Residuals from Supercooled

Droplets and Ice Crystals............................................................................. 94

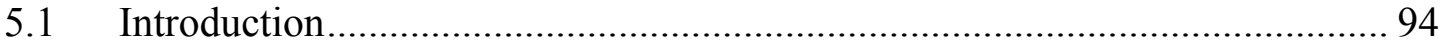

5.2 Experimental section and methods …................................................... 98

5.2.1 Soot generation and characterization................................................. 98

5.2.2 Morphological characterization ......................................................... 98

5.2.3 Supercooled droplet and ice residue collection ................................ 100

5.2.4 Simulation of optical properties ...................................................... 100

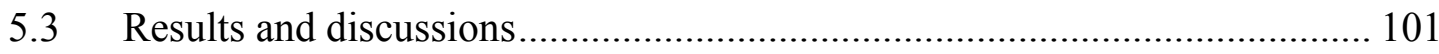

5.3.1 Morphology of residuals................................................................ 101

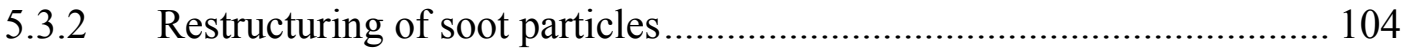

5.3.3 Optical properties of residuals ............................................................. 104

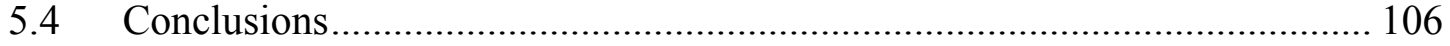

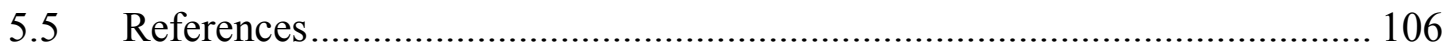

\section{Heterogeneous Ice Nucleation and Water Uptake by Free Tropospheric}

Particles ......................................................................................................................... 112

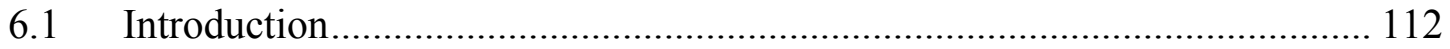

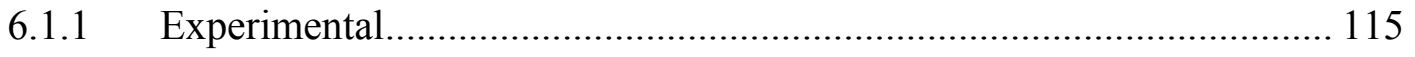

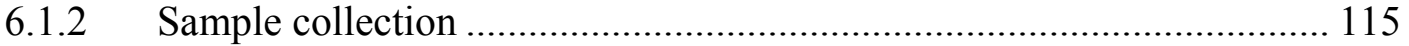

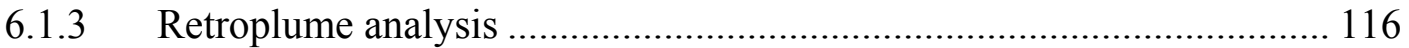

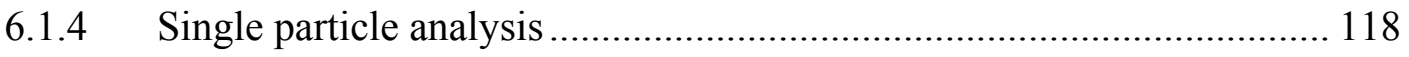

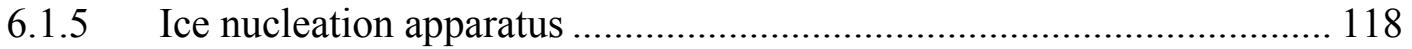


6.1.6 Ice nucleation and water uptake experiments .................................... 119

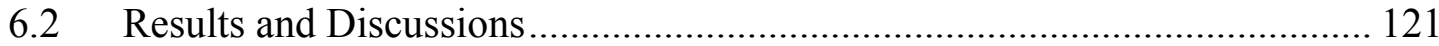

6.2.1 Particle concentrations................................................................... 121

6.2.2 Particle morphology and mixing state ............................................ 122

6.2.3 Onset conditions for deposition ice nucleation .................................. 125

6.2.4 Onset conditions for water uptake and immersion nucleation ............... 126

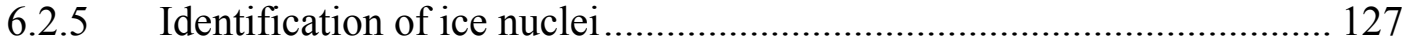

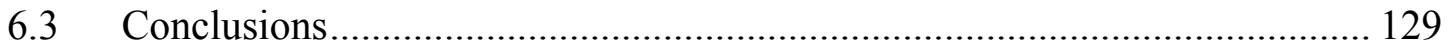

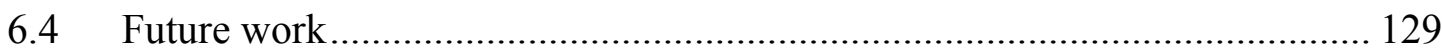

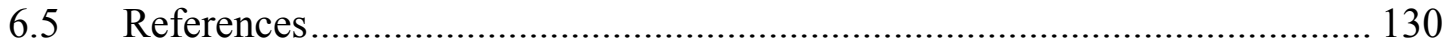

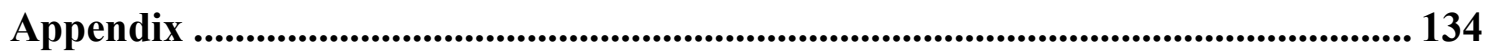

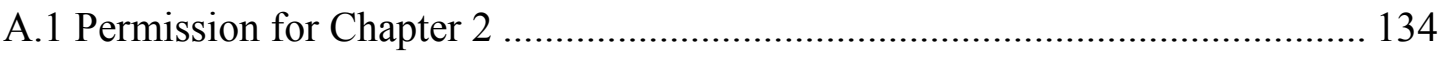

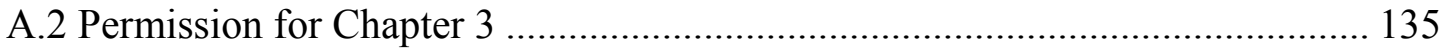




\section{List of Figures}

Figure 2-1: Location of the on-ramp measurement sites (red stars and numbers). The light purple areas in the map indicate the urban areas. Sites 1 and 2 are close to each other and at the edge of the Ann Arbor urban area. (Data courtesy, NOAANational weather service - AWIPS Shapefile Database).

Figure 2-2: Examples of different particle morphologies encountered in this study: a) Particles mixed with some fiber-like material possibly of biological nature. b) mineral dust; c) open-soot; d) collapsed soot; e) particle with multiple inclusions; f) coated soot. 18

Figure 2-3: Example of ensemble fractal dimension estimation for one specific sampling period (site\#4, 3:35 PM to 3:45 PM).

Figure 2-4: Left panel: Examples of different morphological categories of road-side aerosol particles: a) soot; b) irregularly-shaped particle; c) aggregate (nonfractal-like); d) spherical particle. Right panel: Linear regression between fraction of soot (in percent) and traffic density (in number of vehicles per minute) for two different days at site\#6 (grey bubbles) and site\#5 (black bubbles). Each bubble represents data determined from different times of the day. The bubble size represents the fraction (in percent) of HDVs with respect to the total. The open circles on the right side represent the size of the bubbles and the correspondent percentage of HDVs.

Figure 2-5: On the top panel, coating and mixing of soot particles: a) embedded (the residue of an evaporated coating is also visible); b) partly-coated; c) bare and d) soot inclusions. Bottom panel: average fractions of four categories of soot at 6 on-road sites

Figure 2-6: Correlations between different shape descriptors and area equivalent diameter. Average a) aspect ratio; b) circularity and c) roundness of an ensemble of soot particles, each point represents the average value for each filter sample 
collected (total 28 samples) at 6 sites. Each sampling site is represented by a different color. 30

Figure 2-7: Relation between fractal dimension $D_{f}$ and vehicle specific power (VSP) for all the soot particles characterized in this study and for different days and sampling sites. Sampling sites are color-coded and the size of the bubble represents the $\%$ of HDVs. 31

Figure 2-8: Relation between fractal dimension and vehicle age. Vehicle age is divided into three groups, 0-5 years, 5-10 years and older than 15 years. Fractal dimension is divided into five groups from 1.5 to 2.0 , with 0.1 increments...... 34

Figure 3-1: Identification of electronically dark and bright TBs (spherical particles). Field Emission Scanning Electron Microscopy (FE-SEM) micrographs of ambient particles collected from the Las Conchas fire. a) Image at low working distance $(3.4 \mathrm{~mm})$ and low accelerating voltage $(1 \mathrm{kV})$. b) Image of the same particles, but at higher working distance $(13 \mathrm{~mm})$ and higher accelerating voltage $(10 \mathrm{kV})$. Electronically bright and dark TBs are evident at the low accelerating voltage, but not at the high accelerating voltage. The scale bars equal $1 \mu \mathrm{m}$. 49

Figure 3-2: Distribution of gray scale intensities and grouping of "electronically" dark and bright TBs. 50

Figure 3-3: Atomic oxygen content in bright and dark TBs. 51

Figure 3-4: Size distribution of ambient and denuded bright and dark TBs. Size distribution and lognormal fits of: a) ambient particles (435 dark and 930 bright particles); b) denuded particles (415 dark and 1086 bright particles). The number of particles in each size bin is normalized by the bin width in logarithmic space and the mode of the distribution is normalized to one. The light gray lines represent bright TBs and the dark lines represent dark TBs. The difference between the count median diameter for ambient dark and denuded dark TBs is $33 \mathrm{~nm}(209-176 \mathrm{~nm})$; whereas the difference between ambient bright and 
denuded bright TBs is $61 \mathrm{~nm}(173-112 \mathrm{~nm})$. Dark TBs display smaller reduction in size on denuding, consistent with being more refractory. 51

Figure 3-5: Mixing and classification of soot particles. FE-SEM images of four different categories of soot particles: a) embedded, b) partly-coated, c) bare and d) with inclusions. Approximately $50 \%$ of the ambient soot particles are embedded, $34 \%$ are partly-coated and $12 \%$ have inclusions. Only $4 \%$ of the particles are bare soot (not coated or very thinly coated)....................................................... 53

Figure 3-6: Fractal dimension of soot particles. Fractal dimension of ambient-1 (in black) and denuded-1 (in gray) soot particles. The fractal dimension of ambient and denuded soot are $1.85 \pm 0.05(\mathrm{n}=176)$ and $1.53 \pm 0.07(\mathrm{n}=209)$, respectively. Standard errors were calculated from the uncertainty in the mean-square fit considering the uncertainty in $N$ and $d_{\mathrm{p}}$. The insets provide example of ambient1 and denuded-1 soot particles. The scale bars equal $500 \mathrm{~nm}$............................ 55

Figure 4-1: FLEXPART Retroplumes. Left panels ( $a$ and $b$ ) show the transport pattern for event-1, July (06-07), 2012 and right panels for event-2, July (20-21), 2012. Left panels (a and c) show the column-integrated horizontal transport from all height levels while right panels b) and d) show the vertical distribution of transport

Figure 4-2: a) soot b) spherical c) near spherical d) dust and e-i) and e-ii) other irregularly shaped particles. 69

Figure 4-3: Four major types of soot particle mixing states: a) embedded; b) partly coated; c) thinly coated; and d) soot inclusion.

Figure 4-4: The synthetic particles represent fresh, medium-aged and very-aged soot from left to right. 72

Figure 4-5: Left SEM images (a-f) show typical morphologies of soot particles observed at PMO. Right panel g) shows the fraction of thinly coated, partly coated, embedded and inclusion soot for event-1 (July (06-07), 2012) and event-2 (July (20-21), 2012). 
Figure 4-6: Power relationship between projected area and maximum length for a) event-1 and b) event-2. This includes all three kinds of soot particles but

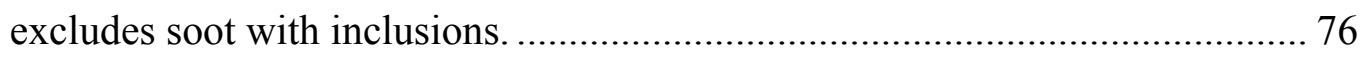

Figure 4-7: Size distribution of thinly coated, partly coated and embedded soot particles for a) event-1 July (06-07) and b) event-2 July (20-21).............................. 77

Figure 4-8: Histograms of roundnes for embedded, partly coated and bare soot particles

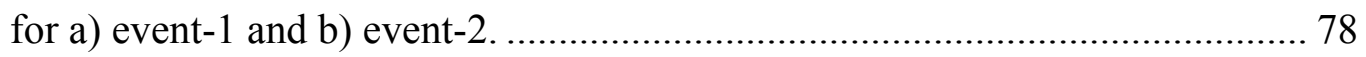

Figure 4-9: Convexity distribution for thinly coated (black), partly coated (light green) and embedded (dark green) soot particles for a) event-1 (July 06-07) and b) event-2 (July 20-July 21).

Figure 4-10: Normalized absorption and scattering cross-sections, single scattering albedo (SSA), and, asymmetry parameter $(g)$ as functions of wavelength for two cases of number of monomers $(N=66$ and $N=150)$. We use the cross sections, SSA and $g$ of fresh soot as normalizing values. 82

Figure 4-11: Mixing state of soot particles collected at different locations and environmental conditions. Number below location represents total number of particles used for analysis 85

Figure 4-12: Distribution of convexity of soot particles. Number in the plot represents the mean convexity 86

Figure 5-1: Size distribution of nascent soot particles from scanning mobility particle sizer (TSI, 3936) sampled from PNNL chamber. 98

Figure 5-2: The synthetic soot particles used in the simulation, representing open fractal-like nascent soot, soot from supercooled droplet residual and ice crystal residual from left to right 101

Figure 5-3: TEM images of nascent soot (left panel), supercooled droplet (SCD) residuals (middle panel) and ice crystal (IC) residuals (right panel)............... 102

Figure 5-4: Aspect ratio (left panel), roundness (middle panel) and convexity (right panel) of nascent soot, soot from supercooled droplet (SCD) and ice crystal (IC) 
residuals. Number of particles analyzed for nascent soot, supercooled and ice crystal residuals were 226, 208 and 241 respectively. 103

Figure 5-5: Two-dimensional fractal dimension for nascent soot (left panel), supercooled (middle panel) droplet and ice crystal residuals (right panel)...... 103

Figure 5-6: Normalized absorption and scattering cross-sections, and single scattering albedo (SSA). Optical cross-sections and SSA for supercooled droplet (SCD) and ice crystal (IC) soot residuals were normalized by the values obtained for nascent soot. 105

Figure 6-1: Retroplumes from FLEXPART for the time periods of collection of the four samples discussed in this paper.

Figure 6-2: Particle concentrations from a 2-channel $(0.3-5 \mu \mathrm{m} ; 0.4-5 \mu \mathrm{m})$ optical particle counter.

Figure 6-3: Typical SEM images of the four samples

Figure 6-4: TEM images of S3. a) mineral dust coated with organic material b) organic particle c) soot coated with organic material and d) sulfate particle trapped inside organic particle. 124

Figure 6-5: Mean onset conditions for ice nucleation via deposition mode (Dep.Mode), immersion mode (Imm.mode) and water uptake (WU). Total 54 ice nucleation events (25 deposition mode and 29 in immersion mode). Error bars are the standard deviation of the observed $\mathrm{RH}_{\text {ice }}$ or experimental uncertainties, whichever is larger. (Note that WU for S1 at $238 \mathrm{~K}$ is not available).............. 126

Figure 6-6: Examples of identified ice nuclei from S2 sample. The asterisk (*) indicates particles that nucleated more than once. 128

Figure 6-7: Examples of identified ice nuclei from S4 sample. The asterisk (*) indicates particles that nucleated more than once.... 


\section{List of Tables}

Table 2-1: List of the sampling sites surveyed during this study 15

Table 2-2: Mean values \pm one standard deviation for the meteorological parameters at the different sampling sites

Table 3-1: Sensitivity analysis of the effect of different input parameters on number of monomers, fractal dimension and prefactor for soot particles.

Table 3-2: Morphological descriptors of soot particles 54

Table 4-1: Morphological parameters of thinly coated, partly coated and embedded soot particles for Event-1 (July 06-07, 2012). Numbers in the parenthesis represents standard deviation. 76

Table 4-2: Morphological parameters of thinly coated, partly coated and embedded soot particles for Event-2 (July 20-21, 2012). Numbers in the parenthesis represents standard deviation.

Table 4-3: Morphological parameters of synthetic soot aggregates. $N$ is number of monomers. 80

Table 5-1: Mean morphological descriptors of nascent soot, soot from supercooled droplet and ice crystal residuals.

Table 6-1: Sampling date, duration, plume age and mean particle concentrations (MPC) for two size-channels $\left(\mathrm{PM}_{0.3}\right.$ for particles between $0.3 \mu \mathrm{m}$ and $5 \mu \mathrm{m}$; and $\mathrm{PM}_{0.4}$ for particles between $0.4 \mu \mathrm{m}$ and $5 \mu \mathrm{m}$ ).

Table 6-2: Sample ID, number of single particles analyzed at the electron microscope $(n)$, mean area equivalent diameter $\left(D_{A e q}\right)$, mean particle number density $\left(N_{d}\right)$ on the substrate exposed during the ice nucleation experiments and total surface area of the particles $\left(N_{s}\right)$ available for ice nucleation. The numbers in parentheses represent the standard deviations for $D_{A e q}$ and $N_{d}$ and uncertainties for $N_{s}$ propagated from $D_{A e q}$ and $N_{d}$. 
Table 6-3: Organic carbon (OC), elemental carbon (EC) and estimated organic mass $(\mathrm{OM})$ from aerosol samples collceted over periods partially overlapping with the collection times of the samples used in the ice nucelation analysis.................. 123

Table 6-4: Pattern of ice nucleation for identified particles. In parenthesis is the number of nucleation events. P represents particle.................................................... 128 


\section{Preface}

Some of the content in this dissertation was published in peer reviewed journals. Chapter two is based on a paper published in the Journal of Environmental Science and Technology (China et al., 2014). Chapter three is based on a paper published in Nature Communications (China et al., 2013). I performed the data analysis and interpretation. Both papers were written by me with input from my advisor Dr. Claudio Mazzoleni and other co-authors. Permission to use the published materials was granted and the documentation of the permission is attached in Appendix. Major portion of chapter four is based on a manuscript that we plan to submit to the Journal of Geophysical Research Letters by summer of 2014. Chapter five is based on a manuscript that we plan to submit to Environmental Research Letters also by the end of summer of 2014. Chapter six is based on a manuscript that we plan to finalize and submit in fall of 2014. Chapter four, five and six will be revised based on suggestions and comments from co-authors. We sincerely thank our co-authors for their contributions. 


\section{Acknowledgments}

I would like to express my sincere gratitude to my research advisor Dr. Claudio Mazzoleni for his continuous support, guidance, and encouragements throughout my $\mathrm{PhD}$ research. I am grateful I had the chance to work with him. He offered invaluable advices and he has been always patient and willing to help. Special thanks to him for getting me involved in different projects and for building up a wide collaboration network that allowed me to be exposed to various studies and to interact with several researchers.

I would like to acknowledge Dr. Will Cantrell, Dr. Raymond Shaw and Dr. Alex Mayer for serving on my $\mathrm{PhD}$ dissertation committee and for their valuable inputs toward my research.

Special thanks to the National Aeronautics and Space Administration, Earth and Space Science Graduate Fellowship for the financial support. This work was also supported by the U.S. National Science Foundation and the U.S. Department of Energy's Atmospheric System Research and the Michigan Technological University Physics Department.

I owe my deepest gratitude to Mr. Owen in Applied Chemical and Morphological Analysis Laboratory in Materials Science Department for providing excellent training and support for electron microscopy work.

I would like to sincerely thank all our collaborators. Thanks to Dr. Barbara Scarnato for her immense help in optical properties modeling. Thanks to our collaborators at the Los Alamos National Laboratory, Dr. Manvendra Dubey, Kyle Gorkowski, Dr. Shang Liu and Dr. Allison Aiken for their support and specially for the aerosol sample collection. I feel very lucky to have been involved in the Pico research group, working with various researchers whom I deeply thank: Dr. Lynn Mazzoleni, Marian Ampadu, Dr. Katja Dzepina, Dr. Robert Owen and Bo Zhang. I owe my greatest gratitude to Dr. Daniel 
Knopf for giving me the opportunity to work in the Stony Brook University and Dr. Peter Alpert for providing excellent training for ice nucleation experiments. I am very thankful to them for their invaluable help and scientific discussion. I would also like to thank the research group at the Pacific Northwest National Laboratory and special thanks to Dr. Gourihar Kulkarni, Dr. Rahul Zaveri and Dr. John Shilling for their tremendous help. I am grateful to Dr. Gourihar Kulkarni for his suggestions and useful inputs on the ice crystal residual study. Last, but not least, I would like to thank Dr. Alexei Kiselev from the Karlsruhe Institute of Technology, Germany, for the opportunity of working with him in one summer.

I would like to thank all my fellow group members, Noopur Sharma, Janarjan Bhandari, Sumit Kumar and Kendra Wright, for their support and useful discussions.

I would like to specially mention personal support and care I received from Neila Salvadori. She has been always available to support me especially during difficult times.

Finally, very special thanks to my parents and my sisters. There are no words that can express their immense love and support. I would also like to thank my brother-in-law for his continuous encouragement and for always being there for me. 


\begin{abstract}
Atmospheric particles are ubiquitous in Earth's atmosphere and impact the environment and the climate while affecting human health and Earth's radiation balance, and degrading visibility. Atmospheric particles directly affect our planet's radiation budget by scattering and absorbing solar radiation, and indirectly by interacting with clouds. Single particle morphology (shape, size and internal structure) and mixing state (coating by organic and inorganic material) can significantly influence the particle optical properties as well as various microphysical processes, involving cloud-particle interactions and including heterogeneous ice nucleation and water uptake. Conversely, aerosol cloud processing can affect the morphology and mixing of the particles. For example, fresh soot has typically an open fractal-like structure, but aging and cloud processing can restructure soot into more compacted shapes, with different optical and ice nucleation properties.
\end{abstract}

During my graduate research, I used an array of electron microscopy and image analysis tools to study morphology and mixing state of a large number of individual particles collected during several field and laboratory studies. To this end, I investigated various types of particles such as tar balls (spherical carbonaceous particles emitted during biomass burning) and dust particles, but with a special emphasis on soot particles. In addition, I used the Stony Brook ice nucleation cell facility to investigate heterogeneous ice nucleation and water uptake by long-range transported particles collected at the Pico Mountain Observatory, in the Archipelago of the Azores. Finally, I used ice nucleation data from the SAAS (Soot Aerosol Aging Study) chamber study at the Pacific Northwest National Laboratory to understand the effects that ice nucleation and supercooled water processing has on the morphology of residual soot particles. Some highlights of our findings and implications are discussed next.

We found that the morphology of fresh soot emitted by vehicles depends on the driving conditions (i.e.; the vehicle specific power). Soot emitted by biomass burning is often Xviii 
heavily coated by other materials while processing of soot in urban environment exhibits complex mixing. We also found that long-range transported soot over the ocean after atmospheric processing is very compacted. In addition, our results suggest that freezing process can facilitate restructuring of soot and results into collapsed soot. Furthermore, numerical simulations showed strong influence on optical properties when fresh open fractal-like soot evolved to collapsed soot. Further investigation of longrange transported aged particles exhibits that they are efficient in water uptake and can induce ice nucleation in colder temperature.

Our results have implications for assessing the impact of the morphology and mixing state of soot particles on human health, environment and climate. Our findings can provide guidance to numerical models such as particle-resolved mixing state models to account for, and better understand, vehicular emissions and soot evolution since its emission to atmospheric processing in urban environment and finally in remote regions after long-range transport. Morphology and mixing state information can be used to model observational-constrained optical properties. The details of morphology and mixing state of soot particles are crucial to assess the accuracy of climate models in describing the contribution of soot radiative forcing and their direct and indirect climate effects. Finally, our observations of ice nucleation ability by aged particles show that nucleated particles are internally mixed and coated with several materials. 


\section{Introduction}

Particles suspended in the atmosphere (aerosol) impact the environment and the climate by affecting Earth's radiation balance, cloud formation, and heterogeneous chemistry. The morphology (shape, size and internal structure) and mixing state of individual atmospheric particles influence their optical properties as well as their interactions with clouds, and therefore their radiative forcing. This dissertation provides an overview of electron microscopy analysis of the morphology of a large number of particles collected in various geographical locations and atmospheric conditions, and discusses the implications that morphology and mixing state have on the particle optical ice nucleation properties.

\subsection{Research motivation}

Atmospheric aerosols have significant impact on human health. By penetrating deep into the lungs they cause respiratory and cardiovascular diseases (Brunekreef and Forsberg, 2005). Particles also impact the environment and the climate by affecting Earth's radiation balance, clouds properties and atmospheric chemistry (Finlayson-Pitts, 2000; Haywood and Ramaswamy, 1998); in addition, particles reduce visibility (Watson, 2002). The effects that particles have on human health, the clouds, the environment, the climate and the atmospheric visibility all depend on several parameters including morphology and their mixing states.

Different particle shapes are present in the atmosphere such as spherical (Barone and Zhu, 2008), chain-like or fractal-like aggregates (soot particles), irregularly shaped, barshaped (elongated rectangular) or fiber-like particles (Dye et al., 2000; Friedlander, 2000; Okada and Heintzenberg, 2003; Xiong and Friedlander, 2001). Particle shape influences the particle transport behavior, the deposition in the human respiratory system (Oberdörster, 2001) and the interaction with lung epithelial cells (Stearns et al., 2001). Aerosol morphology also significantly influences the optical properties of soot 
particles (Bond and Bergstrom, 2006) and mineral dust particles (Kalashnikova and Sokolik, 2004). The complex morphology of atmospheric aerosols with varying composition and mixing state makes it difficult to understand various microphysical processes in the atmosphere, including heterogeneous ice nucleation and water uptake by particles.

In this dissertation, we investigate tar balls (spherical carbonaceous particles emitted during the smoldering phase of biomass burning), dust particles and soot particles, but we place special emphasis on soot particles. Soot or nano-sphere soot ("ns-soot") (Buseck et al., 2014) or black carbon particles are ubiquitous in the atmosphere. Soot particles are generated during combustion process. Internal combustion engines, power plants, biomass burning (Friedlander, 2000; Kocbach et al., 2006) and domestic heating are the main sources of atmospheric soot particles (Horvath, 1993). The terms "soot" and "black carbon" have been used interchangeably in the literature and recently there have been renewed discussions about what the term "black carbon" really means (Buseck et al., 2014; Petzold et al., 2013). These discussions suggest that the use of the correct term critically depends on the measurement technique used to detect the particle or its properties. Soot is consisting of many spherical particles (or nano-spheres) with distinct internal structures of concentrically wrapped, graphene-like layers of carbon (Buseck et al., 2014). Black carbon particles are mostly composed of soot, but can also include other light-absorbing carbonaceous materials. We will use the term "soot" throughout this dissertation as it is one of the most appropriate terms for the main measurement technique that we used in our work, namely "single particle electron microscopy".

\subsubsection{Effect of morphology and mixing state on optical properties}

The morphology and mixing state of absorbing aerosol play an important role in determining the radiative properties of soot. While aging, soot particles can change morphology, oxidize and mix, and become coated by organic and inorganic materials. Coated soot particles (especially when coating is non-absorbing) can significantly 
enhance their light absorption and scattering coefficient. This absorption enhancement is defined as the ratio of the absorption coefficient for the coated (aged) to the uncoated (fresh) soot (Moffet and Prather, 2009). A recent study suggests that internal mixing of soot and organic carbon emitted from biomass burning might enhance absorption by up to $70 \%$ (Lack et al., 2012). However, from another recent study performed in urban environments in California, it appears that the aerosol absorption enhancement expected for mixed black carbon might have been overestimated in past modeling efforts (Cappa et al., 2012), at least in such environments.

Freshly emitted non-spherical soot particles can quickly (within a few hours) evolve due to photochemical processes and can mix with other material (Moffet and Prather, 2009). When soot particle mix with external material (host), soot can be located in off-center positions within the host materials. Knowledge of the position of soot within the host meterial is important to predict their absorption. For example, if the host is not concentric around the soot particle, then those mixed soot particles absorb sunlight less efficiently compared to particles with soot located at the center of the host material (Adachi et al., 2010). These studies suggest that soot morphology and their mixing are important to understand the absorption enhancement.

The fractal-like or chain-like morphology of soot particles also plays an important role in detemining their optical properties (Adachi et al., 2007; Scarnato et al., 2012). However, optical properties modeling and climate modelling studies typically assume soot as mass equivalent or volume equivalent spherical particles, completely ignoring the fractal nature of soot (Chakrabarty et al., 2007; Jacobson, 2012). More exact numerical simulations of the soot optical properties using discrete dipole approximation (Scarnato et al., 2012) and T-matrix (Liu et al., 2008) show that the morphology of soot particles significantly affect their scattering phase function (angular distribution of light intensity scattered by a particle at a given wavelength), and their scattering and absorption cross sections. The diameter of the monomers constituting the soot paticles 
and the refractive index of the balk material they are made of, also influence the soot optical properties.

\subsubsection{Effect of morphology and mixing state on microphysical process}

Aerosol particles influence the microphysical evolution of clouds by acting as cloud condensation nuclei (CCN). Particle can grow (hygroscopic growth) by uptaking water as relative humidity increases. Particles may turn into efficent CCN when are coated with layers of hygroscopic material. For example, bare dust particles are already good $\mathrm{CCN}$, but when they become coated by layers of hygroscopic sulfate, through cloud processing or aqueous phase chemistry, they became even more efficent CCN (Laskin et al., 2005). The large active surface area and the morphology of dust can affect their mixing with hygroscopic material thus affect the CCN activity. The fractal-like morphology of soot may provide active sites for adsorption and deposition of water and other chemical species, thus influences its hygroscopicity; furthermore, it can affect its ability to act as cloud conensation nuclei or ice nuclei (Popovicheva et al., 2008; Zhang et al., 2008).

Ice nuclei can affect the dynamical and microphysical structure of cloud by altering numbers and shapes of the ice crystals (Bailey and Hallett, 2002; Wendisch et al., 2007). Soot particles can act as ice nuclei and faciliate ice formation through heterogenous ice nucleation (Kärcher et al., 2007). An investigation of ice crystal residual particles from cirrus clouds showed that 11 to $25 \%$ of the residuals are composed of carbonaceous material, including soot and organic carbon (Twohy and Poellot, 2005). Soot containg ice crystals or supercooled droplets can undergo various cycles and can sublimate and evaporate in the atmosphere (Heymsfield et al., 2010). Upon sublimation of the host ice crystal, soot particles can fragment into small pieces, or it can aggregate into larger clusters (Kärcher et al., 2007). The morphology of those residual soot particles that remain after the sublimation of the host ice crystal is not well characterized. 


\subsection{Research objectives}

The objective of this dissertation is to understand the morphology of aerosol particles, in particular the morphology of soot and dust particles and their mixing with other material collected in different environments. The goal is that of understanding how the morphology and mixing state of particles influence its optical, water uptake and ice nucleation properties. Scanning electron and transmission electron microscopies along with Energy dispersive X-ray spectroscopy are used here to investigate the morphology and mixing state of individual particles. In particular, in this dissertation we will investigate the following:

a) The morphology of freshly emitted soot particles by vehicles near freeway on-ramps in Southern Michigan (2010), and effects of vehicle driving conditions on soot morphology.

b) The morphology and mixing states of freshly emitted biomass burning particles (Las Conchas wildfire, New Mexico, 2011)

c) The evolution of the morphology and mixing state of soot particles in different atmospheric conditions. At this aim, particles were collected in several geographical locations, including:

- In Mexico City: in the center of the city and in the uplifted boundary layer captured on the top of the Pico de Tres Padres Mountain on the north edge of the city during the MILAGRO (Megacity Initiative: Local and Global Research Observations) field campaign (2006).

- In the Sacramento urban area and the Sierra Nevada foothills in California during the CARES (Carbonaceous Aerosols and Radiative Effects Study) campaign (2010).

- In Detling, a village in UK, during the ClearfLo (Clean Air for London) campaign aimed at studying airmasses transported from London and affected by household biomass burning (2012). 
- The soot morphology in a remote region in the free troposphere, at Pico Mountain Observatory in the Azores, Portugal. The aim of the study is to better understand the aging of soot during its transport from the source to the station, over the Atlantic Ocean (2012).

d) The changes in soot morphology in supercooled droplets and ice crystal residuals after evaporation/sublimation and the effects on the soot optical properties. This was a laboratory study conducted at the Pacific Northwest National Laboratory (20132014).

e) Heterogeneous ice nucleation and water uptake on free tropospheric particles collected in the North Atlantic free troposphere at the Pico Mountain Observatory (2013).

\subsection{Organization of the dissertation}

In this section, I provide a brief description of the structure of the dissertation and organization of the chapters. Each chapter provides a brief introduction, experimental methods, results and discussion, and a conclusion section. Following is a list of chapters and a brief description of their contents:

Chapter two discusses the morphological properties of soot freshly emitted from vehicles at a road site. The samples were collected at six different cloverleaf freeway on-ramps in Southern Michigan. In this chapter we investigate the effect of on-road driving conditions on soot morphology and some possible influence of vehicle type and model year on soot morphology.

Chapter three focuses on the analysis of individual biomass burning particles from the Las Conchas fire (New Mexico, 2011). We discuss the coating and oxidation of tar balls and the morphological properties of soot particles and their mixing with other materials.

Chapter four discusses the evolution of soot morphology and the mixing of soot with other materials in different stages of the soot's "life" in the atmosphere. In particular, in this chapter, we focus on the morphology and mixing state of aged soot particles 
transported over long-ranges in the free-troposphere. The samples were collected at Pico Mountain Observatory, in the Azores Islands (Portugal), in the Northern Atlantic Ocean. We further examine the optical properties of aged soot particles through numerical simulations and compare them with those of less aged and fresh soot particles. This chapter provides a brief summary of the morphology and mixing states of soot particles collected from different geographical locations and environmental conditions and the implications on climate.

Chapter five delves into the morphological changes of soot particles when interacting with water at sub-freezing (supercooled) and freezing temperatures by investigating supercooled droplet residuals and ice crystal residuals in a laboratory study. This chapter also discusses the results obtained from numerical simulations of the optical properties of the soot residuals.

Chapter six discusses the results from laboratory experiments of heterogeneous ice nucleation and water uptake on long-range transported free-tropospheric particles collected at Pico Mountain Observatory. This chapter further discusses the morphological and elemental composition of the nucleated particles.

\subsection{References}

Adachi, Chung, S. H., Friedrich, H., and Buseck, P. R.: Fractal parameters of individual soot particles determined using electron tomography: Implications for optical properties, Journal of Geophysical Research-Atmospheres, 112, 2007.

Adachi, K., Chung, S. H., and Buseck, P. R.: Shapes of soot aerosol particles and implications for their effects on climate, J. Geophys. Res., 115, D15206, 2010.

Bailey, M. and Hallett, J.: Nucleation effects on the habit of vapour grown ice crystals from -18 to $-42^{\circ} \mathrm{C}$, Quarterly Journal of the Royal Meteorological Society, 128, 1461-1483, 2002.

Barone, T. L. and Zhu, Y.: The morphology of ultrafine particles on and near major freeways, Atmospheric Environment, 42, 6749-6758, 2008. 
Bond, T. C. and Bergstrom, R. W.: Light absorption by carbonaceous particles: An investigative review, Aerosol Science and Technology, 40, 27-67, 2006.

Brunekreef, B. and Forsberg, B.: Epidemiological evidence of effects of coarse airborne particles on health, European Respiratory Journal, 26, 309-318, 2005.

Buseck, P. R., Adachi, K., Gelencsér, A., Tompa, É., and Pósfai, M.: ns-Soot: A Material-Based Term for Strongly Light-Absorbing Carbonaceous Particles, Aerosol Science and Technology, doi: 10.1080/02786826.2014.919374, 2014. 00-00, 2014.

Cappa, C. D., Onasch, T. B., Massoli, P., Worsnop, D. R., Bates, T. S., Cross, E. S., Davidovits, P., Hakala, J., Hayden, K. L., Jobson, B. T., Kolesar, K. R., Lack, D. A., Lerner, B. M., Li, S. M., Mellon, D., Nuaaman, I., Olfert, J. S., Petaja, T., Quinn, P. K., Song, C., Subramanian, R., Williams, E. J., and Zaveri, R. A.: Radiative Absorption Enhancements Due to the Mixing State of Atmospheric Black Carbon, Science, 337, 1078-1081, 2012.

Chakrabarty, R. K., Moosmüller, H., Arnott, W. P., Garro, M. A., Slowik, J. G., Cross, E. S., Han, J. H., Davidovits, P., Onasch, T. B., and Worsnop, D. R.: Light scattering and absorption by fractal-like carbonaceous chain aggregates: Comparison of theories and experiment, Applied Optics, 46, 6990-7006, 2007.

Dye, A. L., Rhead, M. M., and Trier, C. J.: The quantitative morphology of roadside and background urban aerosol in Plymouth, UK, Atmospheric Environment, 34, 3139-3148, 2000.

Finlayson-Pitts, B. J. P., J. N: Chemistry of the upper and lower atmosphere: Theory, experiments, and applications, Academic Press, San Diego, CA, 2000.

Friedlander, S. K.: Smoke, Dust, and Haze Fundamentals of Aerosol Dynamics, Oxford University Press, New York, 2000.

Haywood, J. M. and Ramaswamy, V.: Global sensitivity studies of the direct radiative forcing due to anthropogenic sulfate and black carbon aerosols, J. Geophys. Res., 103, 6043-6058, 1998. 
Heymsfield, A., Baumgardner, D., DeMott, P., Forster, P., Gierens, K., and Kärcher, B.: Contrail Microphysics, Bulletin of the American Meteorological Society, 91, 465-472, 2010.

Horvath, H.: Atmospheric light-absorption - a review, Atmospheric Environment Part aGeneral Topics, 27, 293-317, 1993.

Jacobson, M. Z.: Investigating cloud absorption effects: Global absorption properties of black carbon, tar balls, and soil dust in clouds and aerosols, Journal of Geophysical Research, 117, D06205, 2012.

Kalashnikova, O. and Sokolik, I.: Modeling the radiative properties of nonspherical soil-derived mineral aerosols, Journal of Quantitative Spectroscopy and Radiative Transfer, 87, 137-166, 2004.

Kärcher, B., Möhler, O., DeMott, P. J., Pechtl, S., and Yu, F.: Insights into the role of soot aerosols in cirrus cloud formation, Atmospheric Chemistry and Physics, 7, 4203-4227, 2007.

Kocbach, A., Li, Y., Yttri, K., Cassee, F., Schwarze, P., and Namork, E.: Physicochemical characterisation of combustion particles from vehicle exhaust and residential wood smoke, Particle and Fibre Toxicology, 3, 1, 2006.

Lack, D. A., Langridge, J. M., Bahreini, R., Cappa, C. D., Middlebrook, A. M., and Schwarz, J. P.: Brown carbon and internal mixing in biomass burning particles, Proceedings of the National Academy of Sciences, doi: 10.1073/pnas.1206575109, 2012. 2012.

Laskin, A., Iedema, M. J., Ichkovich, A., Graber, E. R., Taraniuk, I., and Rudich, Y.: Direct observation of completely processed calcium carbonate dust particles, Faraday Discussions, 130, 453-468, 2005.

Liu, Mishchenko, M. I., and Arnott, W. P.: A study of radiative properties of fractal soot aggregates using the superposition T-matrix method, Journal of Quantitative Spectroscopy \& Radiative Transfer, 109, 2656-2663, 2008. 
Moffet, R. C. and Prather, K. A.: In-situ measurements of the mixing state and optical properties of soot with implications for radiative forcing estimates, Proceedings of the National Academy of Sciences, 106, 11872-11877, 2009.

Oberdörster, G.: Pulmonary effects of inhaled ultrafine particles, Int Arch Occup Environ Health, 74(1), 1-8, 2001.

Okada, K. and Heintzenberg, J.: Size distribution, state of mixture and morphology of urban aerosol particles at given electrical mobilities, Journal of Aerosol Science, 34, 1539-1553, 2003.

Petzold, A., Ogren, J., Fiebig, M., Laj, P., Li, S.-M., Baltensperger, U., Holzer-Popp, T., Kinne, S., Pappalardo, G., and Sugimoto, N.: Recommendations for the interpretation of" black carbon" measurements, Atmospheric Chemistry and Physics Discussions, 13, 9485-9517, 2013.

Popovicheva, O., Kireeva, E., Persiantseva, N., Khokhlova, T., Shonija, N., Tishkova, V., and Demirdjian, B.: Effect of soot on immersion freezing of water and possible atmospheric implications, Atmospheric Research, 90, 326-337, 2008.

Scarnato, B., Vahidinia, S., Richard, D. T., and Kirchstetter, T. W.: Effects of internal mixing and aggregate morphology on optical properties of black carbon using a discrete dipole approximation model, Atmos. Chem. Phys. Discuss., 12, 2640126434, 2012.

Stearns, R. C., Paulauskis, J. D., and Godleski, J. J.: Endocytosis of ultrafine particles by A549 cells, American Journal of Respiratory Cell and Molecular Biology, 24, 108-115, 2001.

Twohy, C. H. and Poellot, M. R.: Chemical characteristics of ice residual nuclei in anvil cirrus clouds: evidence for homogeneous and heterogeneous ice formation, Atmos. Chem. Phys., 5, 2289-2297, 2005.

Watson, J. G.: Visibility: Science and regulation, Journal of the Air \& Waste Management Association, 52, 628-713, 2002. 
Wendisch, M., Yang, P., and Pilewskie, P.: Effects of ice crystal habit on thermal infrared radiative properties and forcing of cirrus, Journal of Geophysical Research: Atmospheres, 112, D08201, 2007.

Xiong, C. and Friedlander, S. K.: Morphological properties of atmospheric aerosol aggregates, Proceedings of the National Academy of Sciences of the United States of America, 98, 11851-11856, 2001.

Zhang, R., Khalizov, A. F., Pagels, J., Zhang, D., Xue, H., and McMurry, P. H.: Variability in morphology, hygroscopicity, and optical properties of soot aerosols during atmospheric processing, Proceedings of the National Academy of Sciences, 105, 10291-10296, 2008. 


\section{Morphology of Freshly Emitted Soot Particles ${ }^{1}$}

Vehicles represent a major source of soot in urban environments. Knowledge of the morphology and mixing state of soot particles is fundamental to understand their potential health and climatic impacts. We investigate 5,738 single particles collected at six different cloverleaf freeway on-ramps in Southern Michigan, using 2D images from scanning electron microscopy. Of those, 3364 particles are soot. We present an analysis of the morphological and mixing properties of those soot particles. The relative abundance of soot particles shows a positive association with traffic density (number of vehicles per minute). A classification of the mixing state of freshly emitted soot particles shows that most of them are bare (or thinly coated) (72\%) and some are partlycoated $(22 \%)$. We find that the fractal dimension of soot particles (one of the most relevant morphological descriptors) varies from site to site, and increases with increasing vehicle specific power that represents the driving/engine load condition, and with increasing percentage of vehicles older than 15 years. Our results suggest that driving conditions, and vehicle age and type have significant influence on the morphology of soot particles.

\subsection{Introduction}

Traffic related pollution in urban areas can adversely affect human respiratory system and cause various diseases (Brauer et al., 2002; Heinrich and Wichmann, 2004). Carbonaceous soot aggregates (often also termed as black carbon) or ns-soot (nanosphere soot) (Adachi and Buseck, 2013; Buseck et al., 2012) consist of many spherical monomers ranging from 20 to $50 \mathrm{~nm}$ in diameter composed of graphite carbon, and coated with polycyclic aromatic compounds, hydrocarbons, lubricating oil, sulfate layers and/or inorganic materials (Adachi and Buseck, 2008; Adachi and

\footnotetext{
${ }^{1}$ Reprinted (adapted) with permission from Swarup China, Neila Salvadori and Claudio Mazzoleni, Environmental science and Technology, 2014, 48 (6), pp 3128-3135. Copyright (2014) American Chemical Society. See Appendix A.1 for documentation of permission to republish this material.
} 
Buseck, 2013; Kittelson, 1998; Sakurai et al., 2003; Schauer et al., 1999). Soot particles are ubiquitous in the atmosphere (Pusechel et al., 1992) and are generated during combustion processes such as in internal combustion engines, power plants, biomass burning (Friedlander, 2000; Kocbach et al., 2006) and domestic heating (Horvath, 1993). Vehicles are one of the major sources of soot in the atmosphere (Bond et al., 2004). In 2012 the International Agency for Research on Cancer (IARC) and the World Health Organization (WHO) classified diesel exhaust emissions as "carcinogenic to humans" (group 1) (Benbrahim-Tallaa et al., 2012). In addition, soot is an efficient light absorber and it has been suggested to be the second most important anthropogenic climate forcer with a total positive radiative forcing up to $1.1 \mathrm{~W} / \mathrm{m}^{2}$ with high uncertainty (Bond et al., 2013).

Chemical composition, size, mixing and morphology of soot particles determine their properties and their effects on the environment. For example, the mixing state and morphology of soot affect its light scattering and absorption cross sections due to the potential enhancement of these properties upon coating (Adachi and Buseck, 2013; Cappa et al., 2012) or their reduction upon soot aggregate restructuring. In addition, soot morphology can significantly affect their deposition in human respiratory system (Broday and Rosenzweig, 2011).

Due to scale invariance of soot particles, their morphology can be described using fractal formalism introducing Mandelbrot's concept of fractal dimension and following the scaling law (Mandelbrot, 1982):

$$
N=k_{g}\left(\frac{2 R_{g}}{d_{p}}\right)^{D_{f}}
$$

Where $N$ is the number of monomers per aggregate, $R_{g}$ is the radius of gyration, $d_{p}$ is the monomer diameter, $k_{g}$ is the fractal proportionality constant (also called fractal prefactor or structural coefficient), and $D_{f}$ is the mass fractal dimension. The radius of gyration is the root-mean-square distance from the center of each monomer to the 
aggregate center of mass. The prefactor is an important parameter as it is related to the cluster mass, atmospheric transport processing, and optical properties (Oh and Sorensen, 1997). The value of the prefactor $k_{g}$, represents the level of compactness, the smaller the prefactor value the lower the packing density for a given $D_{f}$.

Densely packed or compacted soot particles have higher $D_{f}$ than chain-like branched clusters or open soot structures (Liu et al., 2008). $D_{f}$ for a soot particle reflects its history and is controlled by the particle source, generating conditions, mixing, and aging processes (Adachi et al., 2007). For example, Dye et al. (2000) studied the morphology of urban roadside and background aerosol and observed various agglomerate particles having several morphologies with and without coating. They found a relatively higher fraction of agglomerate compared to non-agglomerate particles in roadside aerosol (94\%) with respect to background aerosol samples (89\%). The perimeter-based fractal dimension was significantly greater at the roadside than at the background site, especially for the $120-220 \mathrm{~nm}$ size range. The authors suggested that the differences between roadside and background aerosols were due to inclusion of particles from other sources and generation of new agglomerates away from the roadside under dilute atmospheric conditions. Similarly, Barone and Zhu (2008) studied changes in atmospheric particle morphology, with increasing distance from a roadside near two major Los Angeles freeways. They found that the fraction of agglomerates was greater near a freeway than $90 \mathrm{~m}$ downwind, while an opposite scenario was observed for multiple-inclusions type particles which contained smaller solid and/or liquid particles inside or on the edge. Collisions of particles increase the faction of multipleinclusions particle downwind from the freeway. The authors suggested that the decrease in the fraction of agglomerated particles away from the freeway was due to secondary aerosol formation.

In this study we report morphological properties of road-side soot particles collected on 28 filters at 6 different cloverleaf freeway on-ramps in Southern Michigan. We study the morphology of soot particles using 2D projected images from scanning electron 
microscopy (SEM) for various on-road driving situations. In this study we investigate single soot particle characteristics to address the following questions: (1) What is the prominent type of particles and how does the particle type relate to traffic density? (2) What are the mixing states of soot? (3) What is the effect of on-road driving conditions on soot morphology? (4) Does soot morphology correlate with vehicle type and model year?

\subsection{Experimental section and methods}

\subsubsection{Sampling sites}

On-road aerosol sampling was conducted in the Detroit-Ann Arbor geographical area, in Southern Michigan, in July-August 2010. The sites were all cloverleaf freeway onramps to allow for the passage of only one vehicle at the time. A total of 28 samples were analyzed from six sites in three different counties (Washtenaw, Oakland, Wayne) (Figure 2-1 and Table 2-1). Samples were collected for $\sim 10$ minutes.

Table 2-1: List of the sampling sites surveyed during this study.

\begin{tabular}{ccccccc}
\hline Site & County & $\begin{array}{c}\text { Lat } \\
(\text { degree })\end{array}$ & $\begin{array}{c}\text { Long } \\
(\text { degree })\end{array}$ & Ramp & $\begin{array}{c}\text { Elev } \\
(\mathrm{m})\end{array}$ & $\begin{array}{c}\text { Slope } \\
(\%)\end{array}$ \\
\hline \hline 1 & Washtenaw & 42.224 & -83.685 & $\begin{array}{c}\text { EB I 94 to NB } \\
\text { US 23 }\end{array}$ & 270 & 1.10 \\
\hline 2 & Washtenaw & 42.227 & -83.686 & $\begin{array}{c}\text { WB I 94 to SB } \\
\text { US 23 }\end{array}$ & 260 & 0.40 \\
\hline 3 & Oakland & 42.495 & -83.446 & $\begin{array}{c}\text { EB 12 Mile Rd to } \\
\text { NB M 5 }\end{array}$ & 263 & 1.45 \\
\hline 4 & Wayne & 42.279 & -83.441 & $\begin{array}{c}\text { EB US 12 to NB } \\
\text { I 275 }\end{array}$ & 213 & 1.80 \\
\hline 5 & Oakland & 42.497 & -83.447 & $\begin{array}{c}\text { WB 12 Mile Rd } \\
\text { to SB M 5 }\end{array}$ & 284 & 1.15 \\
\hline 6 & Oakland & 42.517 & -83.617 & $\begin{array}{c}\text { SB Milford Rd to } \\
\text { EB I 96 }\end{array}$ & 302 & 0.79 \\
\hline
\end{tabular}

EB - East Bound, NB - North Bound, WB - West Bound, SB - South Bound 


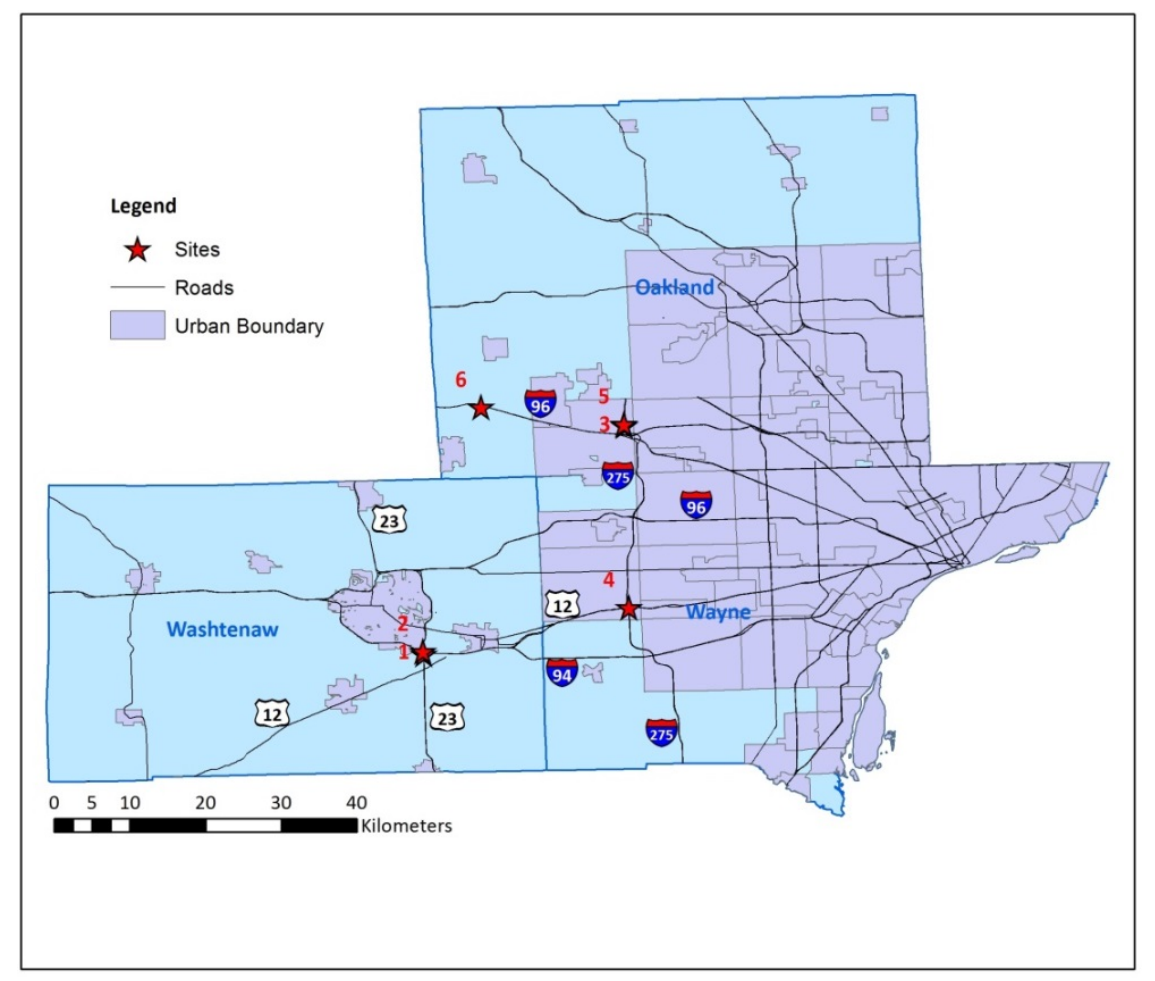

Figure 2-1: Location of the on-ramp measurement sites (red stars and numbers). The light purple areas in the map indicate the urban areas. Sites 1 and 2 are close to each other and at the edge of the Ann Arbor urban area. (Data courtesy, NOAA-National weather service - AWIPS Shapefile Database).

\subsubsection{Instrumentation}

Aerosol samples were collected on nuclepore polycarbonate filters (100 nm pore size) using a custom-made sequential sampler (China et al., 2013; Zaveri, 2012) using filtration technique (Chakrabarty et al., 2006). A field emission scanning electron microscope (FE-SEM) (Hitachi S-4700) was used for imaging. Two video cameras were used to capture the rear license plate of each vehicle passing by the sampling setup for license plate transcription. License plates were transcribed manually from the images and randomly crosschecked by other operators. The license plate database was matched with the Vehicle Identification Number (VIN) database of the Michigan Department of Motor Vehicle (DMV) providing information on model year, manufacturer and country, body-style, vehicle type (MOBILE 6 classification) and fuel 
type. Vehicle speed and acceleration were measured using two diode lasers and two detectors at opposite sides of the road set up at about $10 \mathrm{~cm}$ above the road pavement. Wind speed, wind direction, relative humidity and temperature were measured using a wireless meteorological station (6162 Vantage Pro2 ${ }^{\mathrm{TM}}$ plus by Davis Instruments, CA).

Table 2-2: Mean values \pm one standard deviation for the meteorological parameters at the different sampling sites.

\begin{tabular}{cccc}
\hline Site & Wind speed $\left(\mathrm{ms}^{-1}\right)$ & Temperature $\left({ }^{\circ} \mathrm{C}\right)$ & Relative humidity (\%) \\
\hline \hline 1 & $2.0 \pm 1.4$ & $28.5 \pm 1.8$ & $56.3 \pm 6.8$ \\
\hline 2 & $1.0 \pm 0.6$ & $24.7 \pm 0.1$ & $76.0 \pm 1.0$ \\
\hline 3 & $1.5 \pm 1.5$ & $26.6 \pm 2.6$ & $64.7 \pm 12.2$ \\
\hline 4 & $1.6 \pm 0.5$ & $30.3 \pm 0.8$ & $65.4 \pm 6.3$ \\
\hline 5 & $2.1 \pm 0.9$ & $23.0 \pm 2.4$ & $59.4 \pm 9.5$ \\
\hline 6 & $0.8 \pm 0.5$ & $27.0 \pm 2.4$ & $52.0 \pm 10.2$ \\
\hline
\end{tabular}

\subsubsection{Particle Types and Classification}

Examples of different types of particles with various shapes found on the filters are shown in Figure 2-2. The most abundant are soot particles but we also found several smaller spherical particles. Typically, vehicle-generated nano-particles (diameter $<50$ $\mathrm{nm}$ ) are formed from volatile or semi-volatile compounds during the dilution and cooling of the exhaust and are primarily composed of unburned oil and sulfate (Kittelson, 1998; Sakurai et al., 2003). Other types of particles are also found such as, mineral dust, particles with multiple inclusions, and particles mixed with fibrous material, possibly of biological origin. Energy dispersive X-Ray spectroscopy (EDS) analysis is conducted on selected particles ( $\sim 10 \%$ of total particles) to study their elemental composition and is used to confirm that particles identified as soot are mainly composed of carbon and oxygen, while particles identified as mineral dust are mainly composed of aluminum and silicon. 
Each particle is visually classified within one of four main categories: 1) soot; 2) irregularly-shaped particles; 3) non-fractal-like aggregates and; 4) spherical particles (Figure 2-2). Particles consisting of aggregates of many spherical monomers and chainlike structures (open or closed) are classified as soot. Particles are categorized as irregularly-shaped when the particles have no defined shape and can be considered as a single particle (e.g.; dust particles). Particles are categorized as non-fractal-like aggregates if they are composed of more than one particle, but do not present a chainlike or fractal-like aspect. Particles with circular or close to circular, shape are classified as spherical. A caveat of the filtration sampling method using $100 \mathrm{~nm}$ pore size employed in our study is that particles smaller than the pore size are potentially not retained by the filter, biasing the analysis toward particles larger than $100 \mathrm{~nm}$. Our classification is therefore based on particles in the size range of $50 \mathrm{~nm}$ to $2500 \mathrm{~nm}$. In particular, most of the analysis presented in the following sections is based on soot typically larger than $100 \mathrm{~nm}$.

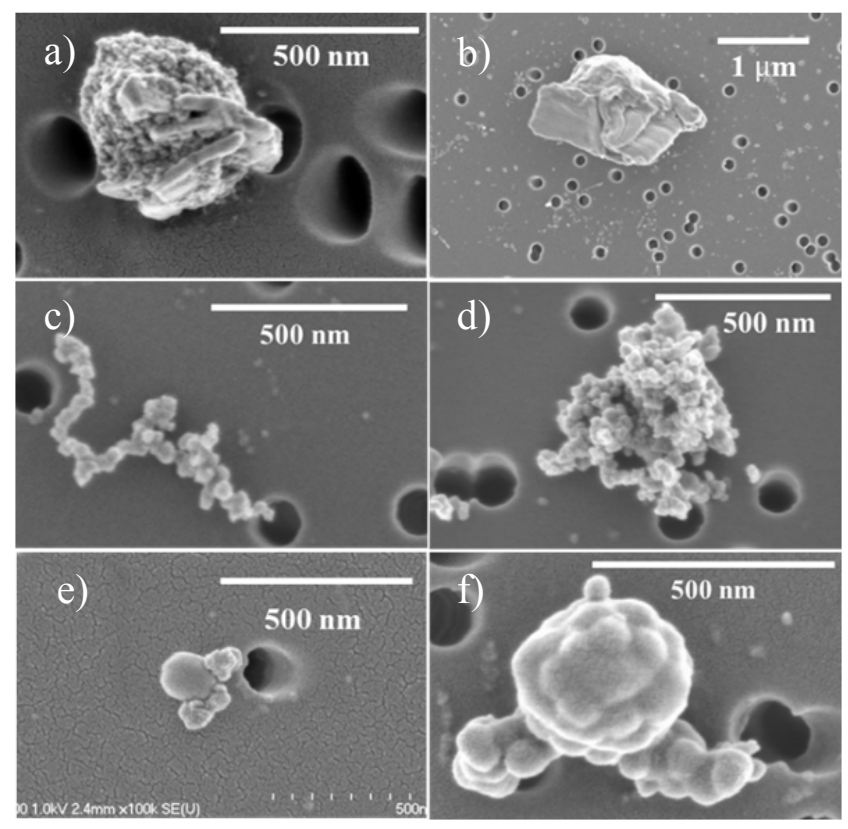

Figure 2-2: Examples of different particle morphologies encountered in this study: a) Particles mixed with some fiber-like material possibly of biological nature. b) mineral dust; c) open-soot; d) collapsed soot; e) particle with multiple inclusions; f) coated soot. 


\subsubsection{Soot Classification}

Soot particles are classified into four categories based on their morphology and visual coating, to understand their mixing state and degree of coating (China et al., 2013): 1) embedded soot (heavily coated), where the particle is completely engulfed with organic or inorganic material (Adachi and Buseck, 2008); 2) partly-coated, where voids in the soot structure are partially or completely filled by coating material, but the soot is not completely within the host particles; c) bare soot (no substantial coating or a thin layer of coating), where coating is not visible from the SEM images and voids between the monomers are not filled, 4) soot inclusions, where soot particles are mixed with other particles and are partially on the surface of the host particle. What we call soot inclusion

particles are similar to attached soot particles discussed by Adachi and Buseck (2008). However, we should caution about the limitations of SEM and two possible sources of bias: 1) the vacuum conditions in the SEM can result in some of the more volatile compounds to be lost 2) the fraction of embedded soot might be biased low because particle would not be classified as soot if the monomers are not visible.

\subsubsection{Area Equivalent Diameter and Shape Descriptors}

High magnification images (e.g., $\times 60 \mathrm{~K}$ to $\times 100 \mathrm{~K}$ ) are used to measure the morphological parameters discussed next. A critical limitation of 2-D imaging is that it can yield different surface area, size and shape of 3-D particles depending on their orientations (Adachi et al., 2007; Van Poppel et al., 2005). The length-scale for every image is calibrated carefully before processing. The FE-SEM magnification and scale is routinely calibrated by factory-trained technicians using a Geller Analytical MRS-4 calibration standard. Thresholds of gray scale for each particle are adjusted to convert the image into a binary image where black pixels represent the particle and white pixels represent the background. A Gaussian blur filter is used to remove the noise from the thresholded image. The parameters calculated from each image include: 1) maximum projected length $\left.\left(L_{\max }\right), 2\right)$ maximum width $\left.\left(W_{\max }\right), 3\right)$ area of monomers $\left(A_{p}\right)$ in 
aggregates, 4) total projected area $\left(A_{a}\right)$, and 5) perimeter of the particle $(P)$. The $L_{\max }$ is the distance between the two most separated points of the particle. The maximum width $\left(W_{\max }\right)$ is the maximum width perpendicular to the line of maximum length. $L_{\max }$ and $W_{\max }$ are independent from the orientation of the image. We measure $A_{a}, L_{\max }$, and $W_{\max }$ of a soot particle multiple times provides results less than $2 \%$ difference (from maximum to minimum). For the perimeter, the difference is around 4 to $6 \%$. However, we should highlight that differences in perimeter up to $40 \%$ for the same particle is recorded when the Gaussian blur filter is not applied. Gaussian blur filter is applied to process all the images. Average area of the monomers is calculated from individual aggregates by measuring 10-15 monomers on average in the aggregate depending upon the distinctness of the monomers in the two dimensional projected image.

The projected area equivalent diameter $\left(D_{A e q}\right)$ is defined as the diameter of a spherical particle of the same projected area (Baron and Willeke, 2001). The $D_{A e q}$ is calculated from eq 2 where $A_{a}$ is the projected area of the particle.

$$
D_{A e q}=\sqrt{\frac{4 A_{a}}{\pi}}
$$

A ratio of two particle size measurements is typically used for quantitative shape characterization. In our study we selected the following shape descriptors: a) aspect ratio, b) circularity, and c) roundness. The aspect ratio is defined as the ratio of the longest dimension $\left(L_{\max }\right)$ to the maximum orthogonal width $\left(W_{\max }\right)$ (equation 3). A related parameter, the elongation, is defined as $\left[1-(\text { Aspect ratio })^{-1}\right]$. Therefore, higher aspect ratio indicates higher elongation. The circularity (equation 4) is sensitive to boundary irregularities, as it depends on the perimeter $(P)$ of the particle whereas roundness is sensitive to $L_{\max }$. As an example, a circularity of 1 represents a perfect circle with no boundary roughness; a circle with "rugged" perimeter would have a lower circularity than a smooth circle, while the roundness would change just slightly. The roundness, as the aspect ratio, represents the elongation of the particle (equation 5). 


$$
\begin{aligned}
& \text { Aspect Ratio }=\frac{L_{\max }}{W_{\max }} \\
& \text { Circularity }=\frac{4 \pi A_{a}}{P^{2}} \\
& \text { Roundness }=\frac{4 A_{a}}{\pi L_{\max }{ }^{2}}
\end{aligned}
$$

\subsubsection{Fractal Analysis}

Fractal dimension of an agglomerate depends on the number of monomers $(N)$ and the radius of gyration $\left(R_{g}\right)$ of the agglomerate; both of these parameters are difficult to measure directly from two-dimensional images and different approximations and estimations are typically employed. Actual Estimation of $N$ of an actual three dimensional soot particle from 2-dimensional projected images is difficult and can introduce biases (Adachi et al., 2007). The value of $N$ in an aggregate is estimated from the projected area of the aggregate $\left(A_{a}\right)$ and the mean projected area of a monomer $\left(A_{p}\right)$ in the aggregate, as follows (Köylü et al., 1995; Oh and Sorensen, 1997; Samson et al., 1987)

$$
N=k_{a}\left(\frac{A_{a}}{A_{p}}\right)^{\alpha}
$$

Where $\alpha$ is an empirical projected area exponent and $k_{a}$ is a constant, normally approximated with a value close to one. The exact value of $\alpha$ and $k_{a}$ depends on the overlap parameter $(\delta)$ which is the ratio of the monomer diameter to the distance between two adjacent and touching monomers center points (e.g.; $\delta=1$ for point contact) (Oh and Sorensen, 1997). A correct estimation of the value of the number of monomers requires an estimated value of $\delta$ and an estimate of the range of $N$ before using the equation 6 (Oh and Sorensen, 1997). However, an accurate estimation of $\delta$ from projected images is difficult (Oh and Sorensen, 1997). The values of $\alpha$ and $k_{a}$ have been investigated by several researchers for flame generated soot using experimental and simulation studies (Cai et al., 1993; Köylü et al., 1995; Meakin, 1984b; Samson et al., 
1987). Meakin (1984b) showed that the value of $\alpha$ approached unity for large clusters using cluster-cluster aggregate simulations. Cai et al. (1993) used the value of $\alpha 1.09$ for $5<N<505$ to estimate the number of monomers and the same value of $\alpha$ is used by Megaridis and Dobbins (1990) for soot generated from an ethylene diffusion flame. Köylü et al. (1995) investigated the structure of soot particles generated from buoyant turbulent diffusion flames and also with computer simulations based on cluster-cluster aggregation. Both experiments and simulations showed a good agreement on the value of $\alpha$ (1.09) but the value of $k_{a}$ was relatively higher (1.15) than earlier estimates of 1.0 (Köylü et al., 1995). For $N=5$ to 580, Oh and Sorensen (Oh and Sorensen, 1997) found $k_{a}=1.17 \pm 0.02$ and $\alpha=1.07 \pm 0.01$ for $\delta=1$ and $k_{a}=1.81 \pm 0.03$ and $\alpha=1.19 \pm 0.01$ for $\delta=2$. While Chakrabarty et al. (2006) used values of $\alpha=1.20,1.14$ and 1.16 and values of $k_{a}$ $=1.50,1.30$ and 1.35 for a light duty passenger vehicle (Buick Century), and two light duty trucks (Chevrolet $\mathrm{C} 2$ and Chevrolet El Camino), respectively; the $N$ varies from 21000 in their study.

For our study, the aggregates have different degrees of overlap due to the mixture of different vehicles, fuels, engine loads, environmental conditions, particle aging etc. Therefore, we decided to estimate approximately the overlap parameter for individual aggregates. Average monomer diameter per particle and average distance between two adjacent and touching monomers center points are calculated from each SEM image of soot particles to estimate an approximate overlap parameter. The values of $\alpha$ and $k_{a}$ are estimated from the relation between $\alpha$ and $k_{a}$ with the overlap parameter provided by Oh and Sorensen (1997). The $\alpha$ and $k_{a}$ values increase with increasing overlaps between monomers. The values of $\alpha$ range from 1.090 to 1.145 and $k_{a}$ ranged from 1.150 to 1.625 in this study. However, sometimes it is difficult to estimate the overlap parameter from the images and a default value $\left(\alpha=1.09\right.$ and $\left.k_{a}=1.15\right)$ is used to estimate the number of monomers in such instances.

The radius of gyration $\left(R_{g}\right)$ is also required to determine the three dimensional fractal dimension. Estimation of the actual radius of gyration is complicated. Several simplified methods have been developed as surrogate for $R_{g}$. One approach is to use the 
maximum length of the aggregate as an approximation for $2 R_{g}$ into equation 1 as follows (Köylü et al., 1995; Samson et al., 1987)

$$
N=k_{L}\left(\frac{L_{\max }}{d_{p}}\right)^{D_{f}}
$$

Here the $D_{f}$ is the three dimensional fractal dimensions and $k_{L}$ is a proportionality constant. In our study the slope of the log-log power fit, which is the fractal dimension, is calculated by using the approximation in equation 7 and assuming that $L_{\max } / 2 R_{g}$ is constant with a value of $L_{\max } / 2 R_{\mathrm{g}}=1.50 \pm 0.05$ (Brasil et al., 1999). The proportionality constants $k_{g}$ and $k_{L}$ are then related to each other through the following relation:

$$
k_{g}=k_{L}\left(\frac{L_{\max }}{2 R_{g}}\right)^{D_{f}}
$$

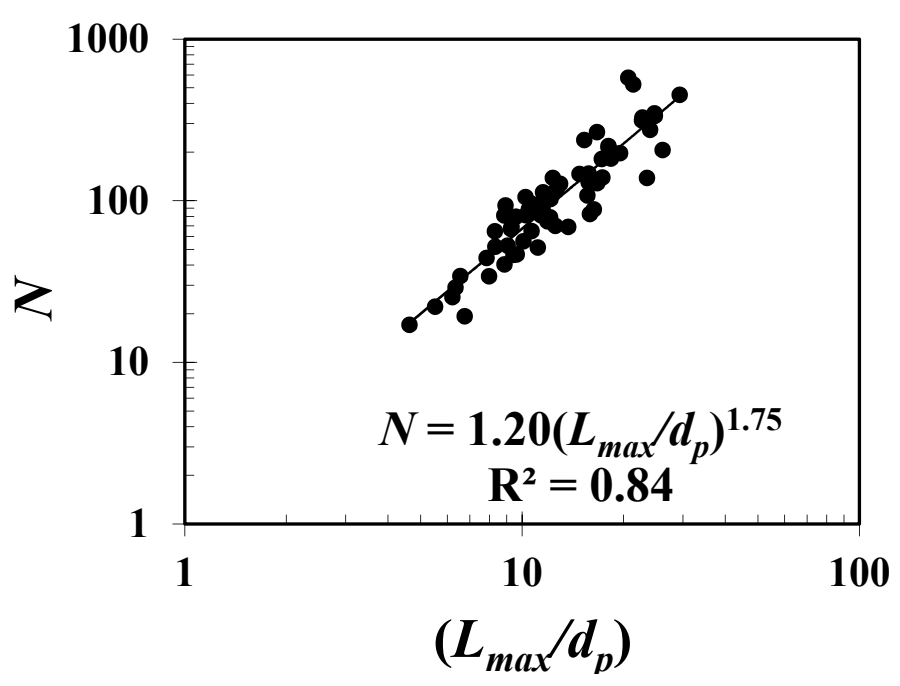

Figure 2-3: Example of ensemble fractal dimension estimation for one specific sampling period (site\#4, 3:35 PM to 3:45 PM).

In Figure 2-3 we show an example of fractal dimension calculation. Ensemble fractal dimension of soot particles are calculated for each samples (total 28 samples). The fractal dimension is 1.75 and the proportionality constant $\left(k_{g}\right)$ estimated from equation 9 
is found to be 2.44 for the example calculation showed in Figure 2-3. The proportionality constant, $k_{g}$, in this study ranged from 1.45 to 4.99 .

\subsubsection{Vehicle Specific Power}

The Vehicle Specific Power (VSP), represents the engine load conditions, and it is defined as the power required by the engine to operate the vehicle at a given speed and acceleration divided by the mass of the vehicle. The VSP (measured in $\mathrm{kW} / \mathrm{Mg}$ ) is estimated through the following formula (Jiménez-Palacios, 1999; Kuhns et al., 2004)

$$
V S P=\left(\frac{\text { Power }}{\text { Mass }}\right)=\left(\frac{P_{\text {Kinetic }}+P_{\text {Potential }}+P_{\text {Rolling }}+P_{\text {Internal Friction }}+P_{\text {Aerodynamic }}}{\text { Mass }}\right)
$$

Where, $P_{\text {Kinetic }}$ is the power needed to accelerate the vehicle at a specified velocity; $P_{\text {Potential }}$ is the power needed to overcome the gravitational force (on a sloped road); $P_{\text {Rolling }}$ is the power needed to overcome the vehicle friction with the road pavement; $P_{\text {Internal Friction }}$ is the power needed to overcome the vehicle internal friction; $P_{\text {Aerodynamic }}$ is the power needed to overcome the aerodynamic drag.

Jiménez-Palacios (1999) suggested that the formula can be developed into the following approximated expression that involves only parameters that are easily observable on the road such as speed, acceleration, wind and road grade

$$
\begin{aligned}
& V S P=v \cdot a\left(1+\varepsilon_{i}\right)+g \cdot \operatorname{grade} \cdot v+g \cdot C_{R} \cdot v+C_{i f} \cdot v+\frac{1}{2} \rho_{a} C_{D} \frac{A}{\text { Mass }}\left(v+v_{w}\right)^{2} \cdot v \\
& \approx 1.1 \cdot v \cdot a+9.81 \cdot \operatorname{grade} \cdot v+0.132 \cdot v+0.000305\left(v+v_{w}\right)^{2} \cdot v
\end{aligned}
$$

Where $v$ is the vehicle speed, $v_{w}$ is the headwind speed, $a$ is the acceleration, the grade is given in terms of rise/run, $\varepsilon_{i}$ is a unitless mass factor, $C_{R}$ is the coefficient of rolling resistance, $C_{D}$ is the coefficient of aerodynamic drag, $C_{i f}$ is the internal friction factor, $\rho_{a}$ is the density of air, $A$ is the frontal area and Mass is the mass of the vehicle (JiménezPalacios, 1999; Kuhns et al., 2004). We use equation 10 with the coefficients provided 
by Jiménez-Palacios (1999) to calculate the VSP and investigate the effect of driving conditions on particle morphology.

\subsection{Results and discussions}

\subsubsection{Abundance of soot particles}

We classify 5,738 individual particles to estimate the contribution of soot to the total number of particles collected on the filters. In Figure 2-4 we show the correlations between the fraction of soot particles and the traffic density (defined as the total number of vehicles per minute) for two different days, July 26 (grey bubbles) and July 29 (black bubbles) at site number 6 and 5, respectively. We selected July 26 and 29 because these two days had the maximum variation in traffic densities. Average fractions of irregularly-shaped particles, non-fractal-like aggregates and spherical particles were $14 \%, 13 \%$ and $3 \%$, respectively on July 26 and similarly $16 \%, 18 \%$ and $8 \%$ on July 29 . The size of the bubbles is proportional to the percentage of heavy-duty vehicles (HDVs). The slopes of linear regressions are similar for the two sites, but the intercept at site 6 is considerably higher; this might reflect different background concentrations of soot particles at the two sites. The intercept of the linear regression for July 26 is statistically significant $\left(p=3.5 \times 10^{-5}\right)$ but not for July 29 data $(p=0.03)$. Site 6 was on the on-ramp from South Bound Milford Road to East Bound on Interstate-96; background particles at this site might have been emitted from the intense traffic on the adjacent cloverleaf of West Bound Interstate-96 and transported to the sampling site. Additionally, there are large department stores and some automotive stores nearby implying possible higher surrounding traffic congestion. Whereas, site 5 was on the onramp from West Bound 12 Mile Road to South Bound M-5 with no near-by shopping centers or highly congested roads. However, the meteorological conditions and long range transport could also have played a role in affecting the background concentrations. Means and standard deviations of the meteorological parameters measured during the sampling period are summarized in Table 2-2. Wind speed was 
higher at site $5\left(2.1 \mathrm{~ms}^{-1}\right)$ than at site $12\left(0.8 \mathrm{~ms}^{-1}\right)$ and the dominant wind at site 6 was from south-west while at site 5 was from north-west and north-east.
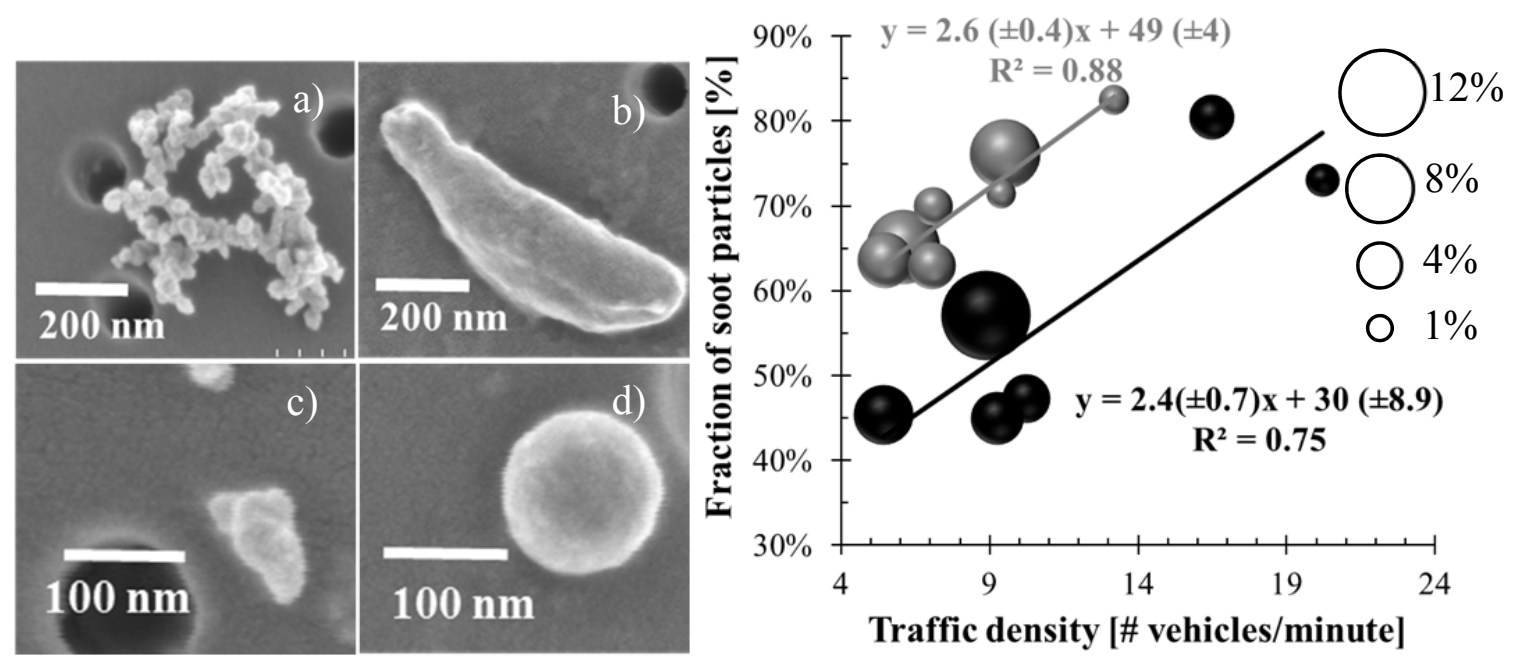

Figure 2-4: Left panel: Examples of different morphological categories of road-side aerosol particles: a) soot; b) irregularly-shaped particle; c) aggregate (non-fractal-like); d) spherical particle. Right panel: Linear regression between fraction of soot (in percent) and traffic density (in number of vehicles per minute) for two different days at site\#6 (grey bubbles) and site\#5 (black bubbles). Each bubble represents data determined from different times of the day. The bubble size represents the fraction (in percent) of HDVs with respect to the total. The open circles on the right side represent the size of the bubbles and the correspondent percentage of HDVs.

For the data of July 29 at site 6, points with higher percentage of HDVs lay above the least square regression line, which reflects the fact that HDVs that are typically dieselpowered might dominate the emissions of soot. This is also observed on July 26, although it is not as evident; possible reasons might be other confounding factors such as the different fraction of diesel vehicles from near-by traffic (which is unknown), different soot backgrounds, driving conditions, vehicle model years and/or meteorological conditions. 


\subsubsection{Mixing state of soot particles}

We classify 3,028 individual soot particles into four categories as discussed earlier. Figure 2-5 (a-d) shows the four categories a) embedded soot, b) partly-coated c) bare soot and d) soot with inclusions. Figure 2-5 (e) shows the distribution of the four categories of soot at the different sites. On average, bare soot particles are the most abundant ( $\sim 2 \%)$, followed by partly-coated $(\sim 22 \%)$ and soot inclusions $(\sim 5.5 \%)$ with a negligible fraction $(\sim 0.5 \%)$ of embedded soot.
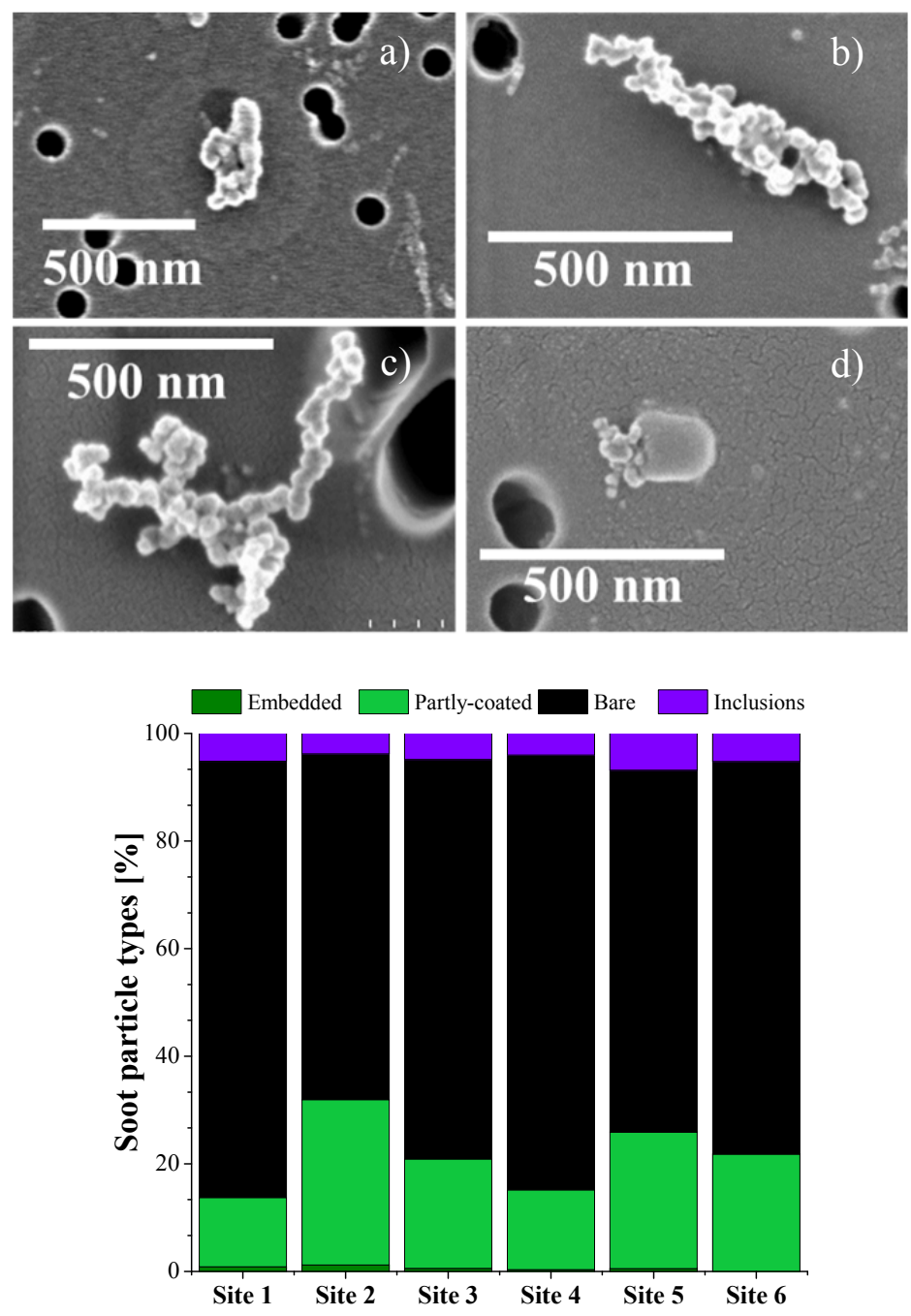

Figure 2-5: On the top panel, coating and mixing of soot particles: a) embedded (the residue of an evaporated coating is also visible); b) partly-coated; c) bare and d) soot inclusions. Bottom panel: average fractions of four categories of soot at 6 on-road sites. 
We find no significant correlation between mixing state of soot and fraction of HDVs or diesel vehicles for individual samples. On average, the highest fraction (31\%) of partlycoated soot is observed at site 2, which had the highest number of HDVs (19\%), suggesting that HDVs emissions might lead to larger coating on soot particles. However, the fraction of partly coated soot can include also particles transported from nearby freeways and from the surroundings.

\subsubsection{Monomer size distribution of soot}

The size of the soot monomers is an important parameter as the $D_{f}$ depends on the average monomer diameter $\left(d_{p}\right)$ for the aggregate as evident from equation 1 . For example, Wentzel et al. (2003) performed a Transmission Electron Microscopy (TEM) analysis and found an average $d_{p}$ of $22.6 \pm 6 \mathrm{~nm}$ for soot particles emitted from a diesel engine and a $D_{f}$ in the range of $1.70 \pm 0.13$. Whereas Chakrabarty et al. (2006) conducted an SEM analysis of particles emitted from spark ignition engines during a dynamometer study and found a bi-modal size distribution of $d_{p}$ (20-24 nm and 54-60 $\mathrm{nm}$ for the two modes, respectively) for more aggressive driving conditions. Adachi et al. (2007) conducted a TEM analysis of traffic samples in Arizona and found $d_{p}$ in the range of 26-44 $\mathrm{nm}$.

Distribution of $d_{p}$ can be influenced by engine load and speed, combustion temperature, and residence time. Zhu et al. (2005) investigated the $d_{p}$ distribution for a 1.7-L lightduty diesel engine at various engine conditions. They found that $d_{p}$ decreases with increasing exhaust temperature, proportionally to the combustion temperature in the cylinders. The authors suggested that particle oxidation at higher temperatures is mainly responsible for the decrease in $d_{p}$. They also found a broader size range $(10-60 \mathrm{~nm})$ at idling conditions $(19.4-32.5 \mathrm{~nm})$. We find broad as well as narrow $d_{p}$ distributions for individual aggregates; the mean $d_{p}$ for our samples ranges from 27 to $44 \mathrm{~nm}$. On average 10-15 monomers are measured per soot aggregate and 3364 individual soot particles are used to estimate the size distribution of monomers. The mode ranges from 
31 to $34 \mathrm{~nm}$ and the monomer distributions in most of the sites have more than one mode. However, we do not observe any clear association between $d_{p}$ and on-road driving conditions (i.e.; the vehicle specific power).

\subsubsection{Shape descriptors of soot}

Figure 2-6 depicts the correlation between aspect ratio, circularity and roundness with $D_{\text {Aeq. }}$. Vertical error bars represent the standard error of circularity, roundness and aspect ratio. Horizontal errors bars represent the standard error of the area equivalent diameter. The standard error is the standard deviation of the mean (i.e. the standard deviation divided by the square root of the total number of particles used for each point of the graphs). Aspect ratio decreases with $D_{A e q}$ up to $165 \mathrm{~nm}$ and increases with increasing $D_{A e q}$ after $165 \mathrm{~nm}$. Similarly, circularity and roundness first increase with $D_{A e q}$ up to about $165 \mathrm{~nm} D_{A e q}$, and then they visibly decrease with increasing $D_{A e q}$. A decreasing trend of roundness and increasing trend of aspect ratio with increasing $D_{A e q}$ as seen in the Figure 2-6, suggest that particles with higher $D_{A e q}$ are more elongated. The overall coefficients of determination $\left(R^{2}\right)$ are $0.26,0.42$ and 0.45 for aspect ratio, circularity and roundness respectively. The decreasing trends of circularity and roundness with increasing $D_{A e q}$ are in agreement with previous study (Chakrabarty et al., 2006). However, the correlation improves $\left(R^{2}=0.37,0.59\right.$ and 0.47 for aspect ratio, circularity and roundness, respectively) after the "break-point" (for particles larger than $165 \mathrm{~nm}$ for circularity, $150 \mathrm{~nm}$ for roundness and $175 \mathrm{~nm}$ for aspect ratio). This "break-point" can be attributed to different mechanisms of soot formation (Virtanen et al., 2004). Monomer cluster aggregation is dominant at the beginning of the coagulation process resulting in a compact cluster. Later the cluster can become more branched out when aggregation is led by cluster-cluster agglomeration. Smaller particles $(<100 \mathrm{~nm})$ can have compact cluster-like structures whereas larger particles $(\sim 200 \mathrm{~nm})$ can be more open as they might be formed during cluster-cluster agglomeration (Virtanen et al., 2004). 

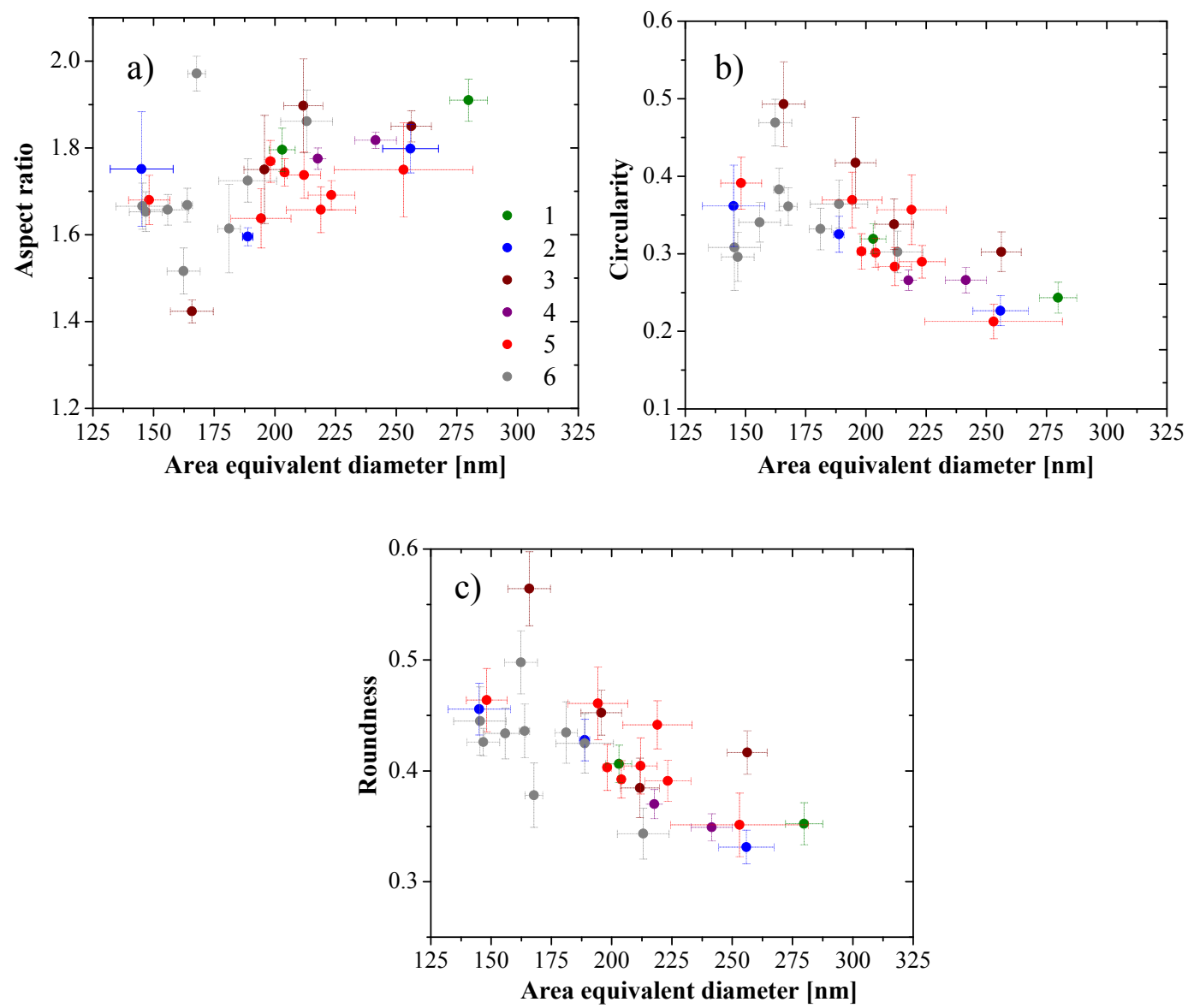

Figure 2-6: Correlations between different shape descriptors and area equivalent diameter. Average a) aspect ratio; b) circularity and c) roundness of an ensemble of soot particles, each point represents the average value for each filter sample collected (total 28 samples) at 6 sites. Each sampling site is represented by a different color.

\subsubsection{Vehicle specific power}

We use VSP as discussed earlier, as a surrogate for driving/engine load conditions to investigate the effect on soot morphology. Various previous studies have been conducted to test the effects of engine load and speed on the fractal dimension $\left(D_{f}\right)$ in laboratory settings and simulated on-road driving conditions. These studies suggest that $D_{f}$ decreases with increasing engine load (Virtanen et al., 2004). Fuel/air equivalence ratio is higher when engine load increases, and this condition favors soot monomers formation. Initially, a compact cluster is formed with high $D_{f}$ close to a value of 3 by a 
monomer-cluster aggregation process. Later, agglomeration is dominated by clustercluster agglomeration resulting in lower $D_{f}$ close to a value of 1.8-2 (Meakin, 1984a). Virtanen et al. (2004) found dense cluster-like structures for smaller particles $(<100 \mathrm{~nm})$ and more open structures for larger particles $(200 \mathrm{~nm})$. Also $D_{f}$ of diesel soot with diameters between 55 and $260 \mathrm{~nm}$, has been found to decrease with increasing engine load (Skillas et al., 1998); their studies suggest that at higher engine load cluster-cluster aggregation dominates over monomer-cluster aggregation processes.

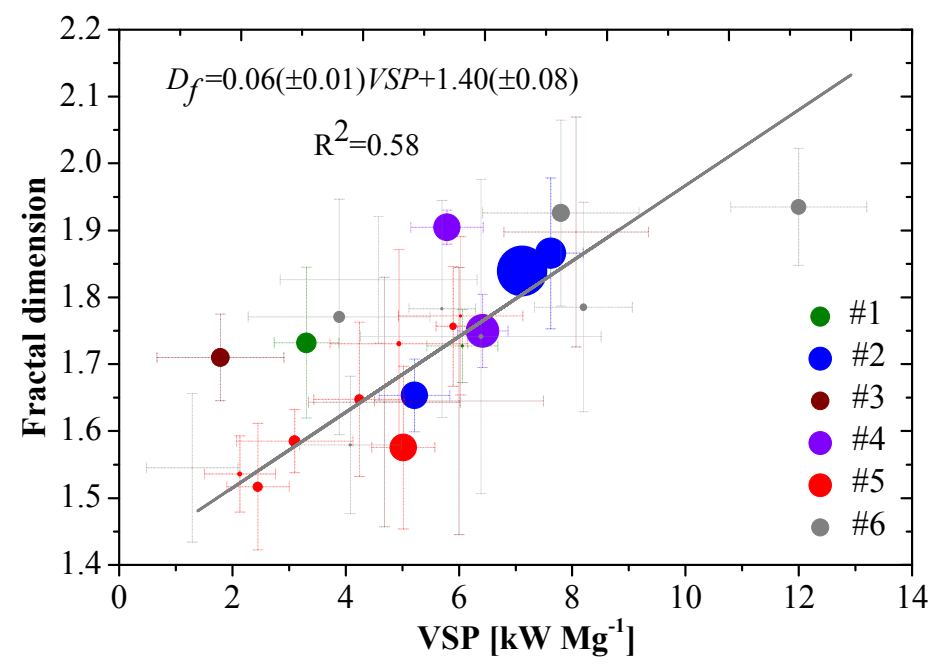

Figure 2-7: Relation between fractal dimension $D_{f}$ and vehicle specific power (VSP) for all the soot particles characterized in this study and for different days and sampling sites. Sampling sites are color-coded and the size of the bubble represents the $\%$ of HDVs.

In Figure 2-7 we plot the ensemble $D_{f}$ estimated from each sample versus the mean of the VSP data during the correspondent sampling period. The color of the points indicates different sites, while the size of the bubbles corresponds to the percentage of HDVs. The largest and smallest sizes of the bubbles correspond to $26 \%$ and $0 \%$ of HDVs, respectively. Horizontal error bars reflect the standard errors in VSP data and vertical error bars are the standard errors in the slope of the power fit of the log-log plots of the number of monomers versus $L_{\max } / d_{p}$. Ensemble $D_{f}$ significantly and positively correlates with VSP. The slope of the linear regression of $D_{f}$ vs. VSP is 
different for each day, but overall the $D_{f}$ increases with increasing $\operatorname{VSP}\left(\mathrm{R}^{2}=0.58\right.$, $\left.\mathrm{p}=2.8 \times 10^{-6}\right)$. Slope and intercept are calculated using a modified least squares linear regression fit as both $V S P$ and $D_{f}$ have large uncertainties (traditional least squares fits assume no, or negligible error on the independent variable, as the methods operates on minimizing only the sum of the square differences of the dependent variable from the predicted line). Considering both $V S P$ and $D_{f}$ as independent variables one at a time (meaning flipping VSP vs. $D_{f}$ or $D_{f}$ vs. $V S P$ ), yields two slopes $m_{V S P}$ and $m_{D f}$ and intercepts. In the case of large and comparable uncertainties in both $\mathrm{x}$ and $\mathrm{y}$ variables, the geometric mean of the slope- 1 with the inverse of slope- 2 is a good estimator of the slope (Norman and Draper, 1998). However, if one variable has more uncertainties than other (here $\sigma_{V S P}>\sigma_{D f}$ ) then a weighted ratio $r$ can be used to estimate modified slope and intercept (Mazzoleni et al., 2004). The ratio $r$ can be expressed as $r=\frac{\left\langle\sigma_{D_{f}}\right\rangle /\left\langle D_{f}\right\rangle}{\left\langle\sigma_{V S P}\right\rangle /\langle V S P\rangle}$ where \langle\rangle indicates the arithmetic mean, and can be used to estimate the modified slope as a weighted geometric mean $m=\left(m_{D f}^{r} \times \frac{1}{m_{V S P}}\right)^{[1 /(1+r)]}$ such that $D_{f}=m$. $V S P+c$. The intercept $\mathrm{c}$ is calculated as $c=\left(\left\langle D_{f}\right\rangle-m \times\langle V S P\rangle\right)$. The error in the slope and intercept represent the half ranges (i.e., [maximum-minimum]/2) of slopes and intercepts using the two fits of $V S P$ vs. $D_{f}$ and $D_{f}$ vs. VSP.

Local environmental conditions, such as wind, temperature and relative humidity (Table 2-2) and various fractions of HDVs at different sites and days might be partially responsible for the scatter in the data. These findings are different from the few studies mentioned earlier where it was found that the $D_{f}$ decreases with increasing engine load (Park et al., 2003; Skillas et al., 1998; Virtanen et al., 2004).

Our findings are also different from a few studies that suggested weak or no dependence of $D_{f}$ on the engine load/speed (Neer and Koylu, 2006; Zhu et al., 2005). However, our results are in agreement with findings from other controlled studies (Lapuerta et al., 2009; Olfert et al., 2007). Lapuerta et al. (2009) studied the morphology of soot particles by controlling the engine parameters independently. They found a statistically 
significant increase in $D_{f}$ of soot with increasing fuel/air ratio. This trend can be explained by two opposite effects. Soot concentration increases with increasing fuel/air ratio leading to less ballistic collisions between agglomerates and resulting in a decrease of the $D_{f}$. On the other side, the increase in fuel/air ratio results in an increase in thermal energy in the exhaust, which increases the probability for thermal restructuring of the agglomerates. The authors suggested that the later effect dominates in the conditions of their study, leading to an overall increase in $D_{f}$ with increasing fuel/air ratio (Lapuerta et al., 2009). Similar trends were qualitatively observed by Olfert et al. (2007).

Additionally, an increase in VSP corresponds to higher fuel/air equivalence ratio or in other words, at higher VSP soot particles are produced in fuel-rich conditions.Cross et al. (2010) found that soot mass fraction was 0.74 at fuel equivalence ratio of 2 , while it was lower (0.32) at higher fuel equivalence ratio (5.0). Fuel-rich conditions result in incomplete combustion, producing more condensable organics (aliphatics and $\mathrm{PAH}$ ) within the flame that consequently coat the soot core. This would result in more voidfilling and might facilitate the collapse of the soot particle structure to a more compacted shape; this might be responsible for the increase in $D_{f}$ with increasing VSP. Sample collection condition can also influence $D_{f}$ as soot collected under cold and diluted condition can have higher $D_{f}$ compared to those collected from hot and undiluted conditions (Lapuerta et al., 2009).

\subsubsection{Vehicle model year}

Next, we investigate the dependence of soot morphology with vehicle model year. Vehicle age is calculated considering 2010 and newer models as of zero age. The vehicles that passed by during the sampling periods are divided into three groups: (1) vehicle age of 0 to 5 years; (2) 5 to 15 years and (3) older than 15 years. $D_{f}$ ranges from 1.52 to 1.94 , and is divided into five groups from 1.5 to 2.0 with increments of 0.1 . In Figure 2-8 we show the summary of the binned data. $D_{f}$ increases with increasing fraction of vehicles older than 15 years (in red) while for vehicle age groups of 0-5 
years (in black) and 5-15 years (in blue) $D_{f}$ does not show any evident correlation with the age fractions. This indicates that the morphology of soot might not have a strong dependence on newer vehicle technologies, but might be affected by older technology such as for vehicles older than 15 years.

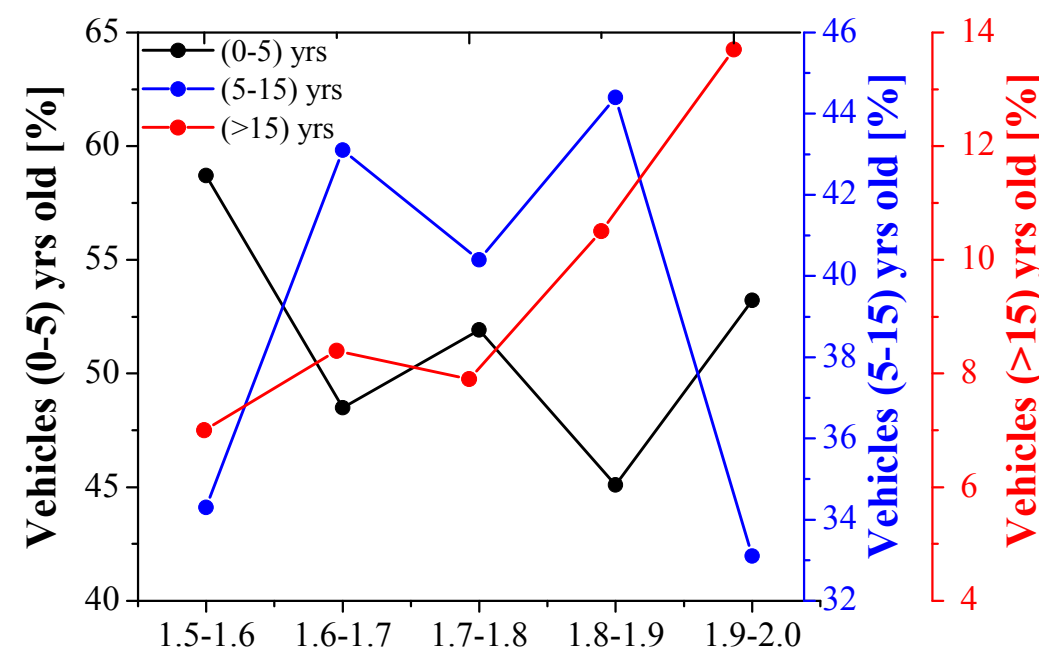

Fractal dimension

Figure 2-8: Relation between fractal dimension and vehicle age. Vehicle age is divided into three groups, $0-5$ years, 5-10 years and older than 15 years. Fractal dimension is divided into five groups from 1.5 to 2.0 , with 0.1 increments.

A previous on-road study of vehicular particulate matter emision factors showed that for vehicles built before 1996 the particluate matter emission factors increase steadily with increasing vehicle age (Kuhns et al., 2004). We speculate that the increasing trend of $D_{f}$ with increasing fraction of vehicles older than 15 years might be due to the fact that older vehicles emit more particles and other condensable material (e.g.; oil and uncombusted fuel), conditions that facilitate the particle collision, coagulation and void filling, resulting in higher $D_{f}$. This seems to be consistent also with the increase of $D_{f}$ with VSP. 


\subsection{Conclusions}

Our results have significant implications for assessing the impact of the morphology of soot emitted by vehicles on human health, environment and climate. However our results are applicable to the conditions we measure and can differ from situation where other fuels are used (e.g.; different regions, or different seasons). Freshly generated soot particles from vehicular emissions can impact passengers while travelling on freeways, as well as humans living in downwind areas. Soot with lower $D_{f}$ tends to deposit in the pulmonary region of adults more efficiently than soot with higher $D_{f}$. However, infants are more vulnerable to proximal deposition of low $D_{f}$ soot (Broday and Rosenzweig, 2011). Therefore, quantification of $D_{f}$ for different traffic and driving conditions is necessary to understand deposition patterns. In addition, optical properties of soot depend on morphology and mixing having significant effect on radiative properties affecting climate. Both scattering and absorption by soot particles can be influenced as soot morphology evolves from low to high $D_{f}$ (Liu et al., 2008) while mixing can enhance both scattering and absorption.

Morphology and mixing state of soot particles can be highly variable depending on the combustion source and operating conditions and the aging processes and time. Quantifying the complex soot morphology and mixing state is necessary to understand the effects of soot emissions from vehicles at the initial stage of the soot life cycle. Our analysis provides quantitative parameters such as morphological descriptors, fractal dimension and mixing classification. We show that freshly emitted soot is mostly very thinly coated with a substantial fraction of partly coated soot $(\sim 22 \%)$. We also show that driving conditions and vehicle age (for vehicles older than 15 years) are quantitatively associated with soot fractal dimension. This analysis can provide guidance to numerical models such as particle-resolved mixing state models (Riemer et al., 2009) to account for, and better understand, vehicular emissions and soot evolution since its emission. 


\subsection{References}

Adachi and Buseck, P.: Internally mixed soot, sulfates, and organic matter in aerosol particles from Mexico City, Atmos. Chem. Phys, 8, 6469-6481, 2008.

Adachi, Chung, S. H., Friedrich, H., and Buseck, P. R.: Fractal parameters of individual soot particles determined using electron tomography: Implications for optical properties, Journal of Geophysical Research-Atmospheres, 112, 2007.

Adachi, K. and Buseck, P. R.: Changes of ns-soot mixing states and shapes in an urban area during CalNex, Journal of Geophysical Research: Atmospheres, 2013. 2013.

Baron, P. A. and Willeke, K.: In Aerosol Measurement: Principles, Techniques, and Applications, Wiley, New York, 2001.

Barone, T. L. and Zhu, Y.: The morphology of ultrafine particles on and near major freeways, Atmospheric Environment, 42, 6749-6758, 2008.

Benbrahim-Tallaa, L., Baan, R. A., Grosse, Y., Lauby-Secretan, B., El Ghissassi, F., Bouvard, V., Guha, N., Loomis, D., and Straif, K.: Carcinogenicity of dieselengine and gasoline-engine exhausts and some nitroarenes, The lancet oncology, 13, 663-664, 2012.

Bond, T., Doherty, S., Fahey, D., Forster, P., Berntsen, T., DeAngelo, B., Flanner, M., Ghan, S., Kärcher, B., and Koch, D.: Bounding the role of black carbon in the climate system: a scientific assessment, Journal of Geophysical Research: Atmospheres, 2013. 2013.

Bond, T. C., Streets, D. G., Yarber, K. F., Nelson, S. M., Woo, J. H., and Klimont, Z.: A technology-based global inventory of black and organic carbon emissions from combustion, Journal of Geophysical Research-Atmospheres, 109, 2004.

Brasil, A. M., Farias, T. L., and Carvalho, M. G.: A recipe for image characterization of fractal-like aggregates, Journal of Aerosol Science, 30, 1379-1389, 1999.

Brauer, M., Hoek, G., Van Vliet, P., Meliefste, K., Fischer, P. H., Wijga, A., Koopman, L. P., Neijens, H. J., Gerritsen, J., and Kerkhof, M.: Air pollution from traffic and the development of respiratory infections and asthmatic and allergic 
symptoms in children, American journal of respiratory and critical care medicine, 166, 1092-1098, 2002.

Broday, D. M. and Rosenzweig, R.: Deposition of fractal-like soot aggregates in the human respiratory tract, Journal of Aerosol Science, 42, 372-386, 2011.

Buseck, P., Adachi, K., Gelencsér, A., Tompa, É., and Pósfai, M.: Are black carbon and soot the same?, Atmos. Chem. Phys. Discuss, 12, 24821-24846, 2012.

Cai, J., Lu, N., and Sorensen, C. M.: Comparison of size and morphology of soot aggregates as determined by light scattering and electron microscope analysis, Langmuir, 9, 2861-2867, 1993.

Cappa, C. D., Onasch, T. B., Massoli, P., Worsnop, D. R., Bates, T. S., Cross, E. S., Davidovits, P., Hakala, J., Hayden, K. L., Jobson, B. T., Kolesar, K. R., Lack, D. A., Lerner, B. M., Li, S. M., Mellon, D., Nuaaman, I., Olfert, J. S., Petaja, T., Quinn, P. K., Song, C., Subramanian, R., Williams, E. J., and Zaveri, R. A.: Radiative Absorption Enhancements Due to the Mixing State of Atmospheric Black Carbon, Science, 337, 1078-1081, 2012.

Chakrabarty, R. K., Moosmüller, H., Arnott, W. P., Garro, M. A., and Walker, J.: Structural and fractal properties of particles emitted from spark ignition engines, Environmental Science \& Technology, 40, 6647-6654, 2006.

China, S., Mazzoleni, C., Gorkowski, K., Aiken, A. C., and Dubey, M. K.: Morphology and mixing state of individual freshly emitted wildfire carbonaceous particles, Nature communications, 4, 2013.

Cross, E. S., Onasch, T. B., Ahern, A., Wrobel, W., Slowik, J. G., Olfert, J., Lack, D. A., Massoli, P., Cappa, C. D., and Schwarz, J. P.: Soot particle studiesinstrument inter-comparison-project overview, Aerosol Science and Technology, 44, 592-611, 2010.

Dye, A. L., Rhead, M. M., and Trier, C. J.: The quantitative morphology of roadside and background urban aerosol in Plymouth, UK, Atmospheric Environment, 34, 3139-3148, 2000. 
Friedlander, S. K.: Smoke, Dust, and Haze Fundamentals of Aerosol Dynamics, Oxford University Press, New York, 2000.

Heinrich, J. and Wichmann, H.-E.: Traffic related pollutants in Europe and their effect on allergic disease, Current opinion in allergy and clinical immunology, 4, 341$348,2004$.

Horvath, H.: Atmospheric light-absorption - a review, Atmospheric Environment Part aGeneral Topics, 27, 293-317, 1993.

Jiménez-Palacios, J., L Understanding and quantifying motor vehicle emissions with vehicle specific power and TILDAS remote sensing, Doctoral Doctoral Thesis, Massachusetts Institute of Technology, 1999.

Kittelson, D. B.: Engines and nanoparticles: A review, Journal of Aerosol Science, 29, 575-588, 1998.

Kocbach, A., Li, Y., Yttri, K., Cassee, F., Schwarze, P., and Namork, E.: Physicochemical characterisation of combustion particles from vehicle exhaust and residential wood smoke, Particle and Fibre Toxicology, 3, 1, 2006.

Köylü, Ü. Ö., Faeth, G. M., Farias, T. L., and Carvalho, M. G.: Fractal and projected structure properties of soot aggregates, Combustion and Flame, 100, 621-633, 1995.

Kuhns, H. D., Mazzoleni, C., Moosmuller, H., Nikolic, D., Keislar, R. E., Barber, P. W., Li, Z., Etyemezian, V., and Watson, J. G.: Remote sensing of PM, NO, CO and $\mathrm{HC}$ emission factors for on-road gasoline and diesel engine vehicles in Las Vegas, NV, Science of the Total Environment, 322, 123-137, 2004.

Lapuerta, M., Ballesteros, R., and Martos, F. J.: The effect of diesel engine conditions on the size and morphology of soot particles, Int. J. Veh. Des., 50, 91-106, 2009.

Liu, Mishchenko, M. I., and Arnott, W. P.: A study of radiative properties of fractal soot aggregates using the superposition T-matrix method, Journal of Quantitative Spectroscopy \& Radiative Transfer, 109, 2656-2663, 2008.

Mandelbrot, B. B.: The Fractal Geometry of Nature, W.H. Freeman, San Francisco, 1982. 
Mazzoleni, C., Kuhns, H. D., Moosmüller, H., Keislar, R. E., Barber, P. W., Robinson, N. F., and Watson, J. G.: On-road vehicle particulate matter and gaseous emission distributions in Las Vegas, Nevada, compared with other areas, Journal of the Air \& Waste Management Association, 54, 711-726, 2004.

Meakin, P.: Computer simulation of cluster-cluster aggregation using linear trajectories: Results from three-dimensional simulations and a comparison with aggregates formed using brownian trajectories, Journal of Colloid and Interface Science, 102, 505-512, 1984a.

Meakin, P.: Diffusion-limited aggregation in three dimensions: Results from a new cluster-cluster aggregation model, Journal of Colloid and Interface Science, 102, 491-504, 1984b.

Megaridis, C. M. and Dobbins, R. A.: Morphological description of flame-generated materials, Combustion Science and Technology, 71, 95-109, 1990.

Neer, A. and Koylu, U. O.: Effect of operating conditions on the size, morphology, and concentration of submicrometer particulates emitted from a diesel engine, Combustion and Flame, 146, 142-154, 2006.

Norman, R. and Draper, H. S.: Applied Regression Analysis, John Wiley \& Sons, New York, 1998.

Oh, C. and Sorensen, C. M.: The effect of overlap between monomers on the determination of fractal cluster morphology, Journal of Colloid and Interface Science, 193, 17-25, 1997.

Olfert, J. S., Symonds, J. P. R., and Collings, N.: The effective density and fractal dimension of particles emitted from a light-duty diesel vehicle with a diesel oxidation catalyst, Journal of Aerosol Science, 38, 69-82, 2007.

Park, K., Cao, F., Kittelson, D. B., and McMurry, P. H.: Relationship between particle mass and mobility for diesel exhaust particles, Environmental Science \& Technology, 37, 577-583, 2003. 
Pusechel, R. F., Blake, D. F., Snetsinger, K. G., Hansen, A. D. A., Verma, S., and Kato, K.: Black carbon (soot) aerosol in the lower stratosphere and upper troposphere, Geophys. Res. Lett., 19, 1659-1662, 1992.

Riemer, N., West, M., Zaveri, R. A., and Easter, R. C.: Simulating the evolution of soot mixing state with a particle-resolved aerosol model, Journal of Geophysical Research-Atmospheres, 114, 2009.

Sakurai, H., Tobias, H. J., Park, K., Zarling, D., Docherty, K. S., Kittelson, D. B., McMurry, P. H., and Ziemann, P. J.: On-line measurements of diesel nanoparticle composition and volatility, Atmospheric Environment, 37, 1199$1210,2003$.

Samson, R. J., Mulholland, G. W., and Gentry, J. W.: Structural-analysis of soot agglomerates, Langmuir, 3, 272-281, 1987.

Schauer, J. J., Kleeman, M. J., Cass, G. R., and Simoneit, B. R. T.: Measurement of Emissions from Air Pollution Sources. 2. C1 through C30 Organic Compounds from Medium Duty Diesel Trucks, Environmental Science \& Technology, 33, 1578-1587, 1999.

Skillas, G., Kunzel, S., Burtscher, H., Baltensperger, U., and Siegmann, K.: High fractal-like dimension of diesel soot agglomerates, Journal of Aerosol Science, 29, 411-419, 1998.

Van Poppel, L. H., Friedrich, H., Spinsby, J., Chung, S. H., Seinfeld, J. H., and Buseck, P. R.: Electron tomography of nanoparticle clusters: Implications for atmospheric lifetimes and radiative forcing of soot, Geophysical Research Letters, 32, 2005.

Virtanen, A. K. K., Ristimaki, J. M., Vaaraslahti, K. M., and Keskinen, J.: Effect of engine load on diesel soot particles, Environmental Science \& Technology, 38, 2551-2556, 2004.

Wentzel, M., Gorzawski, H., Naumann, K. H., Saathoff, H., and Weinbruch, S.: Transmission electron microscopical and aerosol dynamical characterization of soot aerosols, Journal of Aerosol Science, 34, 1347-1370, 2003. 
Zaveri, R. A. e. a.: Overview of the 2010 Carbonaceous Aerosols and Radiative Effects Study (CARES), Atmospheric Chemistry and Physics, 12, 7647-7687, 2012.

Zhu, J. Y., Lee, K. O., Yozgatligil, A., and Choi, M. Y.: Effects of engine operating conditions on morphology, microstructure, and fractal geometry of light-duty diesel engine particulates, Proceedings of the Combustion Institute, 30, 2781$2789,2005$. 


\section{Morphology and Mixing State of Freshly Emitted Wildfire Carbonaceous Particles ${ }^{2}$}

Biomass burning is one of the largest sources of carbonaceous aerosol in the atmosphere, significantly affecting Earth's radiation budget and climate. Tar balls, abundant in biomass burning smoke, absorb sunlight and have highly variable optical properties, typically not accounted for in climate models. We analyze single biomass burning particles from the Las Conchas fire (New Mexico, 2011) using electron microscopy. We show that the relative abundance of tar balls $(80 \%)$ is 10 times greater than soot particles (8\%). We also report two distinct types of tar balls; one less oxidized than the other. Furthermore, the mixing of soot particles with other material affects their optical, chemical and physical properties. We quantify the morphology of soot particles and classify them into four categories: $\sim 50 \%$ are embedded (heavily-coated), $\sim 34 \%$ are partly-coated, $\sim 12 \%$ have inclusions, and $\sim 4 \%$ are bare. Inclusion of these observations should improve climate model performances.

\subsection{Introduction}

Biomass burning (BB) emissions significantly impact radiative forcing of climate at regional and global scales (Ramanathan and Carmichael, 2008). Global annual emissions of black carbon (BC) and organic carbon (OC) aerosols are estimated as $\sim 8$

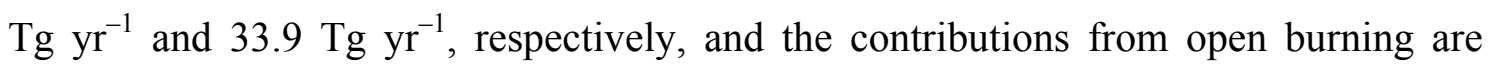
estimated as $42 \%$ for BC, and 74\% for OC (Bond et al., 2004). However, current estimates of BB emissions are highly uncertain (a factor of 3 to 5 for individual aerosol and gaseous species) (Bond et al., 2013). Additionally, the emission of BB carbonaceous aerosols could increase, as future global and regional warming

${ }^{2}$ Copyright $\mathbb{C}$ (2013) Nature publishing group. The material contained in this chapter was previously published in the Nature Communications journal: Swarup China, Claudio Mazzoleni, Kyle Gorkowski, Allison C. Aiken, Manvendra K. Dubey (2013). See Appendix A.2 for documentation of permission to republish this material. 
accentuate favorable conditions for wildfire activities (Westerling et al., 2006). A recent study shows that the radiative forcing from BB can vary non-linearly with the concentration of co-emitted trace gases and aerosols (Mao et al., 2013). BB aerosol is estimated to have a highly uncertain net positive direct radiative forcing (e.g.; $0.03 \pm$ $0.12 \mathrm{Wm}^{-2}$ in (IPCC, 2007; Myhre et al., 2012)). Recently Bond et al. (2013) estimated the direct radiative forcing from the total $\mathrm{BC}$ burden as $+0.71 \mathrm{~W} \mathrm{~m}^{-2}$ (with $90 \%$ uncertainty bounds from $+0.08 \mathrm{~W} \mathrm{~m}^{-2}$ to $1.27 \mathrm{~W} \mathrm{~m}^{-2}$ ). They also estimated the contributions from open burning as $+0.20 \mathrm{~W} \mathrm{~m}^{-2}$ (with $90 \%$ uncertainty bounds from 0.50 to $+1.08 \mathrm{~W} \mathrm{~m}^{-2}$ ). The uncertainty is due to many factors including the balance between a large positive forcing by $\mathrm{BC}$ and a large negative forcing by $\mathrm{OC}$.

Mixing state and composition of the aerosols can strongly influence the balance of radiative forcing by $\mathrm{BC}$ and $\mathrm{OC}$. Models estimate an enhancement of $\mathrm{BC}$ forcing up to a factor of 2.9 when $\mathrm{BC}$ is internally mixed with other aerosols, compared to externally mixed scenarios (Jacobson, 2001). Internal mixing of BC emitted from BB might enhance absorption by $70 \%$, with OC coatings playing a key role (Lack et al., 2012). In contrast, a recent study on urban plumes, suggests that the aerosol absorption enhancement for mixed BC might have been overestimated in models (Cappa et al., 2012). It is unclear how these findings might apply to other BC sources including BB. Following the contrasting results of these and similar studies, there is an intense debate about the issue of absorption enhancement, the appropriateness of scaling point measurements up to scales relevant to global climate models, and conversely, the ability of models to correctly capture the enhancement in different environments (Cappa et al., 2013; Cappa et al., 2012; Jacobson, 2013). To add to the debate, recently there has been a renewed discussion about what the term "BC" really means (Buseck et al., 2012; Petzold et al., 2013). In addition to the $\mathrm{BC}$ mixing state issue, the optical and physical properties of tar balls (TBs) that constitute a large fraction of the total BB aerosols, are highly uncertain (Alexander et al., 2008; Chakrabarty et al., 2010; Reid et al., 2005). Electron microscopy has been used widely to investigate BB particles size, morphology, chemical composition and mixing state. These parameters can vary largely depending 
on aerosol sources, formation temperature, transport, condensation and evaporation of primary and secondary gases (Hand et al., 2005; Li, 2003; Pósfai, 2004; Pósfai et al., 2003).

In this study, we report a detailed analysis of a large number of single BB particles from the Las Conchas fire. We discuss coating and oxidation of TBs and morphological properties of aggregates of carbonaceous nano-spheres and their mixing with other materials. We refer to aggregates of carbonaceous nano-spheres particles as soot. As we analyze particles only from $\mathrm{BB}$ combustion, we consider soot to well represent $\mathrm{BC}$ in BB smoke. As described in the method section, we used a thermodenuder to remove most of the volatile compounds from the BB aerosols, and in the following sections we describe the differences in the properties of ambient versus thermodenuded particles to understand coating effects. We report the existence of two distinct types of TBs, which differ in their degree of oxidation and coating. We also classify soot particles based on their coating and morphology and discuss their properties. Aerosol from BB is still poorly characterized and these findings should improve our understanding of atmospheric processing of $\mathrm{BB}$ aerosol and their effects on climate.

\subsection{Experimental section and methods}

\subsubsection{Aerosol sampling}

The Las Conchas wildfire started on June 26, 2011 in northern New Mexico, USA and burned an area of 245 square miles. This was the second largest wildfire in New Mexico state history and the largest at the time. The particles were collected during the smoldering phase at a distance of $\sim 25 \mathrm{~km}$ from the emission location ( 1-2 hours aged). Aerosol samples were collected on nucleopore filters (100 nm pores) at the Physics Building in Los Alamos National Laboratory during the third week of the wildfire. A thermodenuder (University of Northwest, Switzerland) was used to remove volatile compounds at temperatures up to $200^{\circ} \mathrm{C}$, leaving behind refractory soot and low volatility compounds. We note that even at $200^{\circ} \mathrm{C}$ many non-refractory organic material 
and other inorganic coatings may still remain (Cappa et al., 2013). Two sample lines were used for collecting ambient and denuded particles with automated switching occurring at 5 minutes intervals. Two sets of ambient and denuded samples were collected on July 12th; the first set (ambient-1 and denuded-1) was collected from 13:00 to 17:20 local time, and the second set (ambient-2 and denuded-2), was collected from 17:30 to 18:00. The denuding system was originally set-up also to study the optical properties of the aerosol. To study the changes in optical properties vs. the denuding temperature, the temperature during the sample- 1 period was ramping from $100^{\circ} \mathrm{C}$ to $200^{\circ} \mathrm{C}$ with a mean time-weighted temperature of $152^{\circ} \mathrm{C}$. The analysis and discussion of the optical properties of the aerosols is beyond the scope of this work, as we intentionally focus on the morphological properties. However, to accumulate enough samples for electron microscopy, aerosol was collected during the entire period and we cannot separate particles that underwent different denuding temperatures, although we can still obtain useful information on a statistical basis. On the contrary, for the denuded-2 (D-2) sample, the denuder temperature was kept constant at $200^{\circ} \mathrm{C}$.

\subsubsection{Microscopy analysis}

The individual aerosol particles were investigated using a field-emission scanning electron microscope (FE-SEM, Hitachi S-4700) and energy dispersive X-ray spectroscopy (EDS) to distinguish different carbonaceous particles and their shape, size, elemental composition and mixing state. We used gray scale intensity to classify "electronically" dark and bright tar balls (TBs). Figure 3-2 shows the histogram of the gray scale intensity. The distribution of gray scale intensities ranged from 0 to 256; a threshold of 120 was selected after analyzing the distribution. TBs with gray scale intensity below 120 were categorized as dark and above 120 were categorized as bright. Gray scale intensity for dark particles peaks between 60 and 70, while for bright particles peaks between 250 and 256 . 
Semi-quantitative EDS analysis was conducted on 25 dark TBs and 25 bright TBs of comparable size. First, the dark and bright TBs were selected using a $1 \mathrm{kV}$ accelerating voltage at 2-3 $\mathrm{mm}$ working distances; then the settings of the microscope were changed to $10 \mathrm{kV}$ and $12 \mathrm{~mm}$ working distance to enable the EDS analysis.

\subsubsection{Fractal dimension analysis of soot particles}

The total number of monomers $(N)$ in a fractal aggregate is estimated from the projected area of the aggregate $\left(A_{\mathrm{a}}\right)$ and the mean projected area of the monomers $\left(A_{\mathrm{p}}\right)$ in the aggregate, as follows (Köylü et al., 1995; Oh and Sorensen, 1997; Samson et al., 1987):

$$
N=k_{a}\left(\frac{A_{a}}{A_{p}}\right)^{\alpha}
$$

Where $\alpha$ is an empirical projected area exponent and $k_{\mathrm{a}}$ is a constant, typically approximated with a value close to one. To calculate $N$, we first estimate the overlap parameter, $\delta$ from the two-dimensional images; $\delta$ is defined as the ratio of the monomer diameter to the distance between the centers of two touching monomers ( $\mathrm{Oh}$ and Sorensen, 1997). We then select $\alpha$ and $k_{\mathrm{a}}$ based on a relationship developed by $\mathrm{Oh}$ and Sorensen (1997), as discuss later. A caveat of this approach is that an accurate estimation of $\delta$ from 2-dimensional projected images is difficult ( $\mathrm{Oh}$ and Sorensen, 1997). The estimated values of $\delta$ in our samples ranged from 1 (point contact) to 1.7 with median and mode of 1.5. We used $\alpha=1.13$ and $k_{\mathrm{a}}=1.50$. In Oh and Sorensen (1997), the values of $\alpha$ and $k_{\text {a }}$ for a given $\delta$ are based on the assumption that the soot particles are formed via diffusion-limited cluster aggregation (DLCA). However, most of the soot particles analyzed in our samples are coated by organic or inorganic material, and the effect of coating might limit the validity of this approach. We therefore performed a sensitivity analysis to investigate the effects that different overlap parameters might have on the calculation of $N$, the fractal dimension $D_{\mathrm{f}}$, and the prefactor $k_{g}$. Table 3-1 reports the results of this analysis for different overlap parameters ( $\delta=1$ to 1.5 ) and for $\alpha$ and $k_{\mathrm{a}}$ values most commonly used in literature of 1.09 and 1.15 (or 1), respectively. 
Images of individual soot particles were used for the calculation of the fractal dimension using equation 2

$$
N=k_{L}\left(\frac{L_{\max }}{d_{p}}\right)^{D_{f}}
$$

Where we used the maximum length of the aggregate as an approximation for $2 R_{\mathrm{g}}$ into equation 1 as follows: $L_{\max } / 2 R_{\mathrm{g}}=1.50 \pm 0.05$ (Brasil et al., 1999).

Table 3-1: Sensitivity analysis of the effect of different input parameters on number of monomers, fractal dimension and prefactor for soot particles.

\begin{tabular}{|c|c|c|c|c|c|c|c|c|}
\hline \multirow[b]{2}{*}{$\delta$} & \multirow[b]{2}{*}{$\alpha$} & \multirow[b]{2}{*}{$k_{\mathrm{o}}$} & \multicolumn{3}{|c|}{ Ambient-1 } & \multicolumn{3}{|c|}{ Denuded-1 } \\
\hline & & & $D_{\mathrm{f}}$ & $k_{\mathrm{g}}$ & $N$ & $D_{\mathrm{f}}$ & $k_{\mathrm{g}}$ & $N$ \\
\hline 1 & 1.07 & 1.18 & $\begin{array}{c}1.75 \\
(0.04)\end{array}$ & $\begin{array}{c}2.48 \\
(1.13)\end{array}$ & $\begin{array}{c}277 \\
(502)\end{array}$ & $\begin{array}{c}1.45 \\
(0.06)\end{array}$ & $\begin{array}{c}3.74 \\
(1.15)\end{array}$ & $\begin{array}{c}83 \\
(85)\end{array}$ \\
\hline 1.5 & 1.13 & 1.50 & $\begin{array}{c}1.85 \\
(0.05)\end{array}$ & $\begin{array}{c}3.09 \\
(1.13)\end{array}$ & $\begin{array}{c}498 \\
(995)\end{array}$ & $\begin{array}{c}1.53 \\
(0.06)\end{array}$ & $\begin{array}{c}5.08 \\
(1.16)\end{array}$ & $\begin{array}{c}135 \\
(155)\end{array}$ \\
\hline \multirow[t]{3}{*}{1.7} & 1.145 & 1.625 & $\begin{array}{c}1.88 \\
(0.04)\end{array}$ & $\begin{array}{c}3.66 \\
(1.14)\end{array}$ & $\begin{array}{c}589 \\
(1205)\end{array}$ & $\begin{array}{c}1.56 \\
(0.07)\end{array}$ & $\begin{array}{c}5.63 \\
(1.17)\end{array}$ & $\begin{array}{c}164 \\
(189)\end{array}$ \\
\hline & 1.09 & 1.15 & $\begin{array}{c}1.81 \\
(0.04)\end{array}$ & $\begin{array}{c}2.37 \\
(1.13)\end{array}$ & $\begin{array}{c}303 \\
(567)\end{array}$ & $\begin{array}{c}1.46 \\
(0.06)\end{array}$ & $\begin{array}{c}3.76 \\
(1.15)\end{array}$ & $\begin{array}{c}85 \\
(88) \\
\end{array}$ \\
\hline & 1.09 & 1.0 & $\begin{array}{c}1.81 \\
(0.04)\end{array}$ & $\begin{array}{c}2.10 \\
(1.12)\end{array}$ & $\begin{array}{c}263 \\
(493)\end{array}$ & $\begin{array}{c}1.46 \\
(0.06)\end{array}$ & $\begin{array}{c}3.20 \\
(1.16)\end{array}$ & $\begin{array}{c}74 \\
(76)\end{array}$ \\
\hline
\end{tabular}

Values of $D_{\mathrm{f}}, k_{\mathrm{g}}$ and $N$ for different overlap parameters ( $\delta=1$ to 1.7$)$ and for $\alpha$ and $k_{a}$ values most commonly used in literature of 1.09 and 1.15 (or 1.0), respectively. The numbers in parenthesis represent standard errors for $D_{\mathrm{f}}$ and $k_{\mathrm{g}}$ and standard deviations for $N$.

Particles categorized as "soot with inclusions" were not used for the calculation of $D_{\mathrm{f}}$ as the projected area of the whole particle (including the inclusion) would bias the calculation of $N$ and therefore $D_{\mathrm{f}}$. For the other three types of soot ("bare", "partlycoated" and "embedded") we used only the particles for which we were able to clearly distinguish and measure the diameter of at least a couple of monomers. Only approximately $50 \%$ of all the images acquired for embedded soot particles were used for the calculation of $D_{\mathrm{f}}$. Note that the number of particles in the "bare soot" group is small, as only a small fraction of the total soot population was found to be bare (4\%). In 
general, the data are more scattered in sample- 1 than in sample-2. This variability is probably due to the fact that the denuder was not kept at constant temperature during the collection of sample-1, resulting in the collection of particles with different degrees of denuding.

\subsection{Results and discussions}

\subsubsection{Particle classification}

Based on morphology and elemental composition, we classified over 4200 particles into three categories: 1) TBs, 2) soot and 3) others particles. The classification is similar to that adopted by Adachi and Buseck (2011) except that we combined organic matter and irregularly shaped particles as dust and salt, in the "other" category. We also want to underline that the category "soot" includes soot particles that are coated by other material, as further discussed later. TBs are amorphous, spherical carbonaceous particles that show no crystallographic structure and normally are most abundant in slightly aged (minutes to hours) BB smoke (Pósfai, 2004). TBs are easily identified due to their spherical shape and resistance to electron beam damage ( $\mathrm{Li}, 2003)$. EDS of our samples shows that $\mathrm{TBs}$ are mainly composed of $\mathrm{C}$ and $\mathrm{O}$, and sometimes contain traces of $\mathrm{K}$ and $\mathrm{S}$. It is believed that TBs are similar to high-molecular weight humic-like substances formed during gas to particle phase transitions, involving rapid polymerization of lignin products induced by OH radicals (Hand et al., 2005; Pósfai et al., 2004; Tivanski et al., 2007). In contrast, fresh soot exhibits a characteristic chainlike morphology as agglomerates of small spherical monomers (Buseck et al., 2012). The soot particles investigated here are often mixed with other organic and inorganic material also emitted by fire (Hand et al., 2010). Ambient samples (denoted in this paper as A-1 and A-2) had an average of $80 \%$ TBs by number with an average of $8 \%$ soot and $12 \%$ of other particles. The fraction of TBs is similar to other studies (Hand et al., 2005; Pósfai et al., 2004; Pósfai et al., 2003) where fractions up to $90 \%$ have been reported; although, a lower fraction of TBs $(\sim 15 \%)$ have been found for relatively fresh samples (few minutes of aging) (Adachi and Buseck, 2011). 


\subsubsection{Identification of two kinds of TBs}

Using secondary electron (SE) imaging of individual particles at low accelarating voltage (1 kV) (Ivey, 2010), we identified two distinct kinds of TBs, "electronically" dark and bright (Figure 3-1a); whereas TBs appear indistinguishable at high accelerating voltage $(10 \mathrm{kV})$ (Figure $3-1 \mathrm{~b})$.

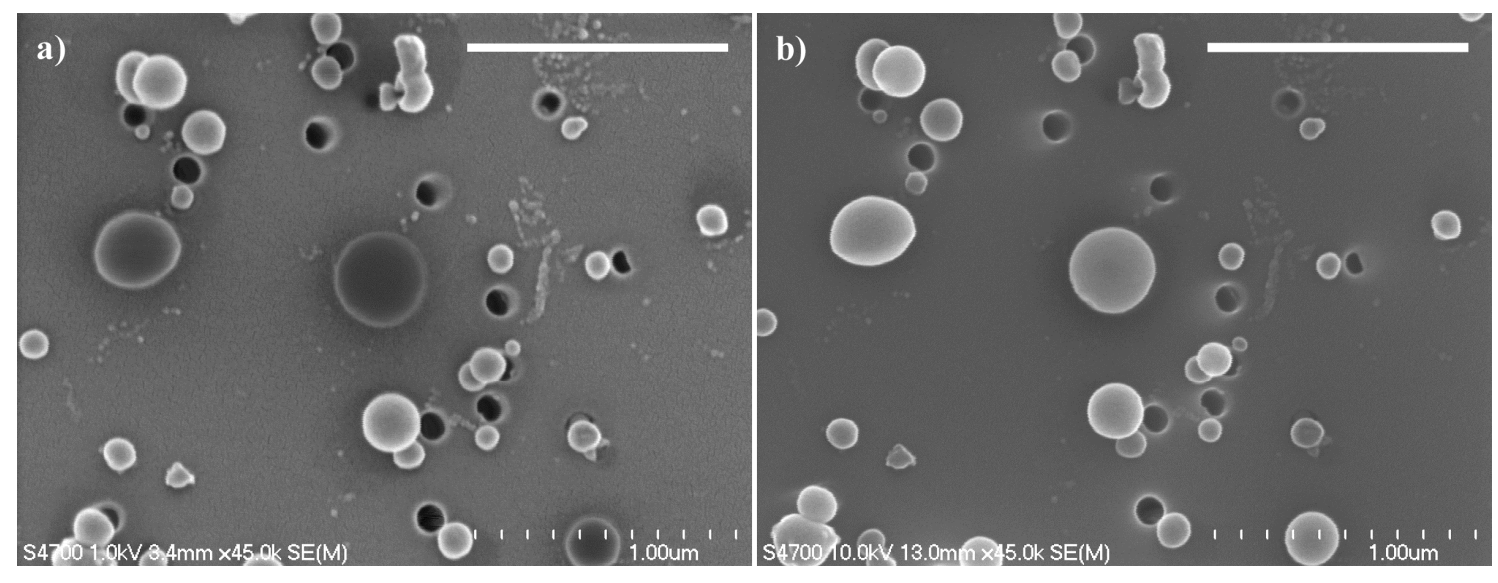

Figure 3-1: Identification of electronically dark and bright TBs (spherical particles). Field Emission Scanning Electron Microscopy (FE-SEM) micrographs of ambient particles collected from the Las Conchas fire. (a) Image at low working distance (3.4 $\mathrm{mm}$ ) and low accelerating voltage $(1 \mathrm{kV})$. (b) Image of the same particles, but at higher working distance $(13 \mathrm{~mm})$ and higher accelerating voltage $(10 \mathrm{kV})$. Electronically bright and dark TBs are evident at the low accelerating voltage, but not at the high accelerating voltage. The scale bars equal $1 \mu \mathrm{m}$.

We conjecture that the enhanced contrast at low accelerating voltages is due to different SE yields owing to various degree of oxidation at the particle's surface. A similar SE contrast effect has been observed on zinc versus zinc oxide samples (Ivey, 2010). However, estimation of SE yields for individual TBs is complicated due to their complex and uncertain composition and mixing. In addtion to SE imaging we imaged the TBs in our samples using backscattered electrons (BSE) and found no prominent contrast difference between the two types of TBs. Typically, detected SEs originate from very small escape depths (a few nanometers deep within the sample) much smaller than the dimensions of the particles, while BSE are detected even when generated from 
relatively large depths (10s to $100 \mathrm{~s}$ of $\mathrm{nm}$ ), which are comparable to the particle size (Egerton, 2005). In other words, SEs are sensitive to the surface, while BSEs are sensitive to the bulk of the particle. Tivanski et al. (2007) found a $40 \mathrm{~nm}$ thick oxygenated interface layer around the TBs after atmospheric processing. The fact that we found different contrasts in the SE images, but not in the BSE images, is consistent with the existence of a layer of different composition at the surface of the TBs.

We classified "electronically" dark and bright TBs based on their gray scale intensity on the SE low accelerating voltage SEM images (Figure 3-2). We found that approximately $32 \%$ of the TBs are dark in ambient samples. Figure $3-4 \mathrm{a}$ and $4 \mathrm{~b}$ show the size distributions of ambient TBs and denuded TBs, respectively. Dark and light gray lines represent the lognormal fit of dark and bright TBs, respectively. Dark TBs are larger in both ambient and denuded samples. The difference between the size of ambient-bright and denuded-bright TBs $(61 \mathrm{~nm})$ is larger than the difference between the size of ambient-dark and denuded-dark TBs $(33 \mathrm{~nm})$, implying that on average more material was removed by the denuder for bright TBs. This could indicate thicker coating and/or coating material having different volatility.

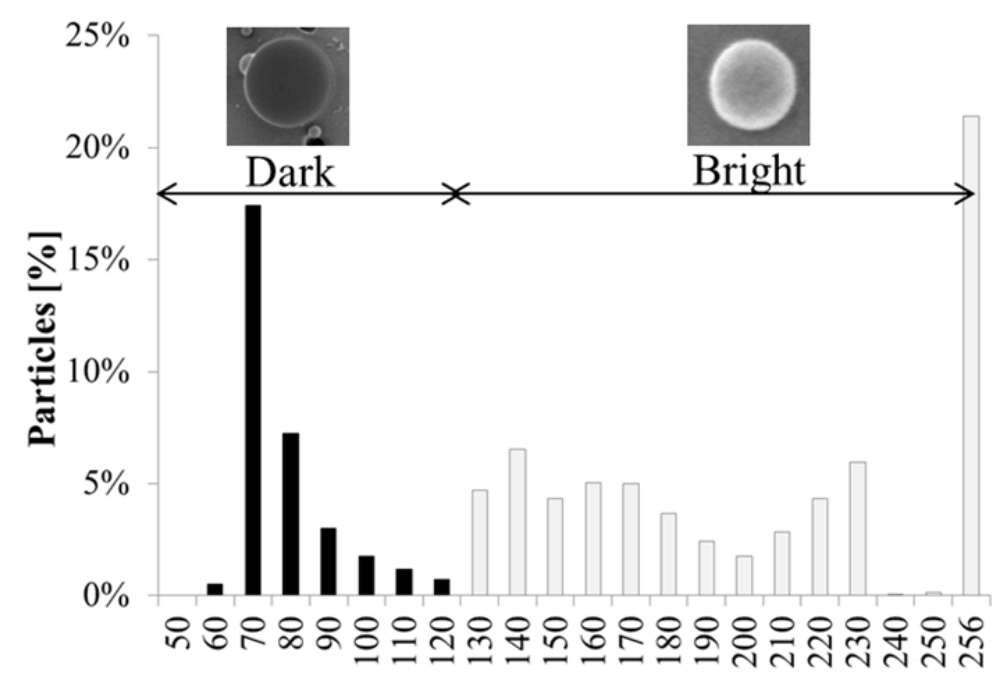

Gray value

Figure 3-2: Distribution of gray scale intensities and grouping of "electronically" dark and bright TBs. 


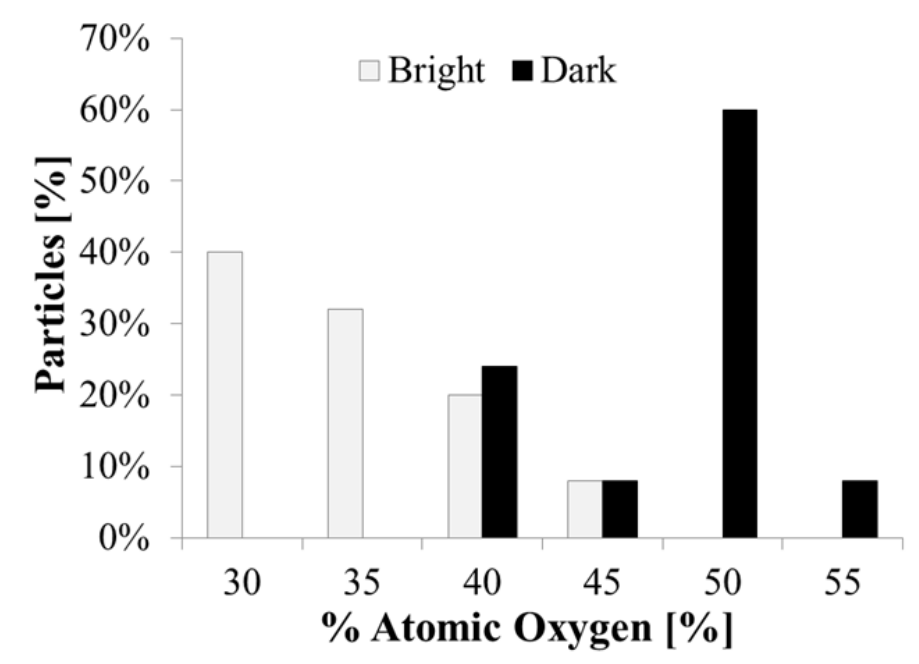

Figure 3-3: Atomic oxygen content in bright and dark TBs.
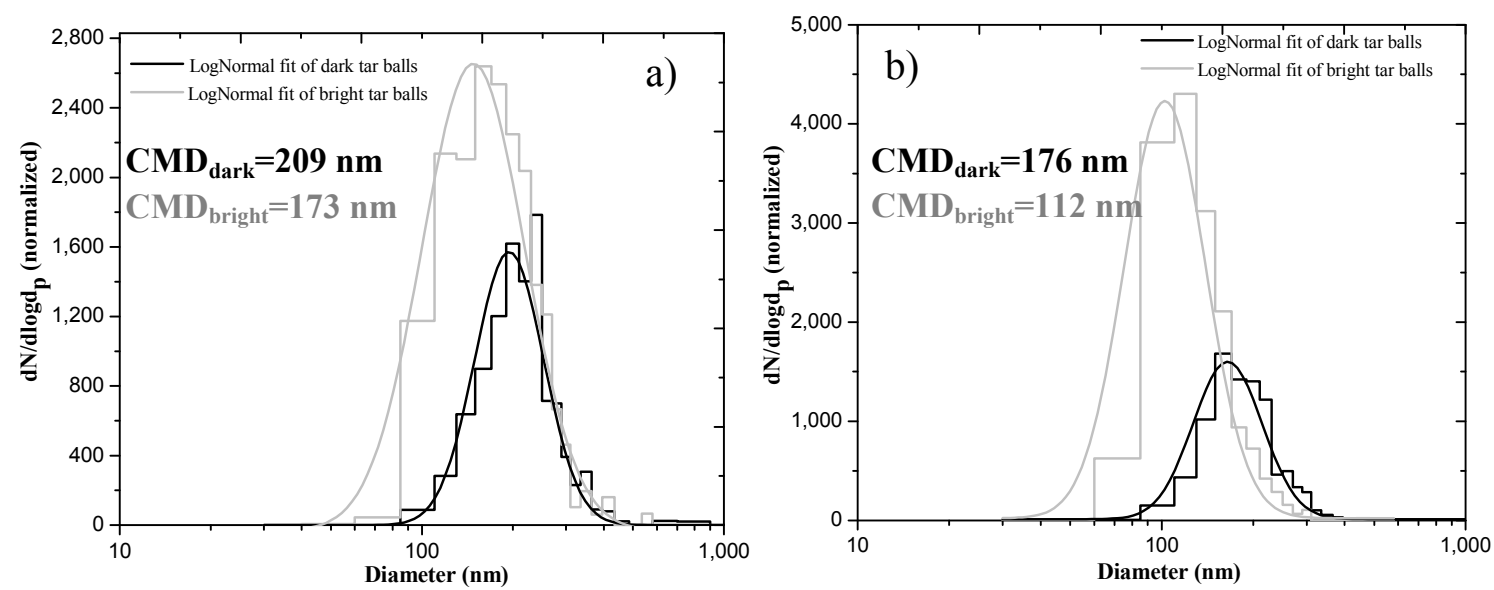

Figure 3-4: Size distribution of ambient and denuded bright and dark TBs. Size distribution and lognormal fits of: a) ambient particles (435 dark and 930 bright particles); b) denuded particles (415 dark and 1086 bright particles). The number of particles in each size bin is normalized by the bin width in logarithmic space and the mode of the distribution is normalized to one. The light gray lines represent bright TBs and the dark lines represent dark TBs. The difference between the count median diameter for ambient dark and denuded dark TBs is $33 \mathrm{~nm}(209-176 \mathrm{~nm})$; whereas the difference between ambient bright and denuded bright TBs is $61 \mathrm{~nm}(173-112 \mathrm{~nm})$. Dark TBs display smaller reduction in size on denuding, consistent with being more refractory. 
Semi-quantitative EDS was conducted on 25 dark and 25 bright TBs of comparable size. Out of the 25 dark TBs, 18 showed higher average oxygen content (50 atomic \%) than in bright TBs (35 atomic \%) (Figure 3-3). The remaining 7 dark TBs showed similar oxygen content to the bright TBs possibly due to the presence of an insulating layer or due to the somewhat subjective segregation of each TBs group. Similarly, Tivanski et al. (2007) found that TBs consist of 55\% atomic carbon and $45 \%$ atomic oxygen and as mentioned earlier, suggested the existence of an oxygenated layer on TBs. This analysis, together with the comparison of the size distribution of denuded vs. ambient TBs (dark TBs display smaller reduction in size upon denuding than bright TBs do), suggests that the dark TBs are more oxidized and possibly have a less volatile coating.

\subsubsection{Mixing state of soot particles}

Figure 3-5 shows an example of soot particles from the Las Conchas fire classified into four categories based on morphology and visual estimation of coating: a) embedded soot, where the particle is heavily coated (Adachi and Buseck, 2008) (potentially corresponding to a large optical absorption enhancement), but where some monomers are still evidently visible; b) partly-coated, where soot voids are filled by coating material, but the soot is not completely engulfed; c) bare soot, where monomers are easily distinguished and no considerable coating is evident from the SEM image, although very thin coating might be present on the monomers (corresponding to no or little optical absorption enhancement); d) soot with inclusions, where soot is mixed with, but not uniformly coated by, other material or particles. Of the 1026 soot particles analyzed $50 \%$ were heavily-coated, $34 \%$ partly-coated, $4 \%$ bare and $12 \%$ with inclusions. We should caution that the count of embedded soot particles might be biased low because when the coating is very thick the monomers of the soot particle might not be distinguishable, and then the particle would not be classified as soot. 


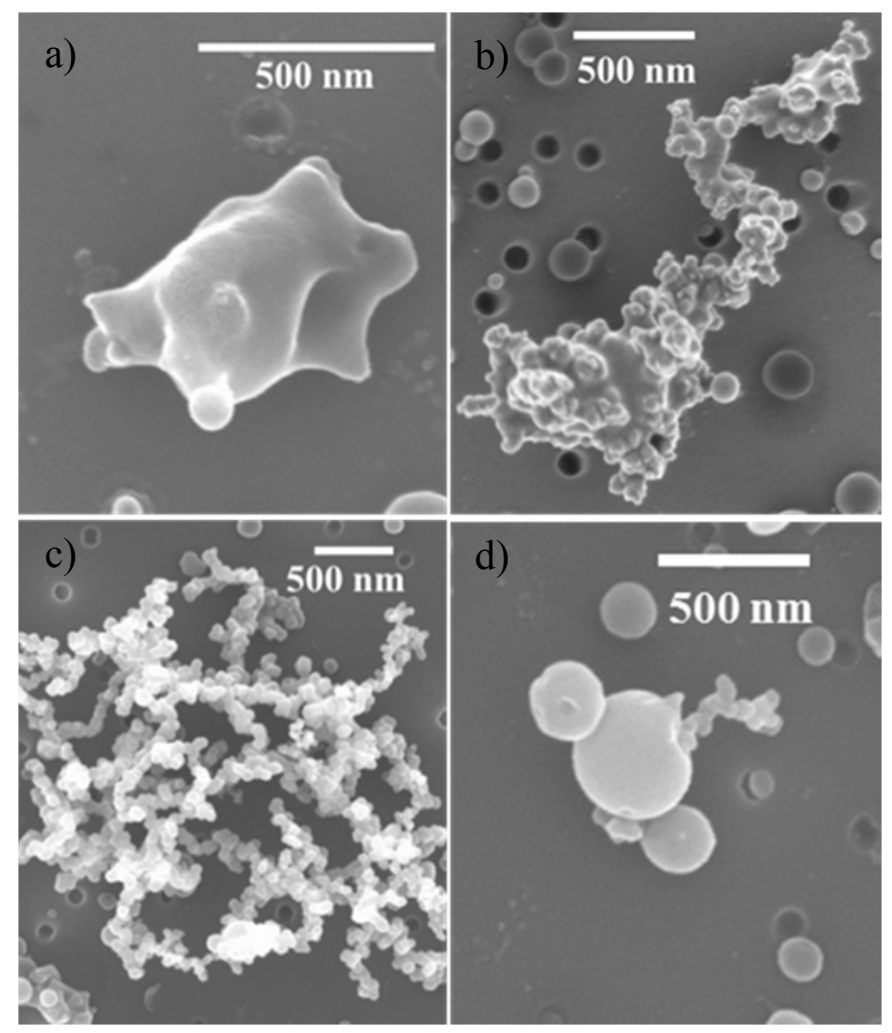

Figure 3-5: Mixing and classification of soot particles. FE-SEM images of four different categories of soot particles: a) embedded, b) partly-coated, c) bare and d) with inclusions. Approximately $50 \%$ of the ambient soot particles are embedded, $34 \%$ are partly-coated and $12 \%$ have inclusions. Only $4 \%$ of the particles are bare soot (not coated or very thinly coated).

\subsubsection{Morphology of ambient and denuded soot particles}

Soot particles are "fractal-like aggregates" and their ensemble morphology can be characterized by analyzing many individual aggregates using the following statistical scaling law (Adachi et al., 2007):

$$
N=k_{g}\left(\frac{2 R_{g}}{d_{p}}\right)^{D_{f}}
$$

where $N$ is the number of monomers per aggregate; $R_{\mathrm{g}}$ is the radius of gyration of the aggregate; $d_{\mathrm{p}}$ is the monomer diameter; $k_{\mathrm{g}}$ is called fractal prefactor; and $D_{\mathrm{f}}$ is the mass fractal dimension. For a given $D_{\mathrm{f}}, k_{\mathrm{g}}$ represents the level of compactness, with a smaller 
prefactor indicating lower packing (Lewis et al., 2009). Figure 3-6 shows an example of the estimation of the fractal dimension of soot particles for ambient-1 and denuded-1 samples. The details of the calculation are provided in the method section.

For completeness, we estimated three other morphological parameters: 1) aspect ratio, 2) roundness, and 3) area equivalent diameter $\left(D_{\text {Aeq }}\right)$ (Chakrabarty et al., 2006). In Table 3-2 we summarize all the morphological descriptors for ambient (A-1 and A-2) and corresponding denuded (D-1 and D-2) particles collected during two different time periods.

Table 3-2: Morphological descriptors of soot particles

\begin{tabular}{cccccccccc}
\hline Sample & $\begin{array}{c}\text { Sampling } \\
\text { time }\end{array}$ & $D_{\mathrm{f}}$ & $k_{\mathrm{g}}$ & $N$ & $R N$ & $A R$ & $\begin{array}{c}L_{\max } \\
{[\mathrm{nm}]}\end{array}$ & $\begin{array}{c}d_{\mathrm{p}} \\
{[\mathrm{nm}]}\end{array}$ & $\begin{array}{c}D_{\text {Aeq }} \\
{[\mathrm{nm}]}\end{array}$ \\
\hline \hline \multirow{2}{*}{$\mathrm{A}-1$} & $13: 03-$ & 1.85 & 3.09 & 498 & 0.59 & 1.71 & 1011 & 56 & 590 \\
& $17: 19$ & $(0.05)$ & $(1.13)$ & $(995)$ & $(0.20)$ & $(0.46)$ & $(709)$ & $(12)$ & $(344)$ \\
\hline \multirow{2}{*}{$\mathrm{D}-1$} & $12: 58-$ & 1.53 & 5.02 & 135 & 0.57 & 1.72 & 508 & 45 & 317 \\
& $17: 24$ & $(0.07)$ & $(1.2)$ & $(155)$ & $(0.16)$ & $(0.41)$ & $(244)$ & $(9)$ & $(129)$ \\
\hline \multirow{2}{*}{$\mathrm{A}-2$} & $17: 35-$ & 1.92 & 2.20 & 437 & 0.61 & 1.65 & 766 & 42 & 438 \\
& $18: 00$ & $(0.06)$ & $(1.18)$ & $(846)$ & $(0.17)$ & $(0.40)$ & $(610)$ & $(11)$ & $(301)$ \\
\hline \multirow{2}{*}{$\mathrm{D}-2$} & $17: 30-$ & 1.74 & 3.60 & 132 & 0.55 & 1.76 & 409 & 37 & 264 \\
& $17: 55$ & $(0.05)$ & $(1.13)$ & $(116)$ & $(0.17)$ & $(0.43)$ & $(242)$ & $(10)$ & $(129)$ \\
\hline
\end{tabular}

$D_{\mathrm{f}}$ : Mass fractal dimension, $k_{\mathrm{g}}$ : prefactor, $N$ : average number of monomers, $R N$ : roundness, $A R$ : aspect ratio, $L_{\max }$ : maximum length, $d_{\mathrm{p}}$ : primary particle diameter, $D_{\text {Aeq }}$ : and area equivalent diameter. Note that the two-dimensional morphological parameters $(R N$ and $A R)$ are the mean values of all the four types of soot particles. $\Delta D_{\mathrm{f}}\left(D_{\mathrm{f} \text {-ambient }}-D_{\mathrm{f} \text {-denuded }}\right)$ is $0.32 \pm 0.09$ and $0.18 \pm 0.08$ for sample-1 and sample-2, respectively. In parenthesis: standard errors for $D_{\mathrm{f}}$ and $k_{\mathrm{g}}$ calculated from the uncertainty in the mean-square fit considering the uncertainty in $N$ and $d_{\mathrm{p}}$, and standard deviations for the other parameters.

As expected, for both samples, $D_{\mathrm{f}}$ is larger for ambient than denuded particles. Different organic and inorganic substances can condense on soot particles (Pósfai et al., 2003); this coating is partially removed during the denuding process, resulting in smaller particles with less-filled voids and therefore lower $D_{\mathrm{f}}$. The conceptual model is that the $D_{\mathrm{f}}$ of the denuded soot particles represents the morphology of the soot particles as they are stripped of most of the volatile coating. What is left after denuding might or might 
not represent the nascent soot immediately after formation depending on the atmospheric processing. In fact, the coating material might actually modify the morphology of the soot core by rearranging the monomers position before the aerosol reaches the sampling location. The reduction in particle size after denuding is evident by noting that $D_{\text {Aeq }}$ decreased by $46 \%$ and $40 \%$ for sample-1 and sample-2, respectively. The values of $d_{\mathrm{p}}(42 \mathrm{~nm}-56 \mathrm{~nm})$ are within the range $(20 \mathrm{~nm}-60 \mathrm{~nm})$ of previous studies (Li, 2003) and decreased by up to $20 \%$ after denuding. The higher maximum length, $L_{\max }$ and the higher $d_{\mathrm{p}}$ in the ambient samples result in higher estimates of $N$ and $D_{\mathrm{f}}$. Filling of the voids by condensed material on ambient particles results in more compact (higher roundness) particles (Table 3-2).

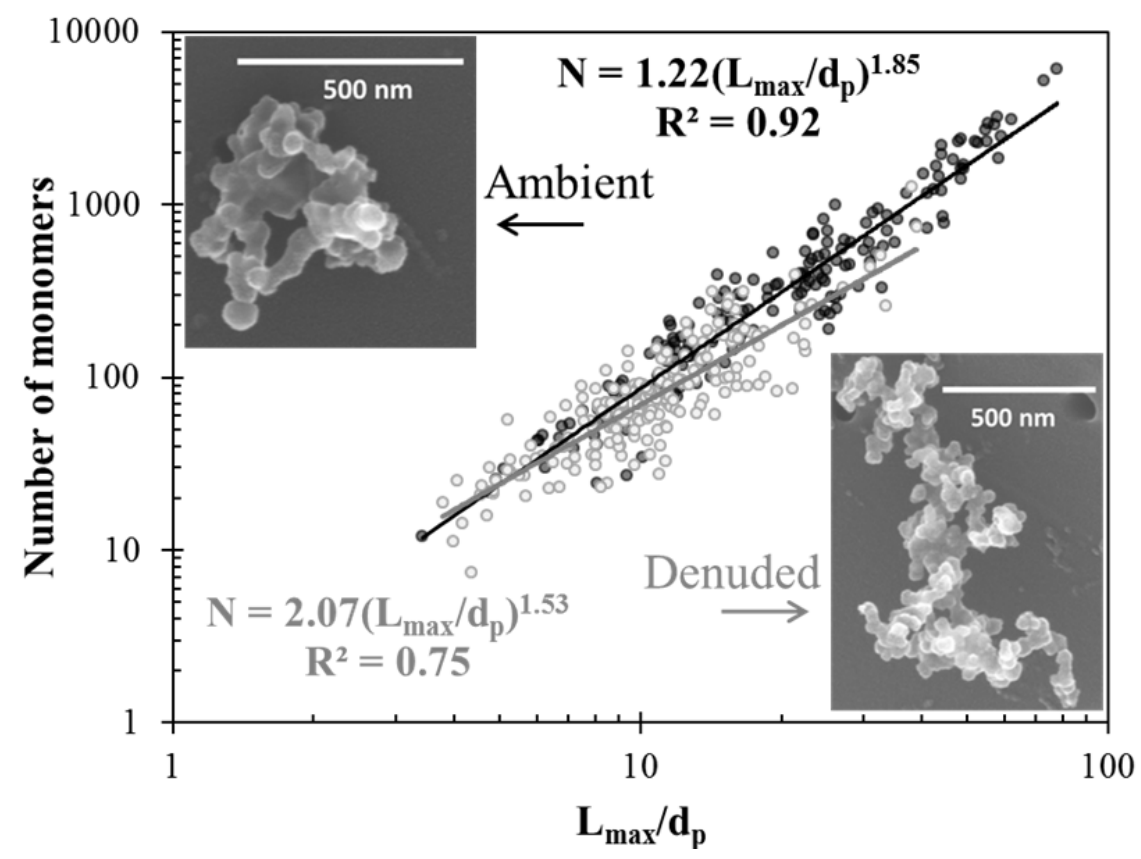

Figure 3-6: Fractal dimension of soot particles. Fractal dimension of ambient-1 (in black) and denuded-1 (in gray) soot particles. The fractal dimension of ambient and denuded soot are $1.85 \pm 0.05(\mathrm{n}=176)$ and $1.53 \pm 0.07(\mathrm{n}=209)$, respectively. Standard errors were calculated from the uncertainty in the mean-square fit considering the uncertainty in $N$ and $d_{\mathrm{p}}$. The insets provide example of ambient- 1 and denuded- 1 soot particles. The scale bars equal $500 \mathrm{~nm}$. 
$D_{\mathrm{f}}$ reflects the history of a fractal-like particle and is controlled by source, combustion conditions, and aging processes (Adachi et al., 2007). Densely packed or compacted soot particles have higher $D_{\mathrm{f}}$ than chain-like branched clusters or open structures (Liu et al., 2008). Compaction of aggregates due to coating contributes to changes in particle size and $D_{\mathrm{f}}$. In a previous laboratory study, the mass-mobility exponent, which is equivalent to $D_{\mathrm{f}}$, of coated soot was found to be higher than for denuded and nascent soot (Cross et al., 2010). The level of compaction depends on the coating material due to surface tension forces, discharge of electrostatic forces (Cross et al., 2010) and/or capillary forces acting on aggregate chains during the condensation-evaporation cycle (Lewis et al., 2009).

In our study, the $D_{\mathrm{f}}$ of three soot types were investigated separately: highest $D_{\mathrm{f}}$ was found for embedded-soot followed by partly-coated and bare soot; although denuded soot did not show a similar pattern, possibly due to restructuring of the soot particles by the denuding process. The changes in $D_{\mathrm{f}}$ for embedded particles $\left(\Delta D_{\mathrm{f}[\text { Embedded }]}=D_{\mathrm{f}}\right.$ ambient $-D_{\mathrm{f} \text {-denuded }}$ ) are statistically significant for both samples, $\Delta D_{\mathrm{f} \text { [Embedded] }}=0.42 \pm 0.17$ ( $\mathrm{p}=0.01$, paired Student's t-test) and $\Delta D_{\mathrm{f}[\text { Embedded }]}=0.34 \pm 0.16(\mathrm{p}=0.03$, paired Student's t-test) for sample-1 and sample-2, respectively. It is interesting to note that the difference between $D_{\mathrm{f}}$ for all ambient and denuded soot (excluding soot with inclusions) is $0.32 \pm 0.09$ and $0.18 \pm 0.08$ for sample- 1 and sample- 2 , respectively. This suggests that in general particles were more coated in sample-1 than sample-2. The changes in morphology of the mixed particle upon denuding are also confirmed by the differences in $D_{\mathrm{Aeq}}$ and $L_{\max }$ in ambient and denuded samples. Finally, we note that for denuded-1 soot, $D_{\mathrm{f}}(1.53)$ is quite smaller than for denuded-2 particles (1.78) even though the average denuder temperature was higher in the denuded-2 sample. This suggests that the structure of the nascent soot in sample-2 was more compact than in sample-1. 


\subsection{Conclusions}

Our analysis of the Las Conchas fire shows that approximately $32 \%$ of the TBs were highly oxidized and $50 \%$ of the soot particles were heavily coated. Increased oxidation of organic aerosol has been found to correlate with enhanced ice nucleation efficiency (Baustian et al., 2012). Similarly, the existence of different oxidation states in TBs could influence cloud condensation nuclei activity, ice nucleation and TB scavenging; this should be the subject of further study to assess the indirect effects of TBs on climate. Furthermore, the oxidation state of atmospheric particles affects their optical properties (Cappa et al., 2011; George and Abbatt, 2010) in terms of their effective index of refraction and size, therefore impacting their direct effect on climate. Typically, TBs and the variability in their optical properties are not accounted for in climate models. However, recently general circulation climate models have started including simplified schemes to account for soot mixing (Aquila et al., 2011; Bauer et al., 2008; Jacobson, 2001; Stier et al., 2005) and for TBs (Jacobson, 2012; Jacobson, 2001) as well on regional scales (Vogel et al., 2009). The refractive index values of TBs vary greatly in the literature and probably differ substantially for various conditions (e.g.; environmental conditions, location, aging, BB fuel type) (Alexander et al., 2008; Chakrabarty et al., 2010). Our analysis shows that the properties of TBs might be highly variable even within the same fire event. Furthermore, aerosol radiative forcing strongly depends on the description of coating and mixing state of BB particles within the models (Jacobson, 2001; Myhre, 2009). Our measurements of soot mixing state provides quantitative observational guidance on the applicability and validity of particle-resolved mixing state models (Riemer et al., 2009). These details are crucial to assess the accuracy of climate models in describing the contribution of BB aerosol radiative forcing (Lack and Cappa, 2010) and their direct and indirect climate effects. Finally, the abundance of embedded soot particles can be used to understand the enhancement potential of (or lack thereof) absorption and scattering of internally mixed soot particles (Cappa et al., 2012). 


\subsection{References}

Adachi and Buseck, P.: Internally mixed soot, sulfates, and organic matter in aerosol particles from Mexico City, Atmos. Chem. Phys, 8, 6469-6481, 2008.

Adachi, Chung, S. H., Friedrich, H., and Buseck, P. R.: Fractal parameters of individual soot particles determined using electron tomography: Implications for optical properties, Journal of Geophysical Research-Atmospheres, 112, 2007.

Adachi, K. and Buseck, P. R.: Atmospheric tar balls from biomass burning in Mexico, Journal of Geophysical Research, 116, 2011.

Alexander, D. T. L., Crozier, P. A., and Anderson, J. R.: Brown carbon spheres in East Asian outflow and their optical properties, Science, 321, 833-836, 2008.

Aquila, V., Hendricks, J., Lauer, A., Riemer, N., Vogel, H., Baumgardner, D., Minikin, A., Petzold, A., Schwarz, J., and Spackman, J.: MADE-in: A new aerosol microphysics submodel for global simulation of insoluble particles and their mixing state, Geosci. Model Dev, 4, 325-355, 2011.

Bauer, S., Wright, D., Koch, D., Lewis, E., McGraw, R., Chang, L., Schwartz, S., and Ruedy, R.: MATRIX (Multiconfiguration Aerosol TRacker of mIXing state): an aerosol microphysical module for global atmospheric models, Atmos. Chem. Phys, 8, 6003-6035, 2008.

Baustian, K. J., Cziczo, D. J., Wise, M. E., Pratt, K. A., Kulkarni, G., Hallar, A. G., and Tolbert, M. A.: Importance of aerosol composition, mixing state, and morphology for heterogeneous ice nucleation: A combined field and laboratory approach, Journal of Geophysical Research-Atmospheres, 117, 2012.

Bond, T., Doherty, S., Fahey, D., Forster, P., Berntsen, T., DeAngelo, B., Flanner, M., Ghan, S., Kärcher, B., and Koch, D.: Bounding the role of black carbon in the climate system: a scientific assessment, Journal of Geophysical Research: Atmospheres, 2013. 2013.

Bond, T. C., Streets, D. G., Yarber, K. F., Nelson, S. M., Woo, J. H., and Klimont, Z.: A technology-based global inventory of black and organic carbon emissions from combustion, Journal of Geophysical Research-Atmospheres, 109, 2004. 
Brasil, A. M., Farias, T. L., and Carvalho, M. G.: A recipe for image characterization of fractal-like aggregates, Journal of Aerosol Science, 30, 1379-1389, 1999.

Buseck, P., Adachi, K., Gelencsér, A., Tompa, É., and Pósfai, M.: Are black carbon and soot the same?, Atmos. Chem. Phys. Discuss, 12, 24821-24846, 2012.

Cappa, C. D., Che, D. L., Kessler, S. H., Kroll, J. H., and Wilson, K. R.: Variations in organic aerosol optical and hygroscopic properties upon heterogeneous $\mathrm{OH}$ oxidation, Journal of Geophysical Research: Atmospheres, 116, D15204, 2011.

Cappa, C. D., Onasch, T. B., Massoli, P., Worsnop, D. R., Bates, T. S., Cross, E. S., Davidovits, P., Hakala, J., Hayden, K. L., Jobson, B. T., Kolesar, K. R., Lack, D. A., Lerner, B. M., Li, S.-M., Mellon, D., Nuaaman, I., Olfert, J. S., Petäjä, T., Quinn, P. K., Song, C., Subramanian, R., Williams, E. J., and Zaveri, R. A.: Response to Comment on "Radiative Absorption Enhancements Due to the Mixing State of Atmospheric Black Carbon", Science, 339, 393, 2013.

Cappa, C. D., Onasch, T. B., Massoli, P., Worsnop, D. R., Bates, T. S., Cross, E. S., Davidovits, P., Hakala, J., Hayden, K. L., Jobson, B. T., Kolesar, K. R., Lack, D. A., Lerner, B. M., Li, S. M., Mellon, D., Nuaaman, I., Olfert, J. S., Petaja, T., Quinn, P. K., Song, C., Subramanian, R., Williams, E. J., and Zaveri, R. A.: Radiative Absorption Enhancements Due to the Mixing State of Atmospheric Black Carbon, Science, 337, 1078-1081, 2012.

Chakrabarty, R. K., Moosmüller, H., Chen, L. W. A., Lewis, K., Arnott, W. P., Mazzoleni, C., Dubey, M. K., Wold, C. E., Hao, W. M., and Kreidenweis, S. M.: Brown carbon in tar balls from smoldering biomass combustion, Atmospheric Chemistry and Physics, 10, 6363-6370, 2010.

Chakrabarty, R. K., Moosmüller, H., Garro, M. A., Arnott, W. P., Walker, J., Susott, R. A., Babbitt, R. E., Wold, C. E., Lincoln, E. N., and Hao, W. M.: Emissions from the laboratory combustion of wildland fuels: Particle morphology and size, Journal of Geophysical Research-Atmospheres, 111, 2006.

Cross, E. S., Onasch, T. B., Ahern, A., Wrobel, W., Slowik, J. G., Olfert, J., Lack, D. A., Massoli, P., Cappa, C. D., and Schwarz, J. P.: Soot particle studies- 
instrument inter-comparison-project overview, Aerosol Science and Technology, 44, 592-611, 2010.

Egerton, R. F.: Physical principles of electron microscopy, Springer, 2005.

George, I. J. and Abbatt, J. P. D.: Heterogeneous oxidation of atmospheric aerosol particles by gas-phase radicals, Nature Chemistry, 2, 713-722, 2010.

Hand, J. L., Day, D. E., McMeeking, G. M., Levin, E. J. T., Carrico, C. M., Kreidenweis, S. M., Malm, W. C., Laskin, A., and Desyaterik, Y.: Measured and modeled humidification factors of fresh smoke particles from biomass burning: role of inorganic constituents, Atmospheric Chemistry and Physics, 10, 61796194, 2010.

Hand, J. L., Malm, W. C., Laskin, A., Day, D., Lee, T., Wang, C., Carrico, C., Carrillo, J., Cowin, J. P., Collett, J., and Iedema, M. J.: Optical, physical, and chemical properties of tar balls observed during the Yosemite Aerosol Characterization Study, Journal of Geophysical Research, 110, 2005.

IPCC: The Physical Science Basis: Contribution of Working Group I to the Fourth Assessment Report of the Intergovernmental Panel on Climate Change, Cambridge, U. K., 2007.

Ivey, D. G.: Electron microscopy techniques applied to materials for energy storage and conversion. In: Microscopy: Science, Technology, Applications and Education, Mendez-Vilas, A. and Diaz, J. (Eds.), Formatex Research Center, 2010.

Jacobson, M. Z.: Comment on "Radiative Absorption Enhancements Due to the Mixing State of Atmospheric Black Carbon", Science, 339, 393, 2013.

Jacobson, M. Z.: Investigating cloud absorption effects: Global absorption properties of black carbon, tar balls, and soil dust in clouds and aerosols, Journal of Geophysical Research, 117, D06205, 2012.

Jacobson, M. Z.: Strong radiative heating due to the mixing state of black carbon in atmospheric aerosols, Nature, 409, 695-697, 2001. 
Köylü, Ü. Ö., Faeth, G. M., Farias, T. L., and Carvalho, M. G.: Fractal and projected structure properties of soot aggregates, Combustion and Flame, 100, 621-633, 1995.

Lack, D. A. and Cappa, C. D.: Impact of brown and clear carbon on light absorption enhancement, single scatter albedo and absorption wavelength dependence of black carbon, Atmospheric Chemistry and Physics, 10, 4207-4220, 2010.

Lack, D. A., Langridge, J. M., Bahreini, R., Cappa, C. D., Middlebrook, A. M., and Schwarz, J. P.: Brown carbon and internal mixing in biomass burning particles, Proceedings of the National Academy of Sciences, doi: 10.1073/pnas.1206575109, 2012. 2012.

Lewis, K., Arnott, W., Moosmüller, H., Chakrabarty, R., Carrico, C., Kreidenweis, S., Day, D., Malm, W., Laskin, A., and Jimenez, J.: Reduction in biomass burning aerosol light absorption upon humidification: roles of inorganically-induced hygroscopicity, particle collapse, and photoacoustic heat and mass transfer, Atmos. Chem. Phys, 9, 8949-8966, 2009.

Li, J.: Individual aerosol particles from biomass burning in southern Africa: 2, Compositions and aging of inorganic particles, Journal of Geophysical Research, 108, 2003.

Liu, Mishchenko, M. I., and Arnott, W. P.: A study of radiative properties of fractal soot aggregates using the superposition T-matrix method, Journal of Quantitative Spectroscopy \& Radiative Transfer, 109, 2656-2663, 2008.

Mao, J., Horowitz, L. W., Naik, V., Fan, S., Liu, J., and Fiore, A. M.: Sensitivity of tropospheric oxidants to biomass burning emissions: implications for radiative forcing, Geophysical Research Letters, 2013. 2013.

Myhre, G.: Consistency Between Satellite-Derived and Modeled Estimates of the Direct Aerosol Effect, Science, 325, 187-190, 2009.

Myhre, G., Samset, B., Schulz, M., Balkanski, Y., Bauer, S., Berntsen, T., Bian, H., Bellouin, N., Chin, M., and Diehl, T.: Radiative forcing of the direct aerosol 
effect from AeroCom Phase II simulations, Atmospheric Chemistry \& Physics Discussions, 12, 22355-22413, 2012.

Oh, C. and Sorensen, C. M.: The effect of overlap between monomers on the determination of fractal cluster morphology, Journal of Colloid and Interface Science, 193, 17-25, 1997.

Petzold, A., Ogren, J., Fiebig, M., Laj, P., Li, S.-M., Baltensperger, U., Holzer-Popp, T., Kinne, S., Pappalardo, G., and Sugimoto, N.: Recommendations for the interpretation of" black carbon" measurements, Atmospheric Chemistry and Physics Discussions, 13, 9485-9517, 2013.

Pósfai, M.: Atmospheric tar balls: Particles from biomass and biofuel burning, Journal of Geophysical Research, 109, 2004.

Pósfai, M., Gelencsér, A., Simonics, R., Arató, K., Li, J., Hobbs, P. V., and Buseck, P. R.: Atmospheric tar balls: Particles from biomass and biofuel burning, J. Geophys. Res., 109, D06213, 2004.

Pósfai, M., Simonics, R., Li, J., Hobbs, P. V., and Buseck, P. R.: Individual aerosol particles from biomass burning in southern Africa: 1. Compositions and size distributions of carbonaceous particles, J. Geophys. Res., 108, 8483, 2003.

Ramanathan, V. and Carmichael, G.: Global and regional climate changes due to black carbon, Nature Geoscience, 1, 221-227, 2008.

Reid, J. S., Eck, T. F., Christopher, S. A., Koppmann, R., Dubovik, O., Eleuterio, D., Holben, B. N., Reid, E. A., and Zhang, J.: A review of biomass burning emissions part III: intensive optical properties of biomass burning particles, Atmospheric Chemistry and Physics, 5, 827-849, 2005.

Riemer, N., West, M., Zaveri, R. A., and Easter, R. C.: Simulating the evolution of soot mixing state with a particle-resolved aerosol model, Journal of Geophysical Research-Atmospheres, 114, 2009.

Samson, R. J., Mulholland, G. W., and Gentry, J. W.: Structural-analysis of soot agglomerates, Langmuir, 3, 272-281, 1987. 
Stier, P., Feichter, J., Kinne, S., Kloster, S., Vignati, E., Wilson, J., Ganzeveld, L., Tegen, I., Werner, M., and Balkanski, Y.: The aerosol-climate model ECHAM5HAM, Atmos. Chem. Phys, 5, 1125-1156, 2005.

Tivanski, A. V., Hopkins, R. J., Tyliszczak, T., and Gilles, M. K.: Oxygenated interface on biomass burn tar balls determined by single particle scanning transmission Xray microscopy, Journal of Physical Chemistry A, 111, 5448-5458, 2007.

Vogel, B., Vogel, H., Bäumer, D., Bangert, M., Lundgren, K., Rinke, R., and Stanelle, T.: The comprehensive model system COSMO-ART-radiative impact of aerosol on the state of the atmosphere on the regional scale, Atmos. Chem. Phys, 9, 8661-8680, 2009.

Westerling, A. L., Hidalgo, H. G., Cayan, D. R., and Swetnam, T. W.: Warming and earlier spring increase western US forest wildfire activity, Science, 313, 940$943,2006$. 


\section{Evolution of Soot Morphology and Mixing State in the Atmosphere ${ }^{3}$}

The evolution of morphology and mixing state of soot particles during long-range transport is still not well characterized. We collected free tropospheric aerosols at the Pico Mountain Observatory, located in the Azores Islands (Portugal) in the North Atlantic Ocean. Using electron microscopy, we analyze the morphology and mixing state of individual soot particles that have been long-range transported over the ocean during two specific events with different plume age. We find that the morphology of aged soot particles is overall much more compacted than freshly emitted soot. We use discrete dipole approximation to perform numerical calculations of the soot optical properties and show that compaction results in increased single scattering albedo. Finally, we provide a brief summary and comparison of morphology and mixing state of soot particles collected from different geographical locations and environmental conditions. We find that soot processing in urban atmospheres results in a complex mixture of coated and uncoated particles with a variety of morphologies and mixing states, while soot particles transported over long ranges are most compacted.

\subsection{Introduction}

Soot particles or ns-soot (nanosphere soot) (Buseck et al., 2014), often referred to as black carbon, are aggregates of carbonaceous monomers produced from incomplete combustion such as fossil fuel and biomass burning. Soot particles strongly absorb sunlight, directly impacting Earth's radiation balance (Bond et al., 2013; Haywood and Ramaswamy, 1998). Soot particles also facilitate atmospheric heterogeneous reactions due to their large surface area (Nyeki and Colbeck, 2000; Zhang et al., 2008) and they can affect climate indirectly by acting as cloud condensation nuclei $(\mathrm{CCN})$ and ice

\footnotetext{
${ }^{3}$ Major portion of this chapter is based on material to be submitted, as China et al., (2014), Geophysical Research letters.
} 
nuclei (Bond et al., 2013; Tritscher et al., 2011; Zhang et al., 2008). Soot warm the atmospheric layer where it is accumulated strengthening atmospheric stability and causing cloud droplet evaporation when within a cloud (Hansen et al., 1997) or potentially causing cloud thickening when above a cloud (Wilcox, 2012). Soot can also be transported over long distances such as to remote Arctic regions or high elevation Himalayan regions and be deposited by wet or dry deposition on snow, reducing its albedo and contributing to snow melt and regional and global warming (Hansen and Nazarenko, 2004; Ramanathan and Carmichael, 2008; Rosen et al., 1981).

Freshly emitted soot particles are typically hydrophobic, and structured as open fractallike aggregates. During transport, soot aggregates undergo various aging processes such as coagulation, condensation and heterogeneous reactions resulting in chemical and morphological changes such as oxidation, mixing, coating, and shape restructuring. These changes affect the soot hygroscopicity, and its light scattering and absorption cross sections (Cross et al., 2010; Khalizov et al., 2009; Lack et al., 2012; Zhang et al., 2008). The aging time scale of soot (i.e., the time required for fresh hydrophobic soot to be converted to hydrophilic soot) is an important parameter in global climate models. Hydrophilic particles can be removed by wet scavenging, affecting the global transport of soot. Models often assume a constant aging time scale with an exponential rate of 1.15 days (Cooke et al., 2002). However, several studies consider both coagulation and condensation as aging process (Jacobson, 2001; Riemer et al., 2003) including chemical oxidation (Huang et al., 2013). Therefore, the aging rate and atmospheric life time of soot are still major sources of uncertainty in global climate models (Liu et al., 2011). The complex morphology (shape, size and internal structure) and mixing states (coating and mixing of other material) of soot significantly impacts its aging time scale as well as atmospheric life time, affecting its global burden and radiative forcing (Van Poppel et al., 2005). Studying the morphology of aged soot particles after long-range transport is therefore essential to understand their aging processes and to accurately model their properties. 
In this study, we investigate the morphology and mixing state of soot particles transported over long-ranges in the free-troposphere and collected at Pico Mountain Observatory, located in the summit caldera of the Pico volcano in the Pico Island in the archipelago of the Azores, Portugal. We use scanning electron microscopy for single particle analysis. Here we present results from samples collected at the site during two events in July 2012, one being a transport with long recirculation time over the marine environment and relatively longer plume age ( 15.7 days as estimated from retroplume simulations), compared to a second event of transport from North America and shorter plume age ( $\sim 9.5$ days). We investigate the morphology of individual soot particles based on their coating, shape and mixing state. We then study the implications of these findings on the optical properties of soot, by using numerical simulations based on discrete dipole approximation.

\subsection{Experimental section and methods}

\subsubsection{Sampling site and measurements}

The Pico Mountain Observatory (PMO) is located in the summit caldera of the Pico Volcano (at $2225 \mathrm{~m}$ asl) in the Azores, Portugal $\left(38.47^{\circ} \mathrm{N}, 28.40^{\circ} \mathrm{W}\right)$. The mountaintop station is typically above the marine boundary layer (Honrath et al., 2004; Rémillard et al., 2012). The station receives air masses often from North America and sometimes from Africa and Europe and is an ideal site to study free-tropospheric aerosol transported over long distances across the Atlantic Ocean.

The first event studied here (event-1) took place in July 06-07, 2012. The second event (event-2) took place in July 20-21, 2012. Retroplume analysis using the Lagrangian particle dispersion model FLEXPART (Owen and Honrath, 2009; Stohl et al., 2005) shows that in both periods the air masses reaching PMO were traveling from west to east. Figure 4-1 shows the horizontal and vertical transport pattern for two events. Figure 4-1 ( $a$ and b) show the transport pattern for event-1, July (06-07), 2012 and Figure 4-1(c and d) show the transport event-2, July (20-21), 2012. FLEXPART 
retroplumes and emission inventories are combined to compute anthropogenic $\mathrm{CO}$ tracer concentrations. Average plume ages for the two events are calculated using the $\mathrm{CO}$ tracer concentrations. The average plume age of the event- 1 was $\sim 15.7$ days and for event-2 was 9.5 days and the retroplume analysis shows a possible air recirculation over the Atlantic Ocean. For the first event air masses were mostly transported to PMO from the south-west Atlantic Ocean, while during the second event air masses reaching PMO were mostly transported from North America. Soot particles analyzed for event-1 are probably more aged compared to those in event- 2 as the plume age of event- 1 is relatively higher ( $\sim 15.7$ days) compared to event-2 ( $\sim 9.5$ days).
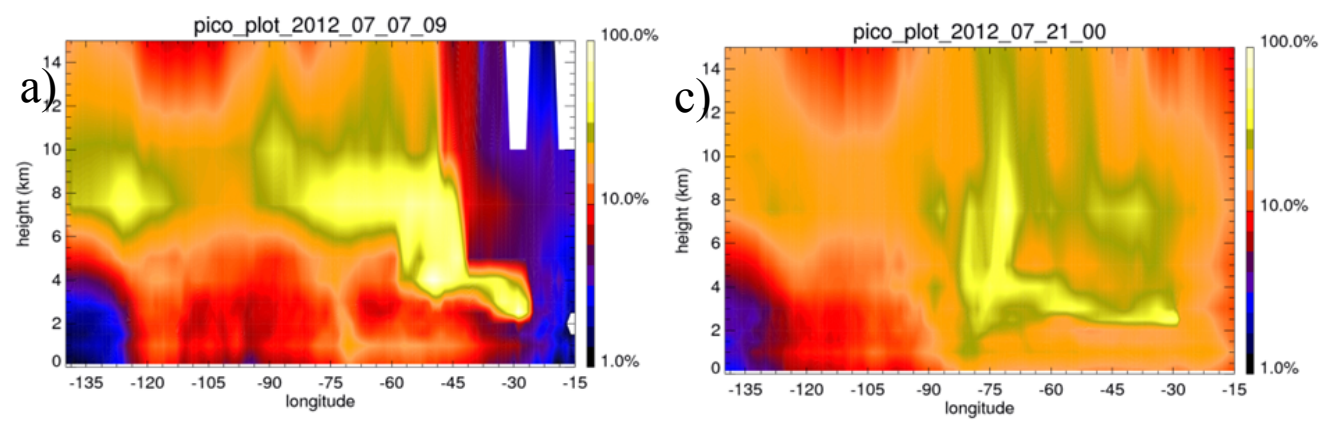

b)

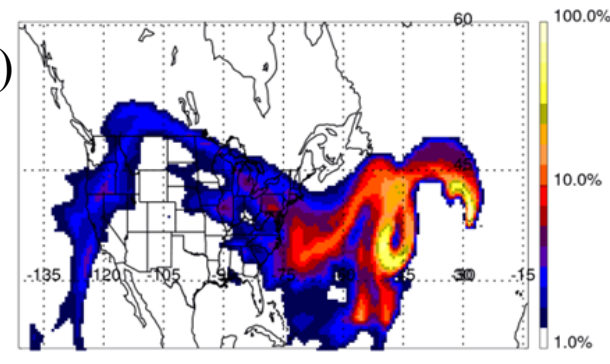

d)

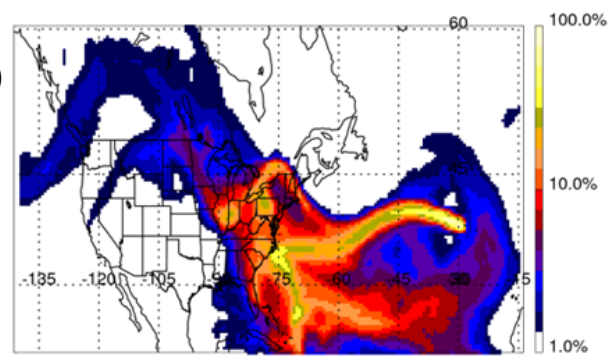

Figure 4-1: FLEXPART Retroplumes. Left panels ( $a$ and $b$ ) show the transport pattern for event-1, July (06-07), 2012 and right panels for event-2, July (20-21), 2012. Left panels (a and c) show the column-integrated horizontal transport from all height levels while right panels ( $b$ and $d$ ) show the vertical distribution of transport.

Atmospheric particles were collected on nuclepore polycarbonate filters $(100 \mathrm{~nm}$ pore size) using a custom-made sequential sampler (China et al., 2013). Particle morphology and mixing state are studied using two-dimensional images of individual particles with 
a field emission scanning electron microscope (FE-SEM) (Hitachi S-4700) coupled with an energy dispersive X-ray spectrometer (EDS).

In particular, this chapter discusses aged soot particles collected at PMO. At the end of this chapter, we provide a brief summary of the morphology and mixing states of soot particles collected from different geographical locations and environmental conditions. Samples from various geographical location includes, samples from Mexico City: in the center of the city and in the uplifted boundary layer captured on the top of the Pico de Tres Padres Mountain on the north edge of the city during the MILAGRO (Megacity Initiative: Local and Global Research Observations) field campaign (2006), samples from the Sacramento urban area and the Sierra Nevada foothills in California during the CARES (Carbonaceous Aerosols and Radiative Effects Study) campaign (2010) and samples from Detling, a village in UK, during the ClearfLo (Clean Air for London) campaign aimed at studying airmasses transported from London and affected by household biomass burning (2012). Samples from fresh vehicular emission (Ann Arbor, MI) and biomass burning emission (Las Conchas fire) (discussed in chapter 2 and 3 respectively) also included in the comparison.

\subsubsection{Particle classification and soot mixing state}

This study focuses on soot particles; the first step is therefore that of identifying the soot particles within all the particles collected on the filters. We do that by classifying the particles into five general categories based on their morphologies and elemental composition: i) soot, ii) spherical particles, iii) near spherical particles, iv) mineral dust, and v) other irregularly shaped particles (Figure 4-2). Particles were classified based on their morphology and elemental composition using energy dispersive X-ray spectroscopy analysis. Note that from this classification we exclude particles smaller than $50 \mathrm{~nm}$ because the pore size of our filters is $100 \mathrm{~nm}$ resulting in reduced collection efficiency for smaller particles. 
Figure 4-2 shows an example of different types of particles with various morphologies that were collected on the filters. Irregularly shaped particles can be salt particles, biological particles or other organic and mixed particles. On average $\sim 27 \%$ and $\sim 54 \%$ of the total number of particles imaged on the filters were soot particles for event- 1 and event-2 respectively. Particle classification is based on particles in the size range of 50 $\mathrm{nm}$ to $3000 \mathrm{~nm}$. Elemental composition from EDS analysis shows that the soot particles are mostly composed of $\mathrm{C}$ and $\mathrm{O}$ and sometimes a fraction of $\mathrm{S}$. Dust particles consist of mostly of Si, Al, O, C and minor fractions of Fe, Mg, S, K and Na. Figure 4-2 (e-I and e-ii) show rectangular crystalline particles with $\mathrm{O}, \mathrm{S}$ and $\mathrm{Ca}$ as the dominant content and a minor fraction of C. Spherical particles are mostly composed of C and O.
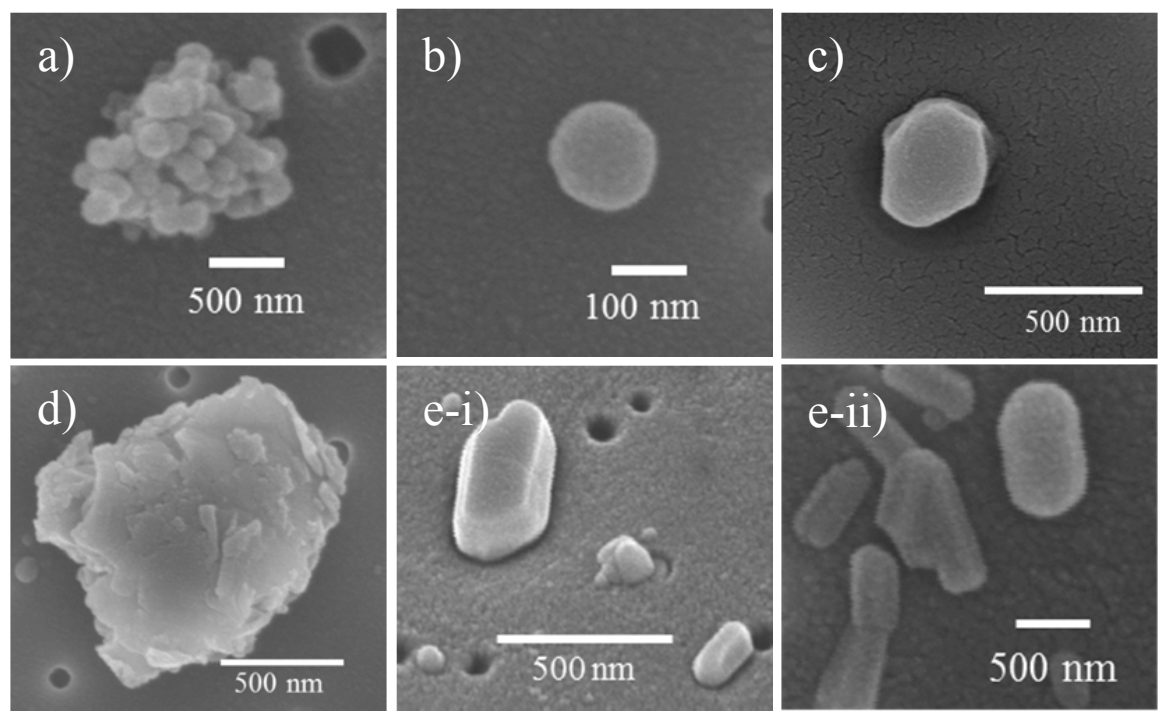

Figure 4-2: a) soot b) spherical c) near spherical d) dust and e-i) and e-ii) other irregularly shaped particles.

Soot particles are identified from their unique aggregate nature made of carbonaceous monomers. In this classification, soot includes soot particles that are mixed with, or coated by other material. The caveat with this classification is that particles made of volatile material might partially evaporate in the vacuum conditions of the SEM chamber, skewing the number of soot particles toward larger fractions than actually present in the atmosphere. A second caveat, is that soot particle that are fully embedded 
into coating material might not be recognized as soot particles as SEM is a surface imaging technique; this artifact can actually result in an undercounting of the soot particles, especially those classified as embedded. However, the method still allows comparing the relative abundances for different events, assuming the volatility of others particles and the abundance of heavily coated particles is approximately the same. Then, the second step is that of examining the mixing state of soot particles by visually classifying the particles based on their coating and mixing. Soot particles are categorized into four groups: 1) embedded soot (Adachi and Buseck, 2008), where the particle is fully engulfed in the coating material; 2) partly coated soot, where the coating material is substatial but thiner than in embedded particles; 3 ) thinly coated soot, where coating on soot is minimal or missing (or bare soot); 4) soot with inclusions, where only a part of the soot particle is mixed with other material or the soot particle is only partially touching another particle (Figure 4-3). Details of this soot classification and its limitations are discussed elsewhere (China et al., 2013).
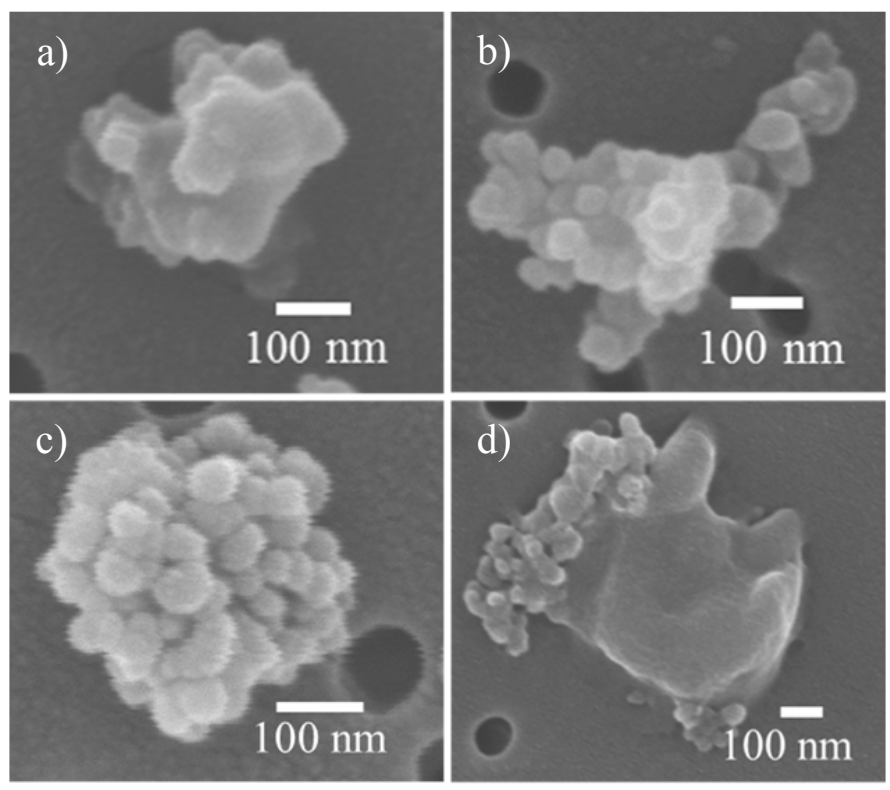

Figure 4-3: Four major types of soot particle mixing states: a) embedded; b) partly coated; c) thinly coated; and d) soot inclusion. 


\subsubsection{Soot morphology}

Soot particles are considered to be fractal-like aggregates, meaning that they exhibit self-similar structures over several length scales (Oh and Sorensen, 1997) and can be described using a mass fractal dimension $\left(D_{f}\right)$ (Mandelbrot, 1982). The ensemble method can be used to calculate the fractal dimension of freshly emitted soot particles from 2-D images (for particles with $D_{f}<2$ ) (Oh and Sorensen, 1997; Wentzel et al., 2003). However, soot particles collected at PMO and discussed here are extremely aged and often highly compacted (with an expected $D_{f}$ larger than 2). Therefore, we did not use the commonly employed ensemble method to estimate the scaling law, we used instead the measurable projected area of the aggregate $\left(A_{a}\right)$ and its maximum length $\left(L_{\max }\right)$ (Lee and Kramer, 2004) in the following scaling law:

$$
A_{a}=k_{2}\left(L_{\max }\right)^{D_{2 f}}
$$

In which we assume $A_{a}$ to be proportional (in log-log space) to the particle mass. Here, the power law exponent, $D_{2 f}$ represents our estimate of the 2-D fractal dimension. We applied the above power relation using ensembles of soot particles to provide a measure of the fractal morphology of soot particles inclusive of eventual coating material that might fill the voids between monomers.

The size of the soot particle, as estimated from 2D SEM images, is expressed in terms of the projected area equivalent diameter, $D_{A e q}$ that is defined as the diameter of the spherical particle of the same projected area as the particle under consideration. We use roundness and convexity to further quantify the compactness of soot particles. Roundness is defined as the ratio of the projected area of the particle to the area of a circle of diameter equal to $L_{\max }$. Convexity, or solidity, is the ratio of the projected area of the particle to the area of the convex hull polygon (smallest convex polygon that fully covers the particle's projected area). 


\subsubsection{Optical properties of soot with different compaction}

We investigate how the optical properties (scattering and absorption cross sections, single scattering albedo, and asymmetry parameter) of soot particles change with three different levels of compaction (open chain-like soot, medium compaction, and very compacted shape, representing fresh, medium aged and very aged soot, respectively) as a function of wavelength. First we use a random walk aggregation algorithm to generate synthetic soot particles (Richard et al., 2011) that closely mimic typical particles found in our study (Figure 4-4). Note that we investigate here the effect of soot compaction on optical properties without considering coating. For fresh emission, we generate the soot particle to get a $D_{f}$ close to 1.80 which is typically used for fresh emission. We use an intermediate $D_{f}$ (between 2 and 2.5) to represent medium aged soot. We use the thinly coated or bare soot particles (represent very aged soot) to estimate the number of monomers and monomer sizes to generate the aggregates for numerical simulation.
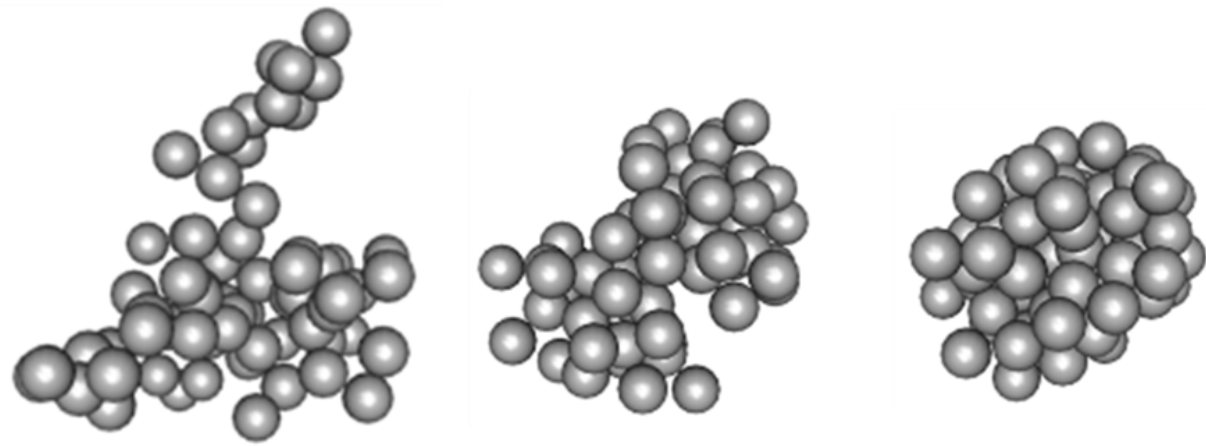

Figure 4-4: The synthetic particles represent fresh, medium-aged and very-aged soot from left to right.

The optical properties of the synthetic soot particles are calculated using the Discrete Dipole Approximation (DDA-DDSCAT7.3 code) (Draine and Flatau, 1994, 2013). Detailed description of the methods for the aggregate generation and DDA simulations is provided elsewhere (Scarnato et al., 2012). For the synthetic aggregate generation we use average morphological parameters (monomer diameter $=34 \mathrm{~nm}$, number of monomers $(N)=66$ and 150) obtained from the analysis of the soot particles collected 
at PMO. Two $N$ values are obtained considering different overlaps between monomers (discussed in section 5.3.4). For the DDA calculations a wavelength-dependent refractive index for soot is used following (Chang and Charalampopoulos, 1990). We calculate scattering and absorption cross sections for 10 wavelengths ranging from 370 $\mathrm{nm}$ to $950 \mathrm{~nm}$ relevant to different measurement techniques including remote sensing and covering the visible and NIR solar spectrum. The optical properties discussed in the following sections are averaged values computed over 1000 random target orientations (Scarnato et al., 2012).

\subsection{Results and discussions}

\subsubsection{Abundance of soot particles}

The main purpose of the general particle classification was to compare the relative abundance of soot particles between the two different transport events. Typically, soot particles can be easily distinguished as they appear as agglomerates of small spherical monomers (14-64 $\mathrm{nm}$ in this study), the exception is when soot particles are completely engulfed in a coating material so thick that the soot particle is not distinguishable from SEM images. For the purpose of the analysis presented here, 1,317 and 806 particles were used for event-1 and event-2, respectively. During event-2, the relative abundance of soot particles was almost double ( $\sim 54 \%)$ compared to event-1 (27\%). During event2 , the fraction of mineral dust and other particle types are $14 \%$ and $7 \%$ respectively. On the contrary, during event-1, we found $\sim 30 \%$ of mineral dust particles and $\sim 29 \%$ of other irregularly shaped particles (dominated by rectangular crystalline particles with $\mathrm{O}$, $\mathrm{S}$ and $\mathrm{Ca}$ content), suggesting that mineral dust might have been transported to PMO from North Africa. This possibility is corroborated by FLEXPART model simulations, suggesting recirculation over the Atlantic Ocean with the possible entrainment of air from southerner latitudes, where dust is often present as it is transported from the Saharan desert westward to the Gulf of Mexico. 


\subsubsection{Mixing states of soot}

Freshly emitted soot particles are normally very thinly coated or bare and most of them have an open chain-like structure (Adachi et al., 2007; China et al., 2014; Wentzel et al., 2003). During atmospheric processing, soot mixes with other compounds or other particles, resulting in different mixing configurations and sometimes in soot restructuring. Figure 4-5(a-f) shows typical morphologies of soot particles collected at PMO that are all very compact in shape. Open chain-like soot aggregates are rarely observed on the membranes collected during both events.
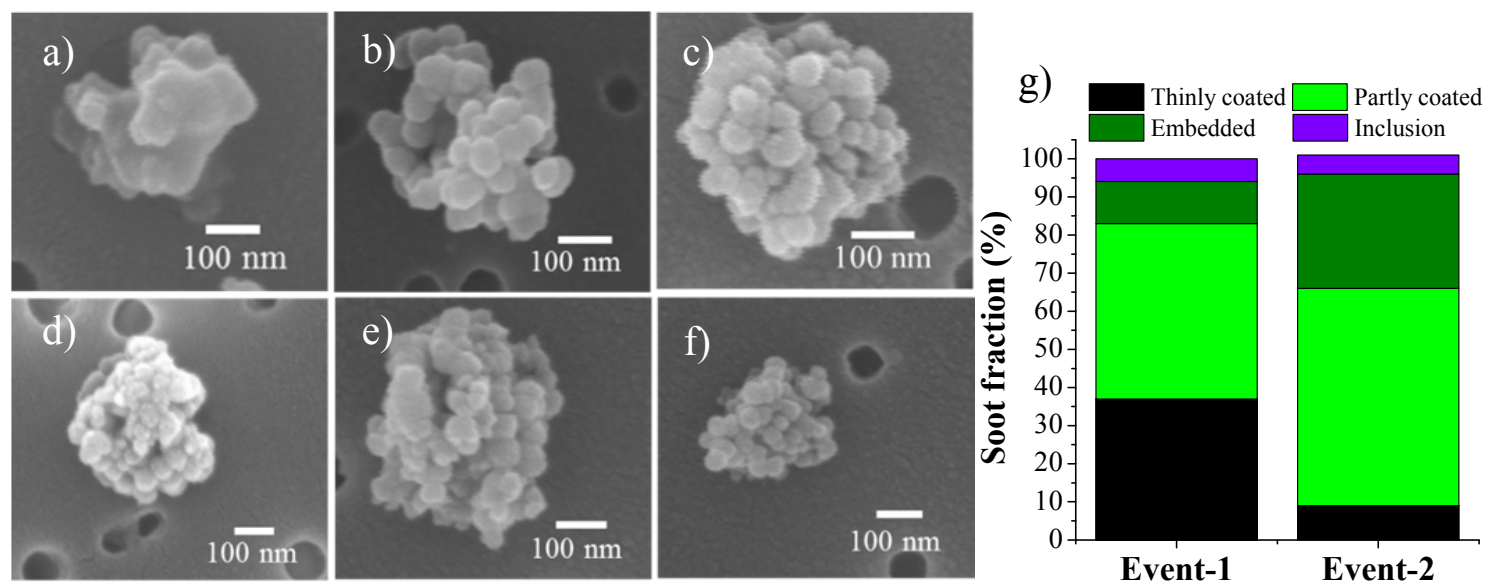

Figure 4-5: Left SEM images (a-f) show typical morphologies of soot particles observed at PMO. Right panel (g) shows the fraction of thinly coated, partly coated, embedded and inclusion soot for event-1 (July (06-07), 2012) and event-2 (July (20-21), 2012).

A total of 413 and 407 individual soot particles were analyzed for event-1 and event-2, respectively. The Approximate fractions of embedded, partly coated, thinly coated, and inclusion soot particles are presented in Figure 4-5 (g). The higher fraction of embedded and partially coated soot (87\%) in event-2 compared to event-1 (57\%) and the higher fraction of thinly coated soot in event-1 (37\%) compared to event-2 (9\%) suggest different atmospheric processing for the comparatively less aged plume in event-2; with condensation of coating material being prominent during event-2. The finding that the fraction of inclusion particles is small for both events suggests that coagulation 
processes were less important compared to condensation processes during the longrange transport over the ocean. Semi-quantitative EDS analysis shows that the particles attached to the soot in the particles categorized as soot inclusions, often contains $\mathrm{C}, \mathrm{O}$ and $\mathrm{S}$ for both events. A previous electron microscopy study found that $10-45 \%$ of sulfate particles contained soot as inclusions in clean air above the remote Southern Ocean (Pósfai et al., 1999). However, for our samples, the elemental composition of the embedded particles is mostly dominated by $\mathrm{C}$ and $\mathrm{O}$ with only a minor fraction of $\mathrm{S}$, suggesting that soot was possibly embedded in organic material.

\subsubsection{Morphology of soot particles}

The fractal dimension of soot particles reflects their aging and is controlled by the particles' source, generating conditions, and atmospheric processing pathways (Adachi et al., 2007). Compacted soot particles have higher $D_{f}$ than chain-like open clusters (Liu et al., 2008). For example, theoretically Figure 4-5 (c and d) should have a 3-D $D_{f}$ close to 3. Figure 4-6 shows the 2-d power law exponent or 2-D fractal dimension $\left(D_{2 f}\right)$ for event- 2 and event-1 as calculated following equation 1 . For the fractal dimension analysis, soot inclusion particles are not used as the projected area of the entire particle (including the inclusion) would bias the calculation of $D$ (China et al., 2014). On average, our 2-D fractal dimension $D_{2 f}$, as estimated from equation (1), is higher for event-2 (1.89 \pm 0.02$)$ than event-1 (1.82 \pm 0.02$)$. Higher $D_{2 f}$ reflects higher coating and/or higher compactness. In Table 4-1 and 4-2 we report the values of $D_{2 f}$ for three classes of soot particles. During both events, embedded soot shows higher $D_{2 f}$ than partly coated and thinly coated soot (Table 4-1 and 4-2). 

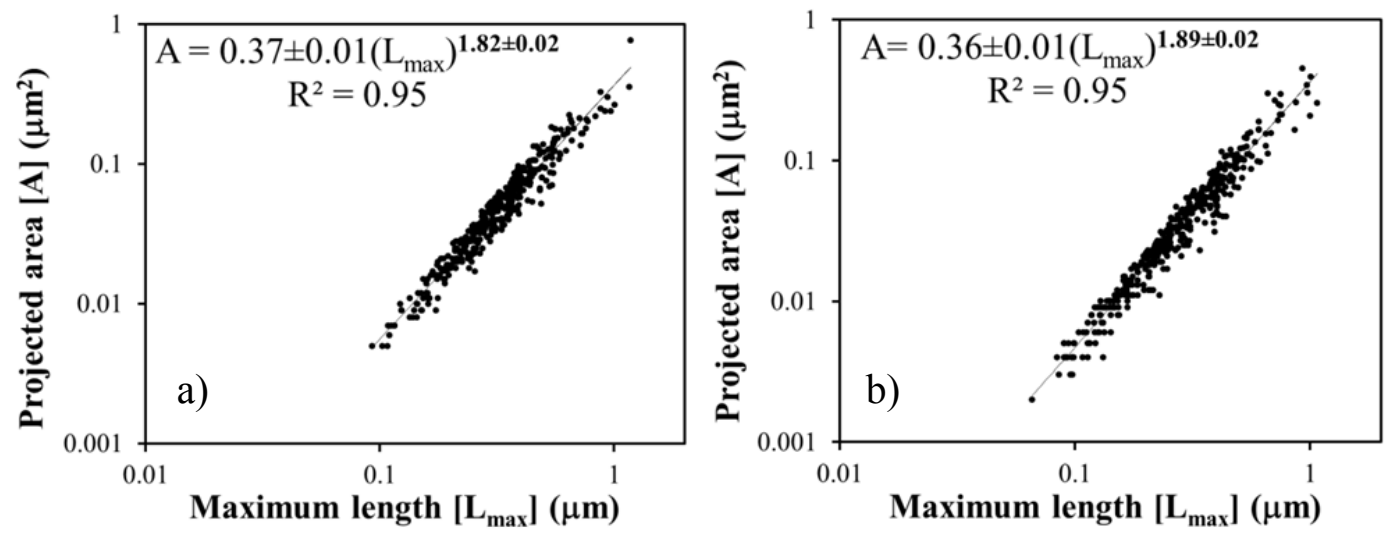

Figure 4-6: Power relationship between projected area and maximum length for a) event-1 and b) event-2. This includes all three kinds of soot particles but excludes soot with inclusions.

Table 4-1: Morphological parameters of thinly coated, partly coated and embedded soot particles for Event-1 (July 06-07, 2012). Numbers in the parenthesis represents standard deviation.

\begin{tabular}{cccccccc}
\hline & $n$ & $D_{\text {Aeq }}\left(\mathrm{nm}^{2}\right)$ & $A R$ & Convexity & $R N$ & $D_{2 f}$ & $k_{2}$ \\
\hline \hline \multirow{2}{*}{ Thinly coated } & \multirow{2}{*}{153} & $\begin{array}{c}249 \\
(95)\end{array}$ & $\begin{array}{c}1.38 \\
(0.20)\end{array}$ & $\begin{array}{c}0.85 \\
(0.07)\end{array}$ & $\begin{array}{c}0.60 \\
(0.11)\end{array}$ & $\begin{array}{c}1.81 \\
(0.04)\end{array}$ & $\begin{array}{c}0.37 \\
(0.02)\end{array}$ \\
\hline \multirow{2}{*}{ Partly coated } & \multirow{2}{*}{189} & $\begin{array}{c}262 \\
(128)\end{array}$ & $\begin{array}{c}1.44 \\
(0.25)\end{array}$ & $\begin{array}{c}0.84 \\
(0.07)\end{array}$ & $\begin{array}{c}0.57 \\
(0.11)\end{array}$ & $\begin{array}{c}1.81 \\
(0.03)\end{array}$ & $\begin{array}{c}0.35 \\
(0.02)\end{array}$ \\
\hline \multirow{2}{*}{ Embedded } & \multirow{2}{*}{46} & $\begin{array}{c}283 \\
(89)\end{array}$ & $\begin{array}{c}1.41 \\
(0.21)\end{array}$ & $\begin{array}{c}0.88 \\
(0.05)\end{array}$ & $\begin{array}{c}0.61 \\
(0.10)\end{array}$ & $\begin{array}{c}1.84 \\
(0.07)\end{array}$ & $\begin{array}{c}0.40 \\
(0.03)\end{array}$ \\
\hline
\end{tabular}

Number of particles analyzed $(n)$, Area equivalent diameter $\left(D_{A e q}\right)$, aspect ratio $(A R)$, convexity, roundness $(R N)$, power law exponent or 2-D fractal dimension $\left(D_{2 f}\right)$ and 2D prefactor $\left(k_{2}\right)$ for thinly coated, partly coated and embedded soot particles. E-1 represents event-1 and E-2 represents event-2.

On average, $D_{A e q}$ of embedded particles is the largest $(283 \mathrm{~nm})$, followed by partly coated $(262 \mathrm{~nm})$ and thinly coated soot particles $(249 \mathrm{~nm})$ for event-1 (Table 4-1), meaning that the size of the particle increases as coating increases. In contrast, for event-2 (Table 4-2) the difference in size between embedded and thinly coated soot is small, suggesting that soot inside the embedded structure might be smaller in size and/or that the coating is thinner. The details of the size distributions for the different 
soot particle types are discussed in the SI. The relatively larger size of thinly coated soot particles might result in those particles being better CCNs.

Table 4-2: Morphological parameters of thinly coated, partly coated and embedded soot particles for Event-2 (July 20-21, 2012). Numbers in the parenthesis represents standard deviation.

\begin{tabular}{cccccccc}
\hline & $n$ & $D_{\text {Aeq }}\left(\mathrm{nm}^{2}\right)$ & $A R$ & Convexity & $R N$ & $D_{2 f}$ & $k_{2}$ \\
\hline \hline \multirow{2}{*}{ Thinly coated } & \multirow{2}{*}{36} & $\begin{array}{c}245 \\
(122)\end{array}$ & $\begin{array}{c}1.57 \\
(0.34)\end{array}$ & $\begin{array}{c}0.79 \\
(0.09)\end{array}$ & $\begin{array}{c}0.50 \\
(0.12)\end{array}$ & $\begin{array}{c}1.85 \\
(0.08)\end{array}$ & $\begin{array}{c}0.32 \\
(0.04)\end{array}$ \\
\hline \multirow{2}{*}{ Partly coated } & \multirow{2}{*}{230} & $\begin{array}{c}206 \\
(106)\end{array}$ & $\begin{array}{c}1.49 \\
(0.30)\end{array}$ & $\begin{array}{c}0.82 \\
(0.07)\end{array}$ & $\begin{array}{c}0.55 \\
(0.11)\end{array}$ & $\begin{array}{c}1.88 \\
(0.03)\end{array}$ & $\begin{array}{c}0.36 \\
(0.02)\end{array}$ \\
\hline \multirow{2}{*}{ Embedded } & \multirow{2}{*}{122} & $\begin{array}{c}236 \\
(130)\end{array}$ & $\begin{array}{c}1.47 \\
(0.28)\end{array}$ & $\begin{array}{c}0.85 \\
(0.08)\end{array}$ & $\begin{array}{c}0.57 \\
(0.12)\end{array}$ & $\begin{array}{c}1.90 \\
(0.04)\end{array}$ & $\begin{array}{c}0.39 \\
(0.02)\end{array}$ \\
\hline
\end{tabular}

Figure 4-7 shows the size distribution of classified soot particles (thinly coated, partly coated and embedded) for event-1 and event-2. Size diributions of event-2 for all the soot types are relatively broader compared to event-1. On average, soot particles (mean values combing all three types) are larger $(259 \mathrm{~nm})$ for event-1compared to event-2 (219 nm). Figure 4-8 shows the roundness distribution for two events. Event-2 shows multiple peaks in the roundness distribution comparted to event-1.
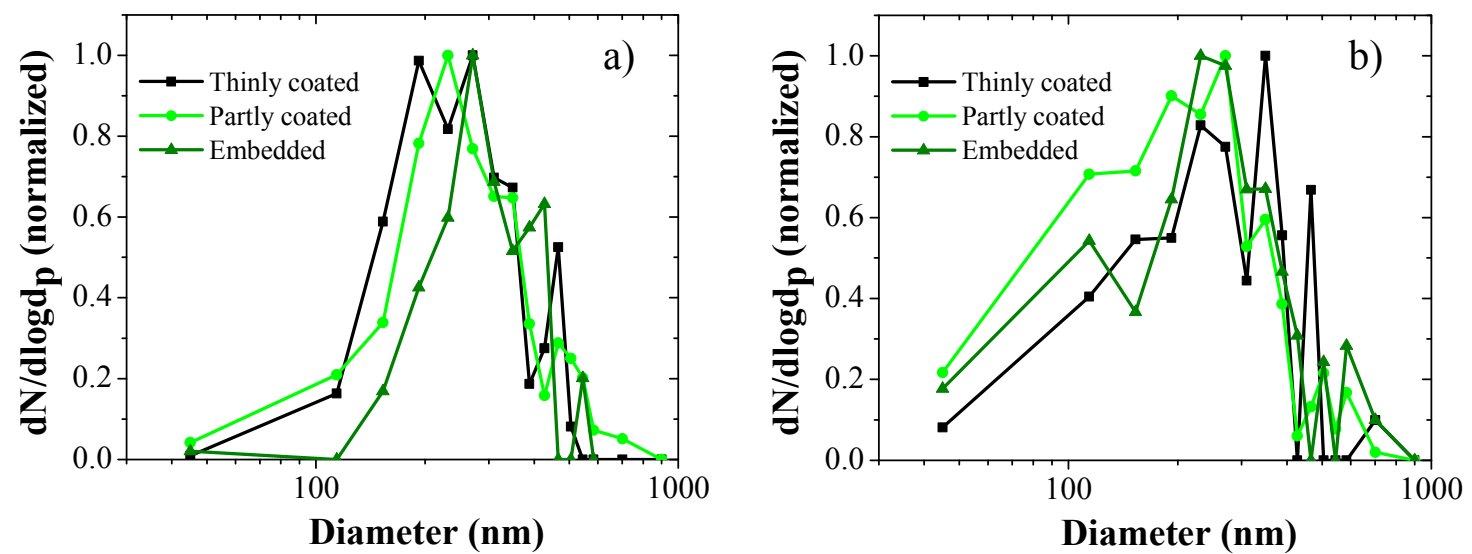

Figure 4-7: Size distribution of thinly coated, partly coated and embedded soot particles for a) event- 1 July (06-07) and b) event-2 July (20-21). 

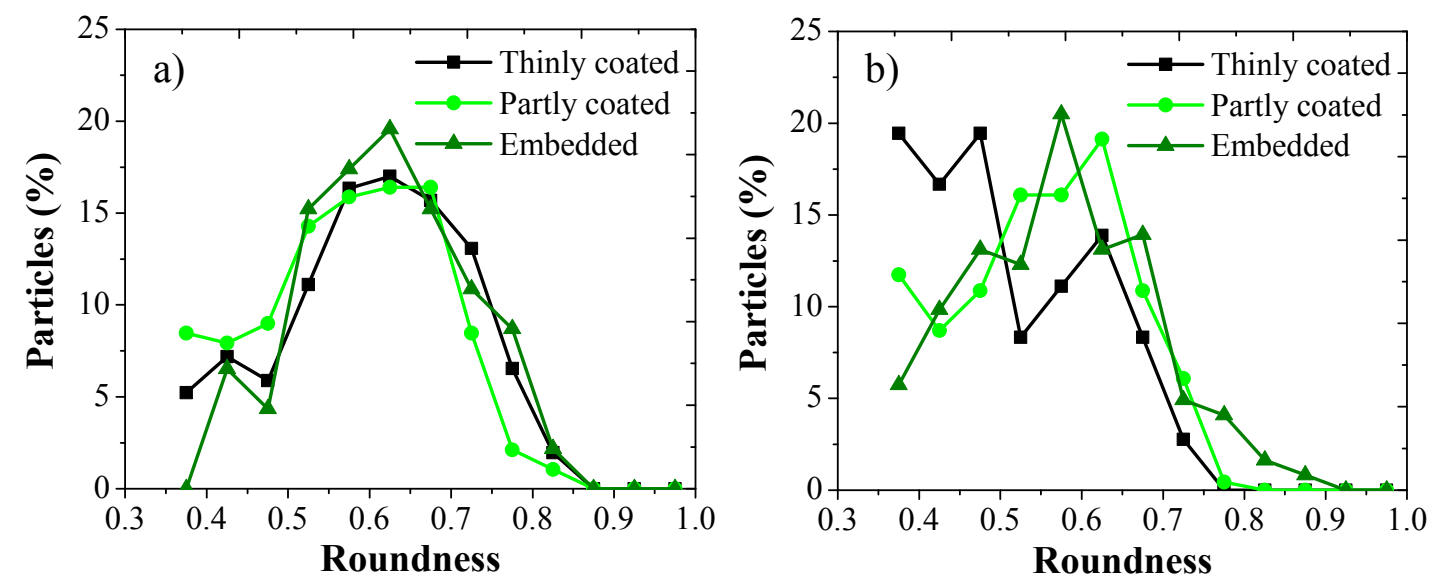

Figure 4-8: Histograms of roundnes for embedded, partly coated and bare soot particles for a) event-1 and b) event-2.

Figure 4-9 shows the distribution of the convexity for thinly coated, partly coated and embedded soot particles for event- 1 and event-2. For both events, the thinly coated soot particles are very compacted suggesting morphological changes (restructuring) during their transport from the source. Laboratory study showed that partially aged soot particles adsorb water under humidification and turn into efficient CCNs, leading to additional compaction of soot particle (Khalizov et al., 2013). This suggests that cloud or water processing might be responsible for the compacted shape of thinly coated soot particles. Previous studies reported collapsing of soot under the influence of water (Mikhailov et al., 1999; Weingartner et al., 1995). Capillary forces induced during condensation or filling of soot cavities with water have been hypothesized to be responsible for the soot restructuring (Tritscher et al., 2011). However, others argue that capillary forces drive the soot restucturing during evaporation of water instead of condenstation (Ebert et al., 2002; Ma et al., 2013). The entrainment of soot particles within cloud droplets can facilitate local warming and even evaporation of clouds (i.e. cloud burning effect) (Ackerman et al., 2000). In addition, soot-water mixing also affect their optical properties (Mishchenko et al., 2014). 

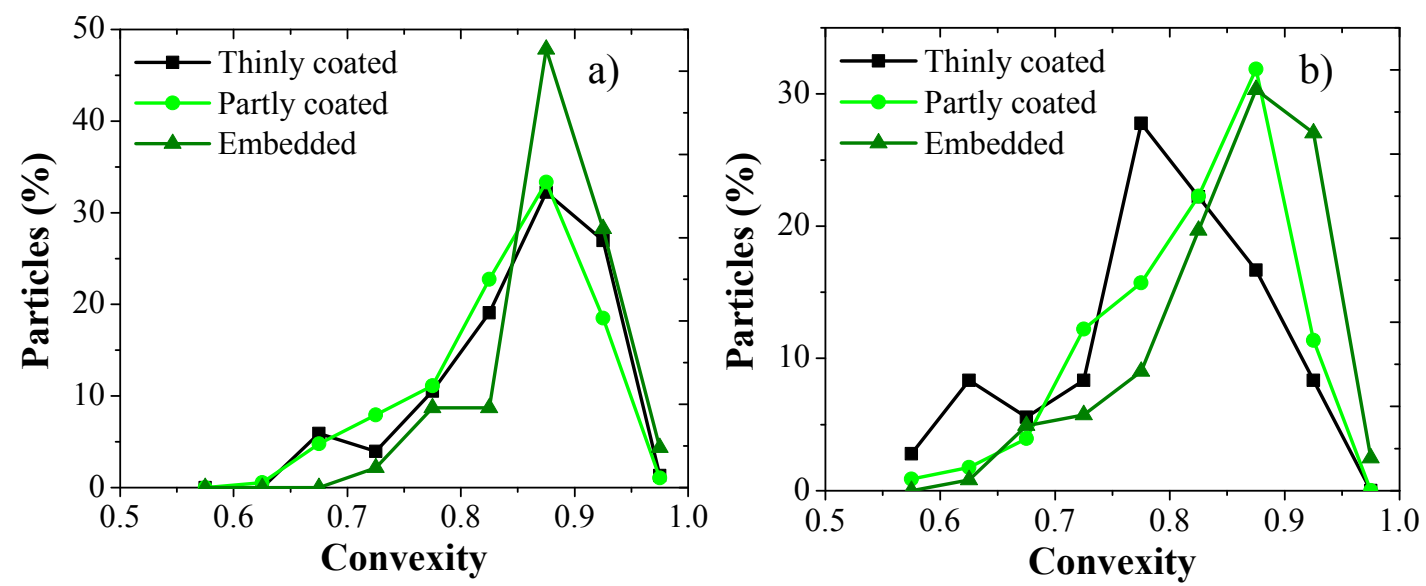

Figure 4-9: Convexity distribution for thinly coated (black), partly coated (light green) and embedded (dark green) soot particles for a) event-1 (July 06-07) and b) event-2 (July 20-July 21).

\subsubsection{Optical properties of soot particles}

The soot particles collected at PMO during these events have very compacted shape. These compacted soot particles however, have been found to be very prominent in several other samples collected at PMO, suggesting that these structures might be very common in the free troposphere and remote regions where soot is transported from far away and/or in marine environments. Therefore, we investigate how the compactions of soot particle influence their optical properties by performing DDA simulations, as these effects might be relevant on global scales.

We estimate the fractal dimension $\left(D_{f}\right)$ of the synthesized soot aggregates and use three different degrees of soot compaction, open chain-like aggregate, medium compacted soot and very compacted soot representing fresh, medium aged and very aged soot, respectively. We generated soot particles with two different number of monomers $(N)$. The actual estimation of $N$ from 2-D projected images are difficult and typically estimated using the projected area of the aggregate $\left(A_{a}\right)$ and the mean projected area of a monomer $\left(A_{p}\right)$ in the aggregate, as follows

$$
N=k_{a}\left(\frac{A_{a}}{A_{p}}\right)^{\alpha}
$$


Where $\alpha$ is an empirical projected area exponent and $k_{a}$ is a constant, normally approximated with a value close to one. The exact values of $\alpha$ and $k_{a}$ depend on the overlap parameter $(\delta)$ which is the ratio of the monomer diameter to the distance between two adjacent and touching monomers center points (e.g.; $\delta=1$ for point contact). In this study we the values typically employed in the literature for $\alpha$ and $k_{a}$ of $\alpha=1.09 ; k_{a}=1.15$ for point contact and for $\delta=2$ we use $\alpha=1.19 ; k_{a}=1.81$, to estimate two different $N$.

Synthesized soot particles are then binarized at random orientaions (at least 50 particles for each case) and the resulting two-dimensional projected images are analyzed. $D_{f}$ of the synthesized soot aggregates is calculated from equation 1 using a contsant value of $\mathrm{k}_{\mathrm{g}}$ (1.6) (Liu et al., 2008). Table 4-3 shows the morphological parameters of the synthesized aggregates.

Table 4-3: Morphological parameters of synthetic soot aggregates. $N$ is number of monomers.

\begin{tabular}{cccccc}
\hline & & Aspect ratio & Convexity & Roundness & $D_{f}$ \\
\hline \hline \multirow{3}{*}{$\mathrm{N}=66$} & Fresh & 1.38 & 0.59 & 0.38 & 1.83 \\
& Medium aged & 1.30 & 0.81 & 0.62 & 2.40 \\
& Very aged & 1.27 & 0.87 & 0.67 & 2.67 \\
\hline \multirow{3}{*}{$\mathrm{N}=150$} & Fresh & 1.66 & 0.55 & 0.32 & 1.83 \\
& Medium aged & 1.38 & 0.68 & 0.48 & 2.13 \\
& Very aged & 1.22 & 0.86 & 0.69 & 2.69 \\
\hline
\end{tabular}

Figure 4-10 illustrates the normalized absorption $\left(C_{a b s}\right)$ and scattering $\left(C_{s c a}\right)$ cross sections (medium aged/fresh and very aged/fresh) of soot particle for two different cases of number of monomers $(N=66$ and $N=150)$. The figure also reports the single scattering albedo (SSA) that is the ratio of the scattering to the extinction cross sections, and the asymmetry parameter ( $\mathrm{g}$ ) that is the cosine-weighted average over the entire scattering angle of the scattering phase function. These last two are critical aerosol parameters that determine, together with the optical depth, the aerosol radiative forcing. The measured fractal dimension $\left(D_{f}\right)$ from 2D projections of the synthesized soot 80 
particles $(N=66)$ for fresh, medium aged (medium-compacted) and very aged (verycompacted) particles are 1.83, 2.40 and 2.67 respectively and the convexities are 0.59 , 0.89 and 0.81 respectively (Table $4-3$ ).

The orientation averaged $C_{a b s}$ ratio is lower than unity for shorter wavelengths but becomes rapidly (around $500 \mathrm{~nm}$ ) larger than unity for visible and near-infrared wavelengths, meaning that compacted, aged particles have higher $C_{a b s}$ compared to fresh soot. A previous T-matrix simulation study also found a similar pattern and suggested two possible reasons responsible for the observed trend. As particles become more compacted, less absorbing materials are directly exposed to the incident light, resulting in lower $C_{a b s}$. On the other hand, $C_{a b s}$ can increase for compacted particles due to an increased electromagnetic interaction between monomers (Liu et al., 2008). The $C_{s c a}$ ratio is higher than 1.4 for $N=66$ and 2.30 for $N=150$ in the visible range, but the ratio decreases (although remaining above unity) in the near infrared region. The effect of compaction is substantially higher for scattering than for absorption, resulting in higher SSA values as the particle becomes more compacted and the magnitude of the SSA ratio decreases as the wavelength increases but always remaining above unity. The asymmetry parameter $(g)$ is both a strong function of particle size and shape (Kahnert et al., 2012; Liu et al., 2008). For smaller $N(N=66), g$ for fresh chain-like soot is higher compared to medium aged and very aged soot, but it shows a different scenario for larger $N$. For $N=155$, medium aged soot exhibits higher g, followed by fresh and aged soot. Similarly, Liu et al. (2008) found that $g$ reaches highest point around $D_{f} \sim 2$ and start decreasing as particle become more compacted. 


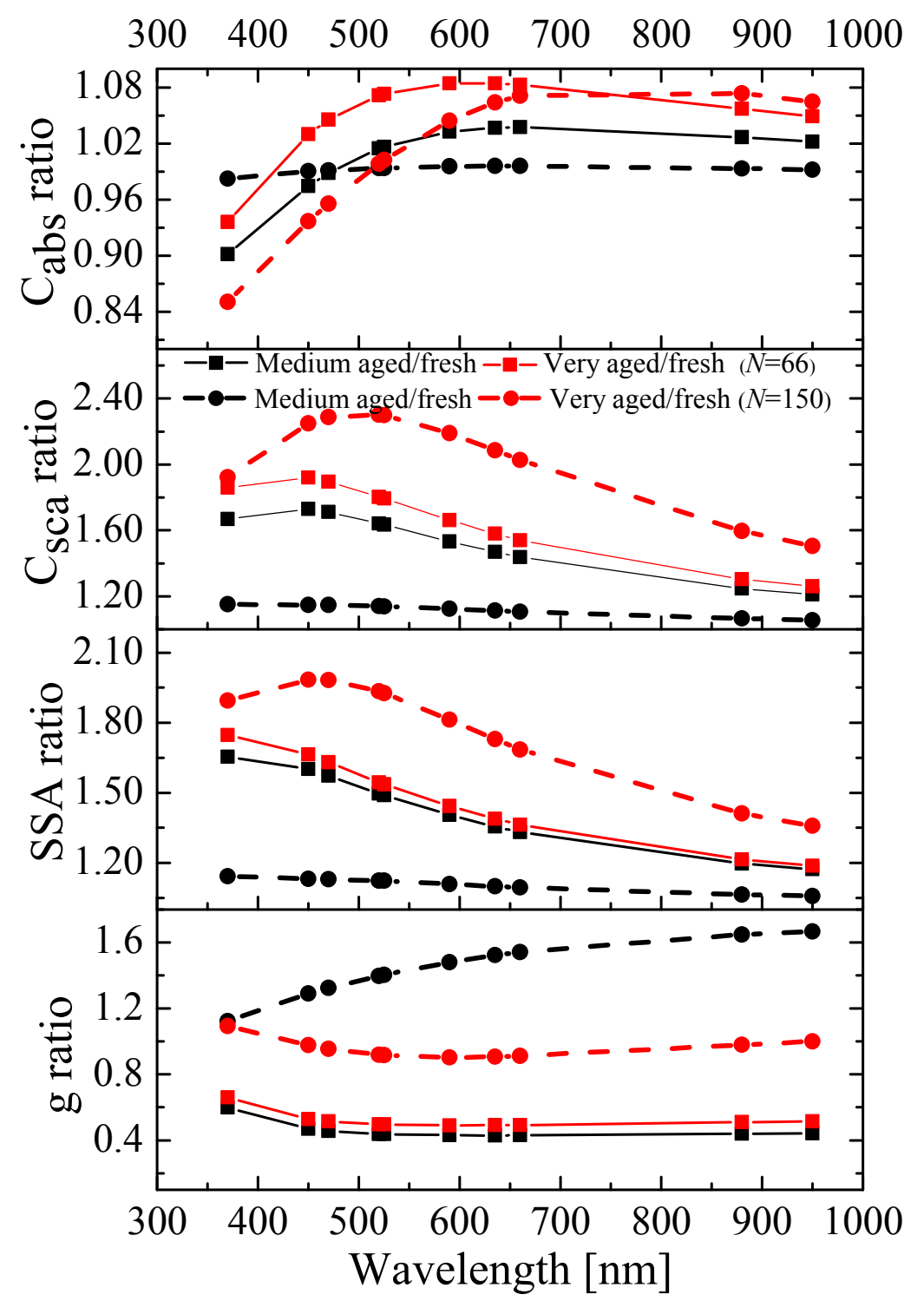

Figure 4-10: Normalized absorption and scattering cross-sections, single scattering albedo (SSA), and, asymmetry parameter $(g)$ as functions of wavelength for two cases of number of monomers $(N=66$ and $N=150)$. We use the cross sections, SSA and $g$ of fresh soot as normalizing values.

Soot particles observed at PMO are possibly cloud processed, and this might be the reason for the very compacted shape. This also implies that soot might have been incorporated into water droplets during they journey over the Atlantic. A recent Tmatrix study (Mishchenko et al., 2014) on soot-water mixing shows that orientation- 
averaged $C_{a b s}$ strongly depend on the soot morphology and their position inside a water droplet. Orientation-averaged $C_{a b s}$ of soot-water mixture is higher for open chain-like soot than compacted soot and $C_{a b s}$ tends to decrease as the soot particle moves from the center of the droplet to the boundary. Finally, $C_{a b s}$ can change by a factor exceeding 6.5 depending on the various scenarios of soot-water mixing. This implies that the soot morphology might have an important role in the semi-direct effect, with soot compaction also resulting in a lower in-cloud absorption and therefore lower positive forcing as well.

\subsubsection{Evolution of soot morphology and mixing state}

This section provides a brief summary and comparison of morphology and mixing state of soot particles collected from different geographical locations and environmental conditions. Samples collected in Ann Arbor, MI represent fresh traffic emissions (discussed in chapter 2). Samples collected during the Las Conchas fire, NM represent biomass burning emission (discussed in chapter 3). Samples collected in Sacramento, CA; Detling, UK and Mexico City represent urban emissions. Finally, samples collected at the Pico Mountain Observatory in Pico Island, Azores represent long range transported, free tropospheric aerosol as discussed earlier in this chapter. Note that the Pico data showed in this section include a number (592) of additional particles from September 24 and 25 (2012) that have not been discussed earlier in this chapter.

Figure 4-11 shows that the soot mixing state varies widely depending on geographical location and source. Freshly emitted soot from vehicles in close proximity to the sampling inlet, exhibited minimum coating (embedded + partly coated, $\sim 22 \%$ ), while freshly emitted biomass burning soot exhibited maximum coating ( $84 \%)$. Soot particles in urban area displayed the highest variability in their mixing state, with relatively higher fraction of soot with multiple inclusions, suggesting complex mixing pathways and a possible higher impact of other processes such as coagulation and coalescence. The fraction of embedded soot at Detling, UK and Mexico City were 
similar $(\sim 10 \%)$ but a smaller fraction was found in Sacramento, CA $(\sim 3 \%)$. The largest fraction of soot inclusion particles were found in Mexico City. In the complex terrain of the Mexico City basin, surrounded by high mountains, particles are expected to have long residence time in the atmosphere and to be exposed to complex processing (Johnson et al., 2005).

The mixing state information can provide insights to interpret and/or model optical scattering and absorption enhancements. For example, embedded soot particles potentially exhibit higher scattering and absorption enhancements (in reference to comparable thinly coated soot) compared to soot with inclusions (Adachi and Buseck, 2013). The lower fraction of embedded particles in Sacramento, CA ( $3 \%)$ compared to biomass burning $(\sim 50 \%)$ suggests that substantially lower absorption enhancement might be expected in California urban plumes with respect to biomass burning plumes. It was in fact shown that the absorption enhancement experimentally measured in California's urban plumes (Sacramento and Los Angeles urban area) was much lower (negligible) than expected assuming an embedded soot mixing model (core-shell Mie model) (Cappa et al., 2012); while much larger values of the absorption enhancement were measured in a biomass burning event in Colorado (Lack et al., 2012). The results reported in Figure 4-11 are therefore qualitatively consistent with the experimentally measured absorption enhancements and underline the importance of studying the details of the soot mixing state, to understand and potentially in future forecast, the absorption enhancement in different atmospheric conditions. 


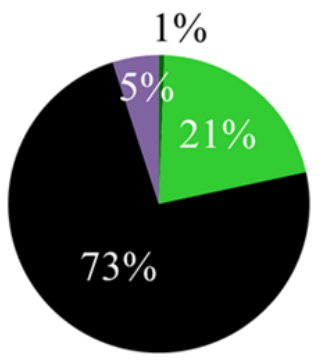

Ann Arbor, MI

3,028

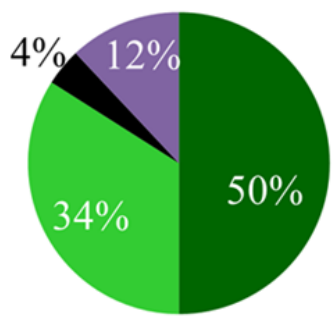

Las Conchas, NM 1,026

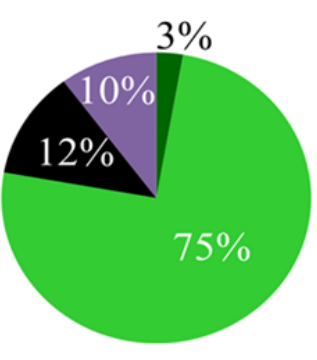

Sacramento, CA

2,705

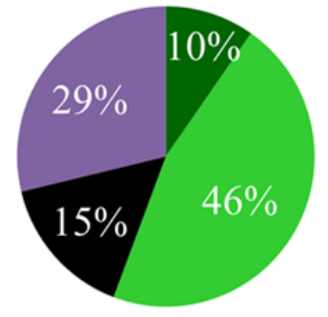

Mexico City

13,581

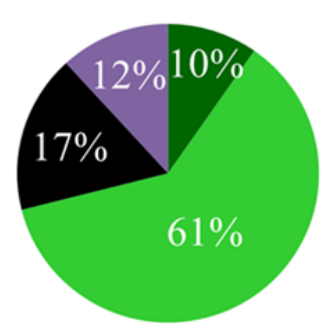

Detling, UK

4,661

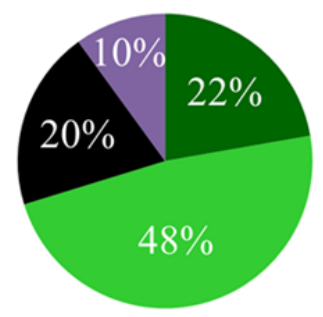

Pico, Azores

1,412

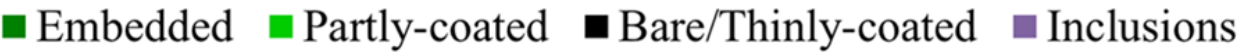

Figure 4-11: Mixing state of soot particles collected at different locations and environmental conditions. Number below location represents total number of particles used for analysis.

Furthermore, we compared convexity of soot particles collected at different locations and environmental conditions as soot morphology can provide insight on particle aging and atmospheric processing. We remind the reader that convexity is a measure of the morphology of the particle that is expected to increase when the structure of an open aggregate is compacted and/or voids are filled by coating material. Figure 4-12 shows the distribution of convexity of soot particles. The number (in bold) in the plot represents the mean convexity values. The distributions show that freshly emitted soot particles have lower convexity, representing soot aggregates with a fractal-like open structure; while soot particles that are processed in the atmosphere during long range transport (as in the case of the samples collected at Pico) have more collapsed structures (highest convexity). Soot from urban plumes exhibits intermediate convexity values, 
once again suggesting complex mixing stages as urban plumes include freshly emitted as well as processed soot depending on the residence time of the particle and semivolatile compounds concentrations. Interestingly, soot in Delting, UK shows relatively higher convexity; foggy weather and household biomass burning practices, might have led to cloud processing and soot coating explaining the higher convexity, especially considering that samples were collected during winter time. As shown in the previous section (6.3.4) both scattering and absorption can increase when soot particle transform from open-soot to collapsed soot.
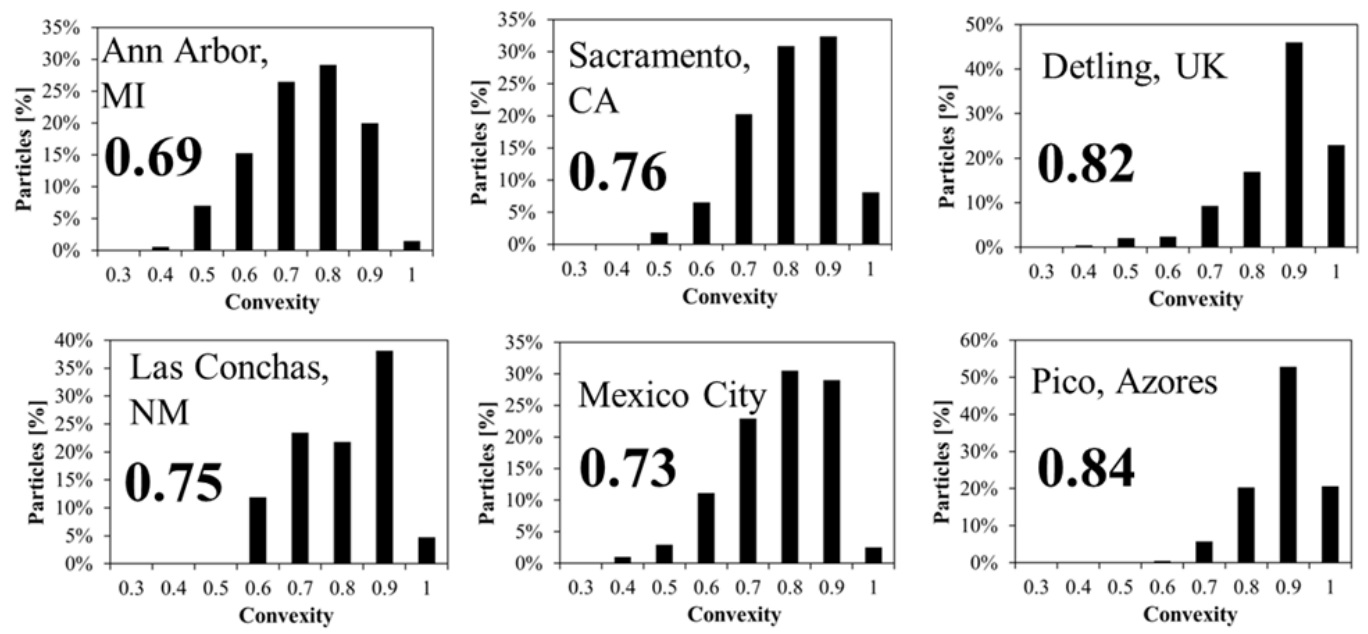

Figure 4-12: Distribution of convexity of soot particles. Number in the plot represents the mean convexity.

\subsection{Conclusions}

The morphology of soot particles transported over long ranges and reaching PMO is very compacted, probably representing very aged soot. Most of the soot particles were coated to some extent. However, thinly coated soot also exhibited very compacted structures with high convexity. Free tropospheric soot particles collected at PMO are possibly cloud processed during their journey over the Atlantic. The water processing is possibly the reason for the vey compacted shape of the soot particles. Compacted and aged soot particles can enhance both scattering and absorption of the particle but with 
an overall resulting increase in single scattering albedo and reduction of the positive, top of the atmosphere, direct radiative forcing. When soot particles are mixed with water, absorption of their mixture can enhanced substantially depending on the degree of compaction of soot particles and their mixing with, finally resulting radiative properties of soot particles.

Here we investigated two specific events; more events will be investigated in the future to further quantify the soot morphology and mixing state in the North Atlantic free troposphere. The results of this study have implications on how soot particles should be represented in particle-resolving mixing state models (Riemer et al., 2009) and in numerical models in remote regions (Wang et al., 2013) of the free troposphere, and how the correct representation might affect the calculation of atmospheric soot radiative forcing.

Comparison of soot morphology and mixing state with other locations suggest that soot mixing state depends on location, source and atmospheric condition. Biomass burning soot can lead to higher single scattering albedo due to large fraction of embedded soot while aged soot at Pico showed more compacted soot compared to soot from urban plume. The evolution of soot morphology and mixing state in the atmosphere have important consequences for soot optical properties, thus direct climate forcing.

A comparison of soot morphology and mixing state with other locations depicts that soot mixing state depends on location, source and atmospheric conditions. The significant coating in embedded soot particles found in biomass burning plumes can lead to higher single scattering albedo; similarly, aged soot at Pico that showed extremely collapsed shape compared to soot from urban plumes, might also exhibit higher single scattering albedo with respect to fresh soot of similar mass. The evolution of soot morphology and mixing state in the atmosphere has important consequences for soot optical and microphysical properties, and thus the effect of soot on climate forcing. 


\subsection{References}

Ackerman, A. S., Toon, O., Stevens, D., Heymsfield, A., Ramanathan, V., and Welton, E.: Reduction of tropical cloudiness by soot, Science, 288, 1042-1047, 2000.

Adachi and Buseck, P.: Internally mixed soot, sulfates, and organic matter in aerosol particles from Mexico City, Atmos. Chem. Phys, 8, 6469-6481, 2008.

Adachi, Chung, S. H., Friedrich, H., and Buseck, P. R.: Fractal parameters of individual soot particles determined using electron tomography: Implications for optical properties, Journal of Geophysical Research-Atmospheres, 112, 2007.

Adachi, K. and Buseck, P. R.: Changes of ns-soot mixing states and shapes in an urban area during CalNex, Journal of Geophysical Research: Atmospheres, 2013. 2013.

Bond, T. C., Doherty, S. J., Fahey, D. W., Forster, P. M., Berntsen, T., DeAngelo, B. J., Flanner, M. G., Ghan, S., Kärcher, B., Koch, D., Kinne, S., Kondo, Y., Quinn, P. K., Sarofim, M. C., Schultz, M. G., Schulz, M., Venkataraman, C., Zhang, H., Zhang, S., Bellouin, N., Guttikunda, S. K., Hopke, P. K., Jacobson, M. Z., Kaiser, J. W., Klimont, Z., Lohmann, U., Schwarz, J. P., Shindell, D., Storelvmo, T., Warren, S. G., and Zender, C. S.: Bounding the role of black carbon in the climate system: A scientific assessment, Journal of Geophysical Research: Atmospheres, 118, 5380-5552, 2013.

Buseck, P. R., Adachi, K., Gelencsér, A., Tompa, É., and Pósfai, M.: ns-Soot: A Material-Based Term for Strongly Light-Absorbing Carbonaceous Particles, Aerosol Science and Technology, doi: 10.1080/02786826.2014.919374, 2014. 00-00, 2014.

Cappa, C. D., Onasch, T. B., Massoli, P., Worsnop, D. R., Bates, T. S., Cross, E. S., Davidovits, P., Hakala, J., Hayden, K. L., Jobson, B. T., Kolesar, K. R., Lack, D. A., Lerner, B. M., Li, S. M., Mellon, D., Nuaaman, I., Olfert, J. S., Petaja, T., Quinn, P. K., Song, C., Subramanian, R., Williams, E. J., and Zaveri, R. A.: Radiative Absorption Enhancements Due to the Mixing State of Atmospheric Black Carbon, Science, 337, 1078-1081, 2012. 
Chang, H. and Charalampopoulos, T.: Determination of the wavelength dependence of refractive indices of flame soot, Proceedings of the Royal Society of London. Series A: Mathematical and Physical Sciences, 430, 577-591, 1990.

China, S., Mazzoleni, C., Gorkowski, K., Aiken, A. C., and Dubey, M. K.: Morphology and mixing state of individual freshly emitted wildfire carbonaceous particles, Nature communications, 4, 2013.

China, S., Salvadori, N., and Mazzoleni, C.: Effect of Traffic and Driving Characteristics on Morphology of Atmospheric Soot Particles at Freeway OnRamps, Environmental science \& technology, 48, 3128-3135, 2014.

Cooke, W. F., Ramaswamy, V., and Kasibhatla, P.: A general circulation model study of the global carbonaceous aerosol distribution, Journal of Geophysical Research: Atmospheres, 107, ACH 2-1-ACH 2-32, 2002.

Cross, E. S., Onasch, T. B., Ahern, A., Wrobel, W., Slowik, J. G., Olfert, J., Lack, D. A., Massoli, P., Cappa, C. D., and Schwarz, J. P.: Soot particle studiesinstrument inter-comparison-project overview, Aerosol Science and Technology, 44, 592-611, 2010.

Draine, B. T. and Flatau, P. J.: Discrete-dipole approximation for scattering calculations, JOSA A, 11, 1491-1499, 1994.

Draine, B. T. and Flatau, P. J.: User guide for the discrete dipole approximation code DDSCAT 7.3, arXiv preprint arXiv:1305.6497, 2013. 2013.

Ebert, M., Inerle-Hof, M., and Weinbruch, S.: Environmental scanning electron microscopy as a new technique to determine the hygroscopic behaviour of individual aerosol particles, Atmospheric Environment, 36, 5909-5916, 2002.

Hansen, J. and Nazarenko, L.: Soot climate forcing via snow and ice albedos, Proceedings of the National Academy of Sciences of the United States of America, 101, 423-428, 2004.

Hansen, J., Sato, M., and Ruedy, R.: Radiative forcing and climate response, Journal of Geophysical Research: Atmospheres (1984-2012), 102, 6831-6864, 1997. 
Haywood, J. M. and Ramaswamy, V.: Global sensitivity studies of the direct radiative forcing due to anthropogenic sulfate and black carbon aerosols, J. Geophys. Res., 103, 6043-6058, 1998.

Honrath, R., Owen, R. C., Val Martin, M., Reid, J., Lapina, K., Fialho, P., Dziobak, M. P., Kleissl, J., and Westphal, D.: Regional and hemispheric impacts of anthropogenic and biomass burning emissions on summertime $\mathrm{CO}$ and $\mathrm{O} 3$ in the North Atlantic lower free troposphere, Journal of Geophysical Research: Atmospheres (1984-2012), 109, 2004.

Huang, Y., Wu, S., Dubey, M. K., and French, N. H. F.: Impact of aging mechanism on model simulated carbonaceous aerosols, Atmos. Chem. Phys., 13, 6329-6343, 2013.

Jacobson, M. Z.: Strong radiative heating due to the mixing state of black carbon in atmospheric aerosols, Nature, 409, 695-697, 2001.

Johnson, K. S., Zuberi, B., Molina, L. T., Molina, M. J., Iedema, M. J., Cowin, J. P., Gaspar, D. J., Wang, C., and Laskin, A.: Processing of soot in an urban environment: case study from the Mexico City Metropolitan Area, Atmospheric Chemistry and Physics, 5, 3033-3043, 2005.

Kahnert, M., Nousiainen, T., Lindqvist, H., and Ebert, M.: Optical properties of light absorbing carbon aggregates mixed with sulfate: assessment of different model geometries for climate forcing calculations, Opt. Express, 20, 10042-10058, 2012.

Khalizov, A. F., Lin, Y., Qiu, C., Guo, S., Collins, D., and Zhang, R.: Role of OHinitiated oxidation of isoprene in aging of combustion soot, Environmental science \& technology, 47, 2254-2263, 2013.

Khalizov, A. F., Zhang, R., Zhang, D., Xue, H., Pagels, J., and McMurry, P. H.: Formation of highly hygroscopic soot aerosols upon internal mixing with sulfuric acid vapor, Journal of Geophysical Research: Atmospheres (19842012), 114, 2009. 
Lack, D. A., Langridge, J. M., Bahreini, R., Cappa, C. D., Middlebrook, A. M., and Schwarz, J. P.: Brown carbon and internal mixing in biomass burning particles, Proceedings of the National Academy of Sciences, doi: 10.1073/pnas.1206575109, 2012. 2012.

Lee, C. and Kramer, T. A.: Prediction of three-dimensional fractal dimensions using the two-dimensional properties of fractal aggregates, Advances in Colloid and Interface Science, 112, 49-57, 2004.

Liu, Fan, S., Horowitz, L. W., and Levy, H.: Evaluation of factors controlling longrange transport of black carbon to the Arctic, Journal of Geophysical Research: Atmospheres, 116, D04307, 2011.

Liu, Mishchenko, M. I., and Arnott, W. P.: A study of radiative properties of fractal soot aggregates using the superposition T-matrix method, Journal of Quantitative Spectroscopy \& Radiative Transfer, 109, 2656-2663, 2008.

Ma, X., Zangmeister, C. D., Gigault, J., Mulholland, G. W., and Zachariah, M. R.: Soot aggregate restructuring during water processing, Journal of Aerosol Science, 66, 209-219, 2013.

Mandelbrot, B. B.: The Fractal Geometry of Nature, W.H. Freeman, San Francisco, 1982.

Mikhailov, E., Vlasenko, S., Kramer, L., and Niessner, R.: Soot particle restructuring due to interaction with water droplets, Journal of Aerosol Science, 30, 1999.

Mishchenko, M. I., Liu, L., Cairns, B., and Mackowski, D. W.: Optics of water cloud droplets mixed with black-carbon aerosols, Opt. Lett., 39, 2607-2610, 2014.

Nyeki, S. and Colbeck, I.: The Influence of Morphological Restructuring of Carbonaceous Aerosol on Microphysical Atmospheric Processes. In: Aerosol Chemical Processes in the Environment, Spurny, K. R. (Ed.), CRC Press, 2000.

Oh, C. and Sorensen, C. M.: The effect of overlap between monomers on the determination of fractal cluster morphology, Journal of Colloid and Interface Science, 193, 17-25, 1997. 
Owen, R. C. and Honrath, R. E.: Technical note: a new method for the Lagrangian tracking of pollution plumes from source to receptor using gridded model output, Atmos. Chem. Phys., 9, 2577-2595, 2009.

Pósfai, M., Anderson, J. R., Buseck, P. R., and Sievering, H.: Soot and sulfate aerosol particles in the remote marine troposphere, Journal of Geophysical Research: Atmospheres (1984-2012), 104, 21685-21693, 1999.

Ramanathan, V. and Carmichael, G.: Global and regional climate changes due to black carbon, Nature Geoscience, 1, 221-227, 2008.

Rémillard, J., Kollias, P., Luke, E., and Wood, R.: Marine Boundary Layer Cloud Observations in the Azores, Journal of Climate, 25, 2012.

Richard, D., Glenar, D., Stubbs, T., Davis, S., and Colaprete, A.: Light scattering by complex particles in the Moon's exosphere: Toward a taxonomy of models for the realistic simulation of the scattering behavior of lunar dust, Planetary and Space Science, 59, 1804-1814, 2011.

Riemer, N., Vogel, H., Vogel, B., and Fiedler, F.: Modeling aerosols on the mesoscale$\gamma$ : Treatment of soot aerosol and its radiative effects, Journal of Geophysical Research: Atmospheres (1984-2012), 108, 2003.

Riemer, N., West, M., Zaveri, R. A., and Easter, R. C.: Simulating the evolution of soot mixing state with a particle-resolved aerosol model, Journal of Geophysical Research-Atmospheres, 114, 2009.

Rosen, H., Novakov, T., and Bodhaine, B.: Soot in the Arctic, Atmospheric Environment (1967), 15, 1371-1374, 1981.

Scarnato, B., Vahidinia, S., Richard, D. T., and Kirchstetter, T. W.: Effects of internal mixing and aggregate morphology on optical properties of black carbon using a discrete dipole approximation model, Atmos. Chem. Phys. Discuss., 12, 2640126434, 2012.

Stohl, A., Forster, C., Frank, A., Seibert, P., and Wotawa, G.: Technical note: The Lagrangian particle dispersion model FLEXPART version 6.2, Atmos. Chem. Phys., 5, 2461-2474, 2005. 
Tritscher, T., Jurányi, Z., Martin, M., Chirico, R., Gysel, M., Heringa, M. F., DeCarlo, P. F., Sierau, B., Prévôt, A. S., and Weingartner, E.: Changes of hygroscopicity and morphology during ageing of diesel soot, Environmental Research Letters, 6, 034026, 2011.

Van Poppel, L. H., Friedrich, H., Spinsby, J., Chung, S. H., Seinfeld, J. H., and Buseck, P. R.: Electron tomography of nanoparticle clusters: Implications for atmospheric lifetimes and radiative forcing of soot, Geophysical Research Letters, 32, 2005.

Wang, H., Easter, R. C., Rasch, P. J., Wang, M., Liu, X., Ghan, S. J., Qian, Y., Yoon, J. H., Ma, P. L., and Vinoj, V.: Sensitivity of remote aerosol distributions to representation of cloud-aerosol interactions in a global climate model, Geosci. Model Dev., 6, 765-782, 2013.

Weingartner, E., Baltensperger, U., and Burtscher, H.: Growth and structural change of combustion aerosols at high relative humidity, Environmental Science \& Technology, 29, 2982-2986, 1995.

Wentzel, M., Gorzawski, H., Naumann, K. H., Saathoff, H., and Weinbruch, S.: Transmission electron microscopical and aerosol dynamical characterization of soot aerosols, Journal of Aerosol Science, 34, 1347-1370, 2003.

Wilcox, E.: Direct and semi-direct radiative forcing of smoke aerosols over clouds, Atmospheric Chemistry and Physics, 12, 139-149, 2012.

Zhang, R., Khalizov, A. F., Pagels, J., Zhang, D., Xue, H., and McMurry, P. H.: Variability in morphology, hygroscopicity, and optical properties of soot aerosols during atmospheric processing, Proceedings of the National Academy of Sciences, 105, 10291-10296, 2008. 


\section{Morphology and Optical Properties of Soot Residuals from Supercooled Droplets and Ice Crystals ${ }^{4}$}

Morphology of soot particle influences their optical properties. Soot morphology within ice crystal residue or supercooled droplet residue is not well known. Changes in the morphology of soot particles in interaction with water were investigated at sub-freezing (supercooled) and freezing temperatures. At $-40^{\circ} \mathrm{C}$ ice crystals were formed on soot particles, while at $-20^{\circ} \mathrm{C}$ water droplets remained in supercooled state. Ice crystal and supercooled droplet soot residuals were analyzed on a single-particle basis using electron microscopy. Soot particles in supercooled residuals were compacted compared to nascent soot. Soot particles from ice crystal residuals exhibited an even higher degree of compaction, suggesting that the collapsing of the soot structure is strongly affected by the freezing process. Numerical simulations of the optical properties of the soot particles collected during this study show that the collapse of the soot structure results in enhanced light scattering and absorption.

\subsection{Introduction}

Soot particles consist of many spherical carbonaceous monomers (spherules) and are ubiquitous in the atmosphere. Combustion sources, such as fossil fuel, biomass burning emit soot in the lower atmosphere, while aviation is one of the major sources in the upper troposphere (Kärcher et al., 1998; Schumann et al., 2013). Soot particles affect climate directly by absorbing and scattering sun-light and indirectly by influecing the microphysical properties of clouds either serving as a cloud condenstaion nuclei (CCN) or ice nuclei (IN) (Bond et al., 2013). Soot particles affect surface albedo by depositing over snow and ice sheets and accelerates melting (Hansson and Ahlberg, 1985;

\footnotetext{
${ }^{4}$ This chapter is based on material to be submitted as China et al., (2014), Environmental Research Letters.
} 
Ramanathan and Carmichael, 2008). Further soot particles might lead to increase in absorption of solar radiation by decreasing cloud cover in the lower troposphere (Lohmann and Feichter, 2005). Soot particles within ice crystal and cloud droplet can also enhance absorption and decrease cloud albedo (Jacobson, 2006; Ramanathan and Carmichael, 2008).

Soot particles can facilitate primary ice formation at supercooled temperatures through heterogenous ice nucleation where soot particles can act as IN (Kärcher et al., 2007). The role of soot as IN is still not well understood, fewer experiments are available and there are discrepancies between several studies (Hoose and Möhler, 2012). The efficiency of soot as IN depends on various parameters such as temperature, relative humidity, supersaturation, soot size, surface oxidation and ice active sites, but the sensitivity of these parameters is still ambiguous (Heymsfield et al., 2010; Hoose and Möhler, 2012; Persiantseva et al., 2004). Soot may not be efficient IN below water satuation and tempeatures above $-35^{\circ} \mathrm{C}$ (DeMott et al., 1999; Dymarska et al., 2006), but soot can be efficient IN (by immersion or condensation mode) when water condenses on soot at relative humidity with respect to ice $\left(\mathrm{RH}_{\text {ice }}\right)$ above water saturation and at temperatures above $-35^{\circ} \mathrm{C}$ (Gorbunov et al., 2001; Mohler et al., 2005). Friedman et al. (2011) found no evidence of ice formation by soot below water saturation, but only droplet formation above water saturation at $-30^{\circ} \mathrm{C}$ and and $-35^{\circ} \mathrm{C}$. They conclude that ice formation at $-40^{\circ} \mathrm{C}$ was formed due to homogeneous freezing. Kanji et al. (2011) showed that graphite soot does not nucleate ice via deposition nucleation at temperatures warmer than $-38^{\circ} \mathrm{C}$. Koehler et al. (2009) also found no ice nucleation by different types of soot at temperatures warmer than $-40^{\circ} \mathrm{C}$.

Aircraft soot emissions play a major role in contrail fomation in the upper troposphere at $-40^{\circ} \mathrm{C}$ or below (Kärcher et al., 1998) as well as induces ice formation in contrails (Petzold et al., 1999). The microphysics of contrails is determined by the chemical and water activation of soot particles (Heymsfield et al., 2010; Kärcher et al., 1996). Environmental $\mathrm{RH}_{\mathrm{ice}}$ controls evaporation of contrails and formation of contrail 
induced cirrus clouds. Contrails can be sustained in an ice-saturated atmosphere, and through heterogeneous ice nucleation modes ice crystals can be formed at these supersaturation conditions. However, contribution of soot to nucleate ice is not well understood, and it is highly uncertain if the ice formation occurs without contrail formation or after evaporation of short-lived contrails (Heymsfield et al., 2010).

Investigation of ice crystal residual particles from cirrus clouds showed that 11 to $25 \%$ of the residuals are composed of carbonaceous material, including soot and organic carbon (Twohy and Poellot, 2005). Higher soot number concentration $\left(0.2 \mathrm{~cm}^{-3}\right)$ was observed in ice crystal residuals from contrail compared to cirrus $\left(0.02 \mathrm{~cm}^{-3}\right)$ (Petzold et al., 1998). They suggsted that soot in the cirrus cloud can be attributed to scavenging of soot by ice crystals during the atmospheric aging. They found that contrail residues are dominated by small soot particles $(<200 \mathrm{~nm})$ composed of mostly carbon $(87 \%)$ and only a minor fraction $(1.6 \%)$ of larger soot particles $(\sim 1000 \mathrm{~nm})$ that was coated with sulfur. Targino et al. (2006) found a small fraction of soot in individual ice crystal residues from orographic wave clouds. Several other studies also found a small fraction of soot in cirrus ice crystal residue (Cziczo and Froyd, 2014; Cziczo et al., 2013).

The complex morphology of soot particles significantly influence their optical properties (Adachi et al., 2007; Scarnato et al., 2012). A the discrete dipole approximation study showed that fractal-like open soot exhibits a higher mass absorption coefficient (absorption cross section/soot mass) compared to more compact soot with monomer diameter of $40 \mathrm{~nm}$ (Scarnato et al., 2012). However, a T-matrix study found lower absorption cross section for for fractal-like open soot compared to more compact soot, with monomer diameter of $15 \mathrm{~nm}$ (Liu et al., 2008).

During cloud processing soot particles experience various cycles of condensation and evaporation (Huang et al., 1994). Cloud processing play a key role in collasping (restructing) of soot aggregates, resulting changes in optical properties of soot (Colbeck et al., 1990; Mikhailov et al., 2006). Filling of soot cavities or any irregular part (active sites) of the particles with water, capillary condensation or other processes (such as 
electrostatic forces) have been proposed as driving the restructuring of soot (Huang et al., 1994; Tritscher et al., 2011). However, other studies found that capillary forces lead to soot restucturing during evaporation of water instead of condensation (Ebert et al., 2002; Ma et al., 2013). The degree of restructing might depend on the source of soot, nascent diesel soot exhibited much smaller collapsing compared to carbon soot (produced from spark discharges between two graphite electrode) (Weingartner et al., 1997). Sulfur content in fuel can be responsible for restructuring of diesel soot: high sulfur content exhibited significanly much lower collapsing compared to low sulfur content (Huang et al., 1994).

In addition soot particles can be scavenged by ice crystals in clouds (at $-25^{\circ} \mathrm{C}$ to- $-45^{\circ} \mathrm{C}$ ) and increase the soot-to-ice mass ratio (Bond et al., 2013). Soot containg ice crystalsor supercooled droplets can undergos various cycles and can sublimate and evaporate in the atmosphere (Heymsfield et al., 2010). After sublimation of ice crystal, soot residuals can facilitate subsequent nucleation event by lowering the supersaturation threshold (preactivation effect) (Hobbs, 1974; Knopf and Koop, 2006). Upon sublimation of ice crystal, soot particles can fragments into small pieces or aggregates into large cluster (Kärcher et al., 2007). Fate of those soot particles inside the ice crystals after their sublimation is not well understood and remain ambiguous. Previous studies showed SEM images of collaped soot from sublimated ice crystal residue collected from contrail and cirrus but morphology of those soot particles were not discussed and quantified (Petzold et al., 1998; Targino et al., 2006).

The goal of this study was to 1) experimentally investigate the morphological and structural properties of soot residuals from supercooled droplets and ice crystals, and 2) model the optical properties of nascent soot and nucleated soot particles (residuals). 


\subsection{Experimental section and methods}

\subsubsection{Soot generation and characterization}

The experiments dicussed here took place at the environmental chamber facility at the Pacific Northwest National Laboratory during November 2013. Soot particles were generated using a diesel engine. A charcoal denuder was used to remove volatile organic carbon components and $\mathrm{NO}_{\mathrm{x}}$. Polydisperse soot particles were charged by a neutralizer, and then size selected (120 nm) (Figure 5-1) according to their electrical mobility with a differential mobility analyzer (DMA, TSI, 3081). Quasi-monodisperse soot particles (due to small fraction of multiply charged particles) were injected into the environmental chamer.

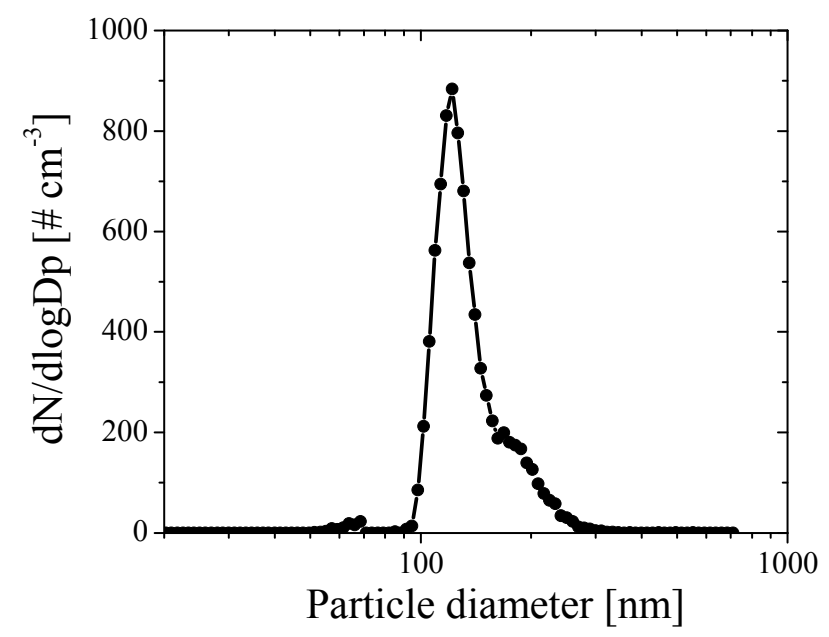

Figure 5-1: Size distribution of nascent soot particles from scanning mobility particle sizer (TSI, 3936) sampled from PNNL chamber.

\subsubsection{Morphological characterization}

Individual nascent soot particles, residuals from sublimated ice crystals and supercooled droplets were investigated using a field-emission SEM (Hitachi S-4700) and TEM (JEOL JEM-2010). Their elemental composition was studied using energy dispersive xray spectroscopy (EDS) to investigate any potential impuities associated with soot 
particles. Soot particles are often represented as fractal-like aggregates due to their selfsimilar structures over several length scales (Oh and Sorensen, 1997) and can be described by the following scaling law.

$$
N=k_{g}\left(\frac{2 R_{g}}{d_{p}}\right)^{D_{f}}
$$

Where $D_{f}$ is the mass fractal dimension, $N$ is the number of monomers per aggregate, $R_{g}$ is the radius of gyration, $d_{p}$ is the monomer diameter, $k_{g}$ is the fractal proportionality constant or fractal prefactor. The radius of gyration is the root-mean-square distance from the center of each monomer to the aggregate center of mass. The prefactor is related to the cluster mass, atmospheric transport processing, and optical properties (Adachi et al., 2007; Oh and Sorensen, 1997), and a large set of values can be found in literature. We used the ensemble method to calculate the fractal dimension of freshly emitted soot particles from 2-D images (Oh and Sorensen, 1997). Typically, in the ensemble method, $N$ is estimated from the projected area of individual soot $\left(A_{a}\right)$ and the mean projected area of a monomer $\left(A_{p}\right)$ in the soot particle, as follows (Köylü et al., 1995; Oh and Sorensen, 1997; Samson et al., 1987):

$$
N=k_{a}\left(\frac{A_{a}}{A_{p}}\right)^{\alpha}
$$

Where $\alpha$ is an empirical exponent (1.09) and $k_{a}(1.15)$ is a constant We used an approximate relation $L_{\max } / 2 R_{\mathrm{g}}=1.50 \pm 0.05$ as a surrogate for $R_{g}$ (Brasil et al., 1999). $D_{f}$ for nascent soot particles (with $D_{f}<2$ ) is then calculated using equation 1.

Soot from supercooled and ice crystal residuals are restructured and compacted, resulting in a $D_{f}>2$ and using equation 2 would underestimate $N$ due to the monomer overlap. Therefore, we calculated a 2 -d fractal dimension $\left(D_{2 f}\right)$ using the directly measurable area of each aggregate $\left(A_{a}\right)$ and its maximum length $\left(L_{\max }\right)$ (Lee and Kramer, 2004) using the following scaling law:

$$
A_{a}=k\left(L_{\max }\right)^{D_{2 f}}
$$


For direct comparison purpose, we calculated $D_{2 f}$ for nascent soot particles as well. We also used several other 2-D morphological descriptors such as aspect ratio, roundness and convexity to characterize nascent soot, and supercooled droplet and ice crystal residuals. Higher roundness indicates particles that are more compacted. The convexity is defined as the ratio of $A_{p}$ and the area of the convex hull polygon (smallest convex polygon in which the particle is inscribed).

\subsubsection{Supercooled droplet and ice residue collection}

Ice nucleation measurements of nascent soot particles were performed using the compact ice chamber (CIC). Ice nucleation measurements were conducted at two different temperatures, $-40^{\circ} \mathrm{C}$ and $-20^{\circ} \mathrm{C}$. Freezing events occurred at $-40^{\circ} \mathrm{C}$ and ice crystals were seperated using a pumped counterflow virtual impactor (PCVI) (Kulkarni et al., 2011), and then impacted on substrates for electron microscopy using a four-stage cascade impactor (MPS-4G1). Soot particles were collected on 300 mesh transmission

electron microscopy (TEM) copper lacey formvar grids. Samples were colelcted on the third and fourth stages of the impactor with $50 \%$ cut off aerodynamic diameters of $150 \mathrm{~nm}$ and $50 \mathrm{~nm}$, respectively. For this study samples from fourth stage only were analyzed to avoid multiply charged particles possibly present on the third stage. Samples were also collected on nucleopre polycarbonate membrane using a custom built aspirated sampler for scanning electron microscopy (SEM) analysis. At $-20^{\circ} \mathrm{C}$ no freezing event was observed and supercooled droplet residuals were similarly seperated from interstitial particles using the PCVI and soot particles were collected again on TEM grids and SEM membranes. Nascent soot particles were also collected directly from the environmental chamber for comparison.

\subsubsection{Simulation of optical properties}

We have investigated the effect of compaction on the optical properties of soot particles as a function of wavelength, using the discrete dipole approximation (DDA- 
DDSCAT7.3) code (Draine and Flatau, 1994, 2013). In particular, in this study we discuss the absorption $\left(C_{a b s}\right)$ and scattering cross-sections $\left(C_{s c a}\right)$, and the single scattering albedo $\left(\mathrm{SSA}=C_{s c a} /\left(C_{a b s}+C_{s c a}\right)\right.$ ). We used a random walk aggregation method to generate soot particles for the DDA simulations (Richard et al., 2011). The detailed method for the generation of the aggregates and for the DDA simulations are described elsewhere (Scarnato et al., 2012). We have generated soot aggregates with 100 monomers with a diameter of $23 \mathrm{~nm}$, in agreement with our observed values for nascent soot, ice crystal and supercooled droplet residuals (Figure 5-2). Then, we computed average values of scattering and absorption cross sections for wavelengths of 405, 532, 550 and $781 \mathrm{~nm}$ and for 1000 random particle orientations (see for discussion on the solution convergence due to the average of number of orientations) (Scarnato et al., 2012). The wavelength dependent soot refractive index provided by Chang and Charalampopoulos (1990) was used in all calculations. The selected wavelengths include the 3-wavelengths of the photoacoustic spectrometer and the $550 \mathrm{~nm}$ wavelength used in many studies, as is of use in many weather or climate models.
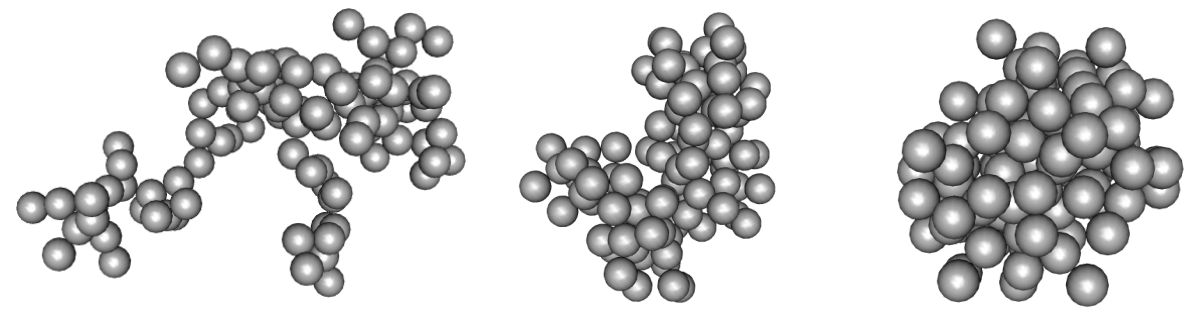

Figure 5-2: The synthetic soot particles used in the simulation, representing open fractal-like nascent soot, soot from supercooled droplet residual and ice crystal residual from left to right.

\subsection{Results and discussions}

\subsubsection{Morphology of residuals}

In this section, we discuss the morphological changes of soot particles after sublimation of ice crystals and evaporation of supercooled water droplets and compare their morphology with nascent soot particles. The left panel in Figure 5-3 shows TEM 
images of individual open fractal-like shape of nascent soot particles and soot from supercooled droplet (middle panel) and ice crystal residuals (right panel). EDS analysis shows carbon and oxygen in all three samples suggesting no potential impurities in all the samples. The open fractal-like structure of nascent soot particle exhibited a $D_{f}$ of $1.53 \pm 0.02$ and a $k_{g}$ of $3.44 \pm 0.06$. For diesel soot, previous studies showed $D_{f}$ values ranging between 1.20 to 1.82 depending on engine conditions and combustion properties (e.g. (Li et al., 2011; Luo et al., 2005).
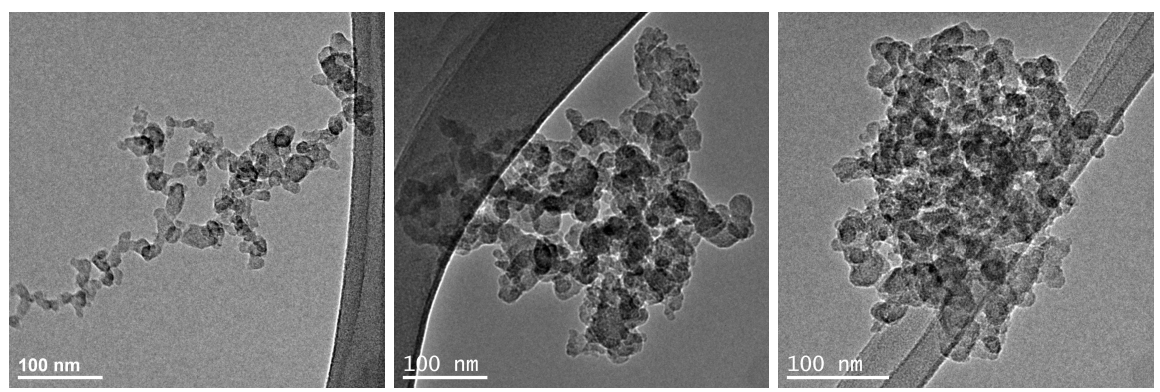

Figure 5-3: TEM images of nascent soot (left panel), supercooled droplet (SCD) residuals (middle panel) and ice crystal (IC) residuals (right panel).

Table 5-1: Mean morphological descriptors of nascent soot, soot from supercooled droplet and ice crystal residuals.

\begin{tabular}{|c|c|c|c|c|c|c|c|c|}
\hline Samples & $n$ & $\begin{array}{c}d_{p} \\
{[\mathrm{~nm}]}\end{array}$ & $\begin{array}{l}D_{A e q} \\
{[\mathrm{~nm}]} \\
\end{array}$ & $A R$ & $R N$ & $C V$ & $D_{2 f}$ & $k_{2 g}$ \\
\hline Nascent soot & 226 & $\begin{array}{l}23 \\
(3)\end{array}$ & $\begin{array}{l}153 \\
(45)\end{array}$ & $\begin{array}{c}1.75 \\
(0.48)\end{array}$ & $\begin{array}{c}0.41 \\
(0.12)\end{array}$ & $\begin{array}{c}0.71 \\
(0.10)\end{array}$ & $\begin{array}{c}1.42 \\
(0.05)\end{array}$ & $\begin{array}{c}0.13 \\
(0.03)\end{array}$ \\
\hline $\begin{array}{c}\text { Supercooled } \\
\text { droplet residuals }\end{array}$ & 208 & $\begin{array}{l}23 \\
(5) \\
\end{array}$ & $\begin{array}{l}179 \\
(75) \\
\end{array}$ & $\begin{array}{l}1.65 \\
(0.37) \\
\end{array}$ & $\begin{array}{c}0.45 \\
(0.12) \\
\end{array}$ & $\begin{array}{c}0.75 \\
(0.10) \\
\end{array}$ & $\begin{array}{c}1.61 \\
(0.03)\end{array}$ & $\begin{array}{c}0.20 \\
(0.02) \\
\end{array}$ \\
\hline Ice crystal residuals & 241 & $\begin{array}{l}24 \\
(4) \\
\end{array}$ & $\begin{array}{l}201 \\
(61) \\
\end{array}$ & $\begin{array}{c}1.46 \\
(0.27) \\
\end{array}$ & $\begin{array}{c}0.55 \\
(0.11) \\
\end{array}$ & $\begin{array}{c}0.83 \\
(0.08) \\
\end{array}$ & $\begin{array}{c}1.71 \\
(0.04) \\
\end{array}$ & $\begin{array}{c}0.28 \\
(0.02) \\
\end{array}$ \\
\hline
\end{tabular}

$n$, number of individual particles analyzed; $d_{p}$, monomer diameter; $D_{A e q}$, projected area equivalent diameter; $A R$, aspect ratio; $R N$, roundness; $C V$, convexity; $D_{2 f}, 2-\mathrm{d}$ fractal dimension; $k_{2 g}, 2$-d prefactor. In parenthesis: standard error for $D_{2 f}$ and $k_{2 g}$ calculated from the uncertainty in the mean-square fit, and standard deviation for the other parameters. 

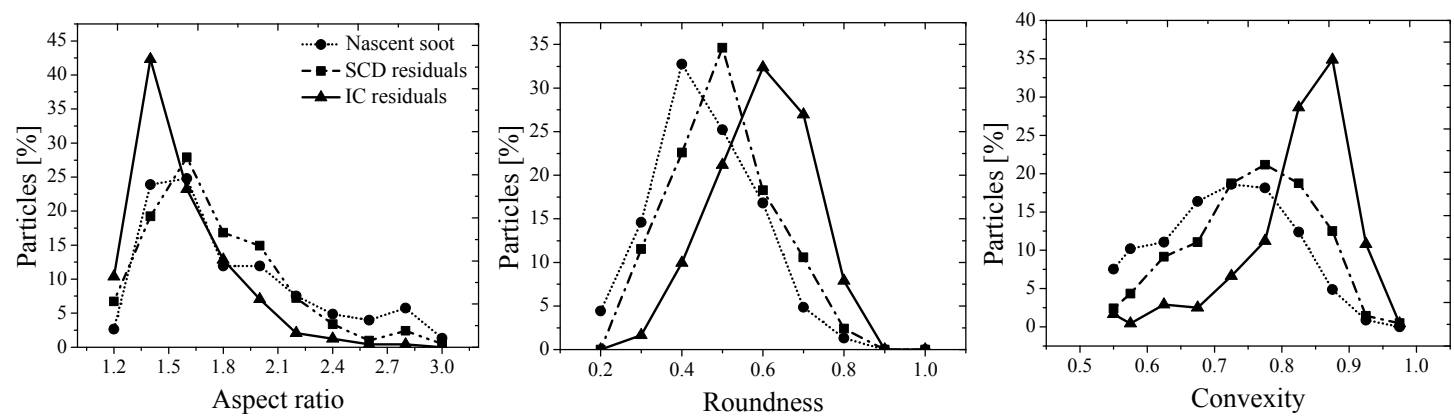

Figure 5-4: Aspect ratio (left panel), roundness (middle panel) and convexity (right panel) of nascent soot, soot from supercooled droplet (SCD) and ice crystal (IC) residuals. Number of particles analyzed for nascent soot, supercooled and ice crystal residuals were 226, 208 and 241 respectively.
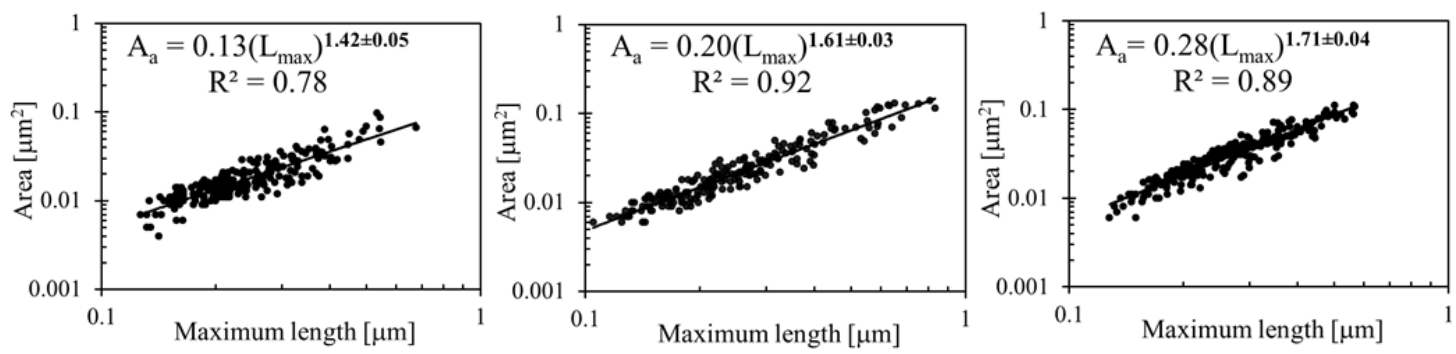

Figure 5-5: Two-dimensional fractal dimension for nascent soot (left panel), supercooled (middle panel) droplet and ice crystal residuals (right panel).

Figure 5-4 compares the distribution of aspect ratio (top panel), roundness (middle panel) and convexity (right panel) between nascent soot, soot from supercooled droplet and ice crystal residuals, respectively. The distributions show that soot particles from ice crystal residuals are the most compacted (higher roundness and convexity and lower aspect ratio) followed by supercooled droplet residuals and nascent soot particles. Compacted soot from ice crystal residual suggest that the freezing process can potentially influence soot collapsing. Table 5-1 summarizes the mean and standard deviations for several morphological descriptors (aspect ratio, roundness and convexity) including 2-D fractal dimension and prefactor (Figure 5-5). Monomer size of the soot particles depicts no significant change in soot from ice crystal and supercooled droplet residuals compared to nascent soot. A consistent pattern is evident for 2-d fractal 
dimension; $D_{2 f}$ is highest for soot from ice crystal residuals followed by soot from supercooled droplet residuals and finally by nascent soot. Higher $D_{2 f}$ represents more compacted structures.

\subsubsection{Restructuring of soot particles}

We found significantly higher collapsed soot (soot with a compact shape) from ice crystal residuals than supercooled droplet residuals, suggesting that freezing process might be reponsible for further collapsing. However, the actual mechanisim is still under investigation. Sublimation or evaporation of melted ice crystal in PCVI can influence the restructuring of soot particles. Another possible explanation for the soot restructuring is that the increase of pressure inside the frozen drop can (Visagie, 1969) deform the soot structure. The average fragementation energies for dry and wet diesel soot are approximately $0.52 \times 10^{-16} \mathrm{~J}$ and $1.2 \times 10^{-10} \mathrm{~J}$ respectively (Rothenbacher et al., 2008). Structural deformation of soot due to mechanical stress while freezing can alter the shape and maginitude of the soot-water contact angle and filling angle (Butt and Kappl, 2009). Change in the soot-water contact angle and filling angle can influence the capilary force, which can result collapsing of the soot structure.

\subsubsection{Optical properties of residuals}

Optical properties of nascent soot, as well as soot from supercooled droplet and ice crystal residuals were simulated using discrete dipole approximation (DDA) model. Figure 5-6 shows the spectral dependency of several optical properties, such as absorption $\left(C_{a b s}\right)$ and scattering $\left(C_{s c a}\right)$ cross sections, and single scattering albedo (SSA) of soot residuals from supercooled droplets and ice crystal normalized by the corresponded property of nascent soot. DDA predicts higher optical cross sections and $S S A$ for compact aggregates. Soot residuals from ice crystal have a slightly higher $C_{a b s}$ and a substantially higher scattering cross section $C_{s c a}$ than the soot residuals from supercooled droplets. Similarly, a T-matrix simulation study showed an increase in $C_{a b s}$ and $C_{s c a}$ at $870 \mathrm{~nm}$ for compact soot compared to less compacted soot. Less absorbing 
material are exposed to the light when soot particles become collapsed, which should decrease the absorption, but at the same time, monomer-monomer interactions increase, resulting in a small enhancement of absorption (Liu et al., 2008). These results imply an overall higher SSA for collapsed soot particles with implications for the radiative forcing of soot processed by water and ice in clouds.

Soot specific absorption can be enhanced when soot and water are mixed in a water droplet, and the degree of enhancement depends on the details of the soot-water mixing (e.g. the soot location within the water droplet). Absorption is maximized when the same soot mass is fragmented in the monomers and quasi-uniformly distributed inside the droplet (Mishchenko et al., 2014), which is a probable case to some extent as previously described for fragmentation of soot particles inside frozen drop.

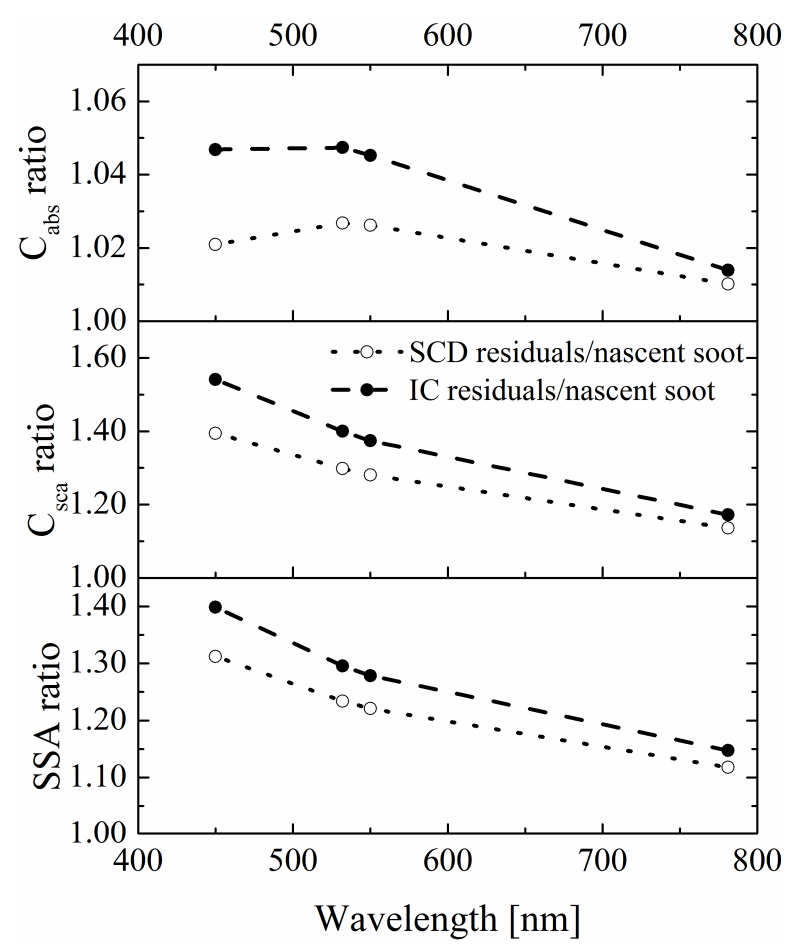

Figure 5-6: Normalized absorption and scattering cross-sections, and single scattering albedo (SSA). Optical cross-sections and SSA for supercooled droplet (SCD) and ice crystal (IC) soot residuals were normalized by the values obtained for nascent soot. 


\subsection{Conclusions}

This work investigates the effect of freezing and sub-freezing temperature during ice crystal and supercooled droplet formation, respectively, on individual soot particle morphology. Soot particles from ice crystal residuals show restructuring of soot, resulting in very compacted structures, compared to supercooled droplet residuals and nascent soot. Soot contained in ice crystals and supercooled cloud droplets can facilitate local warming and even evaporation of clouds (i.e. cloud burning effect) [Ackerman et al., 2000]. As we demonstrated that both supercooling of water and freezing in soot containing droplets can lead to soot restructuring, changing the soot optical properties, these results have implications to the radiative forcing due to soot in superocooled and ice clouds.

\subsection{References}

Adachi, Chung, S. H., Friedrich, H., and Buseck, P. R.: Fractal parameters of individual soot particles determined using electron tomography: Implications for optical properties, Journal of Geophysical Research-Atmospheres, 112, 2007.

Bond, T. C., Doherty, S. J., Fahey, D. W., Forster, P. M., Berntsen, T., DeAngelo, B. J., Flanner, M. G., Ghan, S., Kärcher, B., Koch, D., Kinne, S., Kondo, Y., Quinn, P. K., Sarofim, M. C., Schultz, M. G., Schulz, M., Venkataraman, C., Zhang, H., Zhang, S., Bellouin, N., Guttikunda, S. K., Hopke, P. K., Jacobson, M. Z., Kaiser, J. W., Klimont, Z., Lohmann, U., Schwarz, J. P., Shindell, D., Storelvmo, T., Warren, S. G., and Zender, C. S.: Bounding the role of black carbon in the climate system: A scientific assessment, Journal of Geophysical Research: Atmospheres, 118, 5380-5552, 2013.

Brasil, A. M., Farias, T. L., and Carvalho, M. G.: A recipe for image characterization of fractal-like aggregates, Journal of Aerosol Science, 30, 1379-1389, 1999.

Butt, H.-J. and Kappl, M.: Normal capillary forces, Advances in Colloid and Interface Science, 146, 48-60, 2009. 
Chang, H. and Charalampopoulos, T.: Determination of the wavelength dependence of refractive indices of flame soot, Proceedings of the Royal Society of London. Series A: Mathematical and Physical Sciences, 430, 577-591, 1990.

Colbeck, I., Appleby, L., Hardman, E., and Harrison, R. M.: The optical properties and morphology of cloud-processed carbonaceous smoke, Journal of Aerosol Science, 21, 527-538, 1990.

Cziczo, D. J. and Froyd, K. D.: Sampling the composition of cirrus ice residuals, Atmospheric Research, 142, 15-31, 2014.

Cziczo, D. J., Froyd, K. D., Hoose, C., Jensen, E. J., Diao, M., Zondlo, M. A., Smith, J. B., Twohy, C. H., and Murphy, D. M.: Clarifying the dominant sources and mechanisms of cirrus cloud formation, Science, 340, 1320-1324, 2013.

DeMott, P. J., Chen, Y., Kreidenweis, S. M., Rogers, D. C., and Sherman, D. E.: Ice formation by black carbon particles, Geophys. Res. Lett., 26, 2429-2432, 1999.

Draine, B. T. and Flatau, P. J.: Discrete-dipole approximation for scattering calculations, JOSA A, 11, 1491-1499, 1994.

Draine, B. T. and Flatau, P. J.: User guide for the discrete dipole approximation code DDSCAT 7.3, arXiv preprint arXiv:1305.6497, 2013. 2013.

Dymarska, M., Murray, B. J., Sun, L., Eastwood, M. L., Knopf, D. A., and Bertram, A. K.: Deposition ice nucleation on soot at temperatures relevant for the lower troposphere, Journal of Geophysical Research: Atmospheres, 111, D04204, 2006.

Friedman, B., Kulkarni, G., Beránek, J., Zelenyuk, A., Thornton, J. A., and Cziczo, D. J.: Ice nucleation and droplet formation by bare and coated soot particles, Journal of Geophysical Research: Atmospheres, 116, D17203, 2011.

Gorbunov, B., Baklanov, A., Kakutkina, N., Windsor, H. L., and Toumi, R.: Ice nucleation on soot particles, Journal of Aerosol Science, 32, 199-215, 2001.

Hansson, H. C. and Ahlberg, M. S.: Dynamic shape factors of sphere aggregates in an electric-field and their dependence on the Knudsen number, Journal of Aerosol Science, 16, 69-79, 1985. 
Heymsfield, A., Baumgardner, D., DeMott, P., Forster, P., Gierens, K., and Kärcher, B.: Contrail Microphysics, Bulletin of the American Meteorological Society, 91, 465-472, 2010.

Hobbs, P. V.: Ice physics, Oxford: Clarendon Press, 1974, 1, 837, 1974.

Hoose, C. and Möhler, O.: Heterogeneous ice nucleation on atmospheric aerosols: a review of results from laboratory experiments, Atmos. Chem. Phys. Discuss., $12,12531-12621,2012$.

Huang, P.-F., Turpin, B. J., Pipho, M. J., Kittelson, D. B., and McMurry, P. H.: Effects of water condensation and evaporation on diesel chain-agglomerate morphology, Journal of aerosol science, 25, 447-459, 1994.

Jacobson, M. Z.: Effects of Externally-Through-Internally-Mixed Soot Inclusions within Clouds and Precipitation on Global Climate†, The Journal of Physical Chemistry A, 110, 6860-6873, 2006.

Kanji, Z. A., DeMott, P. J., Möhler, O., and Abbatt, J. P. D.: Results from the University of Toronto continuous flow diffusion chamber at ICIS 2007: instrument intercomparison and ice onsets for different aerosol types, Atmos. Chem. Phys., 11, 31-41, 2011.

Kärcher, B., Busen, R., Petzold, A., Schröder, F. P., Schumann, U., and Jensen, E. J.: Physicochemistry of aircraft-generated liquid aerosols, soot, and ice particles: 2. Comparison with observations and sensitivity studies, Journal of Geophysical Research: Atmospheres, 103, 17129-17147, 1998.

Kärcher, B., Möhler, O., DeMott, P. J., Pechtl, S., and Yu, F.: Insights into the role of soot aerosols in cirrus cloud formation, Atmospheric Chemistry and Physics, 7, 4203-4227, 2007.

Kärcher, B., Peter, T., Biermann, U. M., and Schumann, U.: The Initial Composition of Jet Condensation Trails, Journal of the Atmospheric Sciences, 53, 3066-3083, 1996.

Knopf, D. A. and Koop, T.: Heterogeneous nucleation of ice on surrogates of mineral dust, Journal of Geophysical Research: Atmospheres, 111, D12201, 2006. 
Koehler, K. A., DeMott, P. J., Kreidenweis, S. M., Popovicheva, O. B., Petters, M. D., Carrico, C. M., Kireeva, E. D., Khokhlova, T. D., and Shonija, N. K.: Cloud condensation nuclei and ice nucleation activity of hydrophobic and hydrophilic soot particles, Physical Chemistry Chemical Physics, 11, 7906-7920, 2009.

Köylü, Ü. Ö., Faeth, G. M., Farias, T. L., and Carvalho, M. G.: Fractal and projected structure properties of soot aggregates, Combustion and Flame, 100, 621-633, 1995.

Kulkarni, G., Pekour, M., Afchine, A., Murphy, D. M., and Cziczo, D. J.: Comparison of experimental and numerical studies of the performance characteristics of a pumped counterflow virtual impactor, Aerosol Science and Technology, 45, 382-392, 2011.

Lee, C. and Kramer, T. A.: Prediction of three-dimensional fractal dimensions using the two-dimensional properties of fractal aggregates, Advances in Colloid and Interface Science, 112, 49-57, 2004.

Li, Z., Song, C., Song, J., Lv, G., Dong, S., and Zhao, Z.: Evolution of the nanostructure, fractal dimension and size of in-cylinder soot during diesel combustion process, Combustion and Flame, 158, 1624-1630, 2011.

Liu, Mishchenko, M. I., and Arnott, W. P.: A study of radiative properties of fractal soot aggregates using the superposition T-matrix method, Journal of Quantitative Spectroscopy \& Radiative Transfer, 109, 2656-2663, 2008.

Lohmann, U. and Feichter, J.: Global indirect aerosol effects: a review, Atmos. Chem. Phys., 5, 715-737, 2005.

Luo, C.-H., Grace Lee, W.-M., Lai, Y.-C., Wen, C.-Y., and Liaw, J.-J.: Measuring the fractal dimension of diesel soot agglomerates by fractional Brownian motion processor, Atmospheric Environment, 39, 3565-3572, 2005.

Mikhailov, E., Vlasenko, S., Podgorny, I., Ramanathan, V., and Corrigan, C.: Optical properties of soot-water drop agglomerates: An experimental study, Journal of Geophysical Research: Atmospheres (1984-2012), 111, 2006. 
Mishchenko, M. I., Liu, L., Cairns, B., and Mackowski, D. W.: Optics of water cloud droplets mixed with black-carbon aerosols, Opt. Lett., 39, 2607-2610, 2014.

Mohler, O., Linke, C., Saathoff, H., Schnaiter, M., Wagner, R., Mangold, A., Kramer, M., and Schurath, U.: Ice nucleation on flame soot aerosol of different organic carbon content, Meteorologische Zeitschrift, 14, 477-484, 2005.

Oh, C. and Sorensen, C. M.: The effect of overlap between monomers on the determination of fractal cluster morphology, Journal of Colloid and Interface Science, 193, 17-25, 1997.

Persiantseva, N. M., Popovicheva, O. B., and Shonija, N. K.: Wetting and hydration of insoluble soot particles in the upper troposphere, Journal of Environmental Monitoring, 6, 939-945, 2004.

Petzold, A., Döpelheuer, A., Brock, C. A., and Schröder, F.: In situ observations and model calculations of black carbon emission by aircraft at cruise altitude, Journal of Geophysical Research: Atmospheres, 104, 22171-22181, 1999.

Petzold, A., Ström, J., Ohlsson, S., and Schröder, F. P.: Elemental composition and morphology of ice-crystal residual particles in cirrus clouds and contrails, Atmospheric Research, 49, 21-34, 1998.

Ramanathan, V. and Carmichael, G.: Global and regional climate changes due to black carbon, Nature Geoscience, 1, 221-227, 2008.

Richard, D., Glenar, D., Stubbs, T., Davis, S., and Colaprete, A.: Light scattering by complex particles in the Moon's exosphere: Toward a taxonomy of models for the realistic simulation of the scattering behavior of lunar dust, Planetary and Space Science, 59, 1804-1814, 2011.

Rothenbacher, S., Messerer, A., and Kasper, G.: Fragmentation and bond strength of airborne diesel soot agglomerates, Particle and fibre toxicology, 5, 2008.

Samson, R. J., Mulholland, G. W., and Gentry, J. W.: Structural-analysis of soot agglomerates, Langmuir, 3, 272-281, 1987.

Scarnato, B., Vahidinia, S., Richard, D. T., and Kirchstetter, T. W.: Effects of internal mixing and aggregate morphology on optical properties of black carbon using a 
discrete dipole approximation model, Atmos. Chem. Phys. Discuss., 12, 2640126434, 2012.

Schumann, U., Jeßberger, P., and Voigt, C.: Contrail ice particles in aircraft wakes and their climatic importance, Geophysical Research Letters, 40, 2867-2872, 2013.

Targino, A. C., Krejci, R., Noone, K. J., and Glantz, P.: Single particle analysis of ice crystal residuals observed in orographic wave clouds over Scandinavia during INTACC experiment, Atmos. Chem. Phys., 6, 1977-1990, 2006.

Tritscher, T., Jurányi, Z., Martin, M., Chirico, R., Gysel, M., Heringa, M. F., DeCarlo, P. F., Sierau, B., Prévôt, A. S., and Weingartner, E.: Changes of hygroscopicity and morphology during ageing of diesel soot, Environmental Research Letters, 6, 034026, 2011.

Twohy, C. H. and Poellot, M. R.: Chemical characteristics of ice residual nuclei in anvil cirrus clouds: evidence for homogeneous and heterogeneous ice formation, Atmos. Chem. Phys., 5, 2289-2297, 2005.

Visagie, P.: Pressures inside freezing water drops, J. Glaciol, 8, 301-309, 1969.

Weingartner, E., Burtscher, H., and Baltensperger, U.: Hygroscopic properties of carbon and diesel soot particles, Atmospheric Environment, 31, 2311-2327, 1997. 


\section{Heterogeneous Ice Nucleation and Water Uptake by Free Tropospheric Particles}

Heterogeneous ice nucleation plays a major role in cloud microphysics. The effect of particle morphology and mixing state on heterogeneous ice nucleation is not well understood. During long-range transport, particles experience several atmospheric aging processes that alter their morphology and mixing state. Here, we report heterogeneous ice nucleation and water uptake activities of aged particles after long-range transport over the Atlantic Ocean. The onset (first observed nucleation event) conditions for heterogeneous ice nucleation and water uptake are investigated as a function of particle temperature $\left(T_{p}\right)$ and relative humidity with respect to ice $\left(R H_{\text {ice }}\right)$. Overall, at $223 \mathrm{~K}$, ice nucleation occurred below homogeneous ice nucleation limit, suggesting that aged particles are efficient ice nuclei. Particles that nucleated ice are mostly mineral dust but often internally mixed with other material.

\subsection{Introduction}

In cloud ice nucleation directly affects the climate system, Earth's atmosphere and the hydrological cycle by affecting precipitations, cloud electrification and atmospheric radiative transfer (Cantrell and Heymsfield, 2005). More than 50\% of Earth's precipitation originates via ice phase ( $\mathrm{Lau}$ and $\mathrm{Wu}, 2003$ ). Ice forms in the atmosphere through homogeneous or heterogeneous pathways. Heterogeneous ice nucleation occurs in presence of aerosol particles acting as ice nuclei (IN) at warmer temperature compared to homogeneous ice nucleation that occurs for water droplets below $\sim 238 \mathrm{~K}$ (Pruppacher and Klett, 1997). Heterogeneous nucleation can occur at relatively lower relative humidity with respect to ice $\left(R H_{i c e}\right)$ whereas homogeneous ice nucleation requires highly supersaturated conditions with $R H_{\text {ice }} \sim 150-170 \%$ (DeMott et al., 2003a; Pruppacher and Klett, 1997). Heterogeneous ice nucleation plays an important role in the formation of mixed-phase clouds (mixture of supercooled liquid droplets and ice 
crystals) and cirrus clouds (containing ice crystals) by altering ice crystal concentrations and shape (Avramov and Harrington, 2010; Morrison et al., 2012). These clouds further impact atmospheric radiative fluxes and the energy balance (Kärcher and Ström, 2003; McFarquhar et al., 2007).

Heterogeneous nucleation can occur in the atmosphere by the following modes: 1) deposition in which water vapor in supersaturated conditions deposits on an IN and an ice crystal forms directly on it, 2) immersion freezing in which an IN is immersed within a liquid droplet that freezes forming an ice crystal, 3) condensation freezing in which water in supercooled conditions condenses on an IN acting as a CCN and immediately freezes, or 4) contact freezing in which ice formation initiates at the water surface by collision between a supercooled droplet and an aerosol particle (Vali, 1985).

A recent study summarized field measurements of ice crystal residues (the leftover aerosol after the ice is sublimated) and found that mineral dust is typically the most abundant residue in cirrus-forming regions (Cziczo and Froyd, 2014). Similarly, a previous ice nucleation study on free tropospheric particles, collected at Storm Peak Laboratory, located on Mt. Werner (elevation 3,200 m amsl) in western Colorado suggested that mineral dust or fly ash particles (33\%) and metallic particles (25\%) are major constituents of ice nuclei with contribution from both natural $(\sim 80 \%)$ and anthropogenic $(\sim 20 \%)$ sources (DeMott et al., 2003a). In some cases mineral dust particles were mixed with biological material as found in IN residues during some field studies (Pratt et al., 2009). Sulfate and organic aerosols were also found in tropical tropopause cirrus ice crystal residues (Froyd et al., 2010). While in other studies, ice crystal residuals from cirrus and mixed phase clouds showed the presence of metalbearing particles, organic material, sulfate, sea salt, carbonaceous and Ca-rich particles (Chen et al., 1998; Ebert et al., 2011). Some other field campaigns, soot and biomass burning particles in cirrus ice crystal residuals were found to be scarce (Cziczo and Froyd, 2014; Twohy and Poellot, 2005); however, in a different study a significant 
fraction of soot has been observed in contrail residuals (Petzold et al., 1998). This field studies point out complex mixtures of ice nuclei that are present in the atmosphere.

Laboratory experiments showed that anthropogenically emitted particles collected in Mexico City and dominated by an organic composition can efficiently initiate ice nucleation under conditions relevant for cirrus cloud formation (Knopf et al., 2010). Organic species can be present as liquids but also as amorphous solid particles (Virtanen et al., 2010). In the upper troposphere, at lower temperatures, organic species can be transformed into glasses. It was suggested that glassy aerosols may resist water uptake and may not initiate ice nucleation below ice saturation levels. However, other studies suggested that glassy aerosols likely influence heterogeneous ice nucleation in tropical tropopause cirrus clouds (Froyd et al., 2010; Murray, 2008).

During long range transport, particles experience several aging processes including condensation of volatile organic compounds and hydrophilic material, oxidation by atmospheric oxidant such as $\mathrm{O}_{3}, \mathrm{OH}, \mathrm{NO}_{3}$, and coagulation and mixing with other organic and inorganic materials (George and Abbatt, 2010; Liu et al., 2011; Seinfeld and Pandis, 2006; Wang et al., 2011). A laboratory study showed that the efficiency of deposition ice nucleation could be reduced by organic particles after exposure to $\mathrm{O}_{3}$ (Wang and Knopf, 2011). Another laboratory study suggested that sulfate and organic coatings on mineral dust make them less effective ice nuclei (Cziczo et al., 2009). However, field measurements suggested that dust from North African and Asia can act as efficient ice nuclei even after long range transport (DeMott et al., 2003b; Sassen, 2005).

In this study, we report the onset conditions (first observed nucleation event) for heterogeneous ice nucleation in deposition and immersion modes, and the water uptake at four different temperatures by long-range transported and aged particles. These particles were collected in the free troposphere on top of the Pico Mountain, in the Azores, in the North Atlantic Ocean. We investigated four samples with different airmass ages and transport patterns, as modeled by the FLEXPART lagrangian transport 
model. After the ice nucleation and water uptake experiments were concluded, the same substrates were used for morphological and elemental composition analysis of the particles deposited on them using scanning electron microscopy. We identified and characterized total 20 nucleated particles in two out of four samples.

\subsubsection{Experimental}

\subsubsection{Sample collection}

Particle samples were collected at Pico Mountain Observatory (PMO) during summer 2013. PMO (2225 m asl) is located in the summit caldera of the Pico mountain in Pico Island, in the Azores, Portugal $\left(38.47^{\circ} \mathrm{N}, 28.40^{\circ} \mathrm{W}\right)$. Samples were deposited on silicon nitride coated discs ( $3 \mathrm{~mm}$ diameter, PELCO®, Ted Pella, Inc.) using a four-stage cascade impactor (MPS-4G1). Samples used for this study were collected on the second stage of the imapctor with a $50 \%$ cut off diameter of $0.50 \mu \mathrm{m}$. In addition, particle concentrations were measured using a 2 channels $(0.3-5 \mu \mathrm{m} ; 0.4-5 \mu \mathrm{m})$ laser particle counter (MetOne GT521). Four high-volume samplers (Hi-Vols; EcoTech HiVol 3000) were used to collect PM2.5 (particulate matter with aerodynamic diameters $\leq 2.5 \mu \mathrm{m}$ ) aerosol on quartz filters (Whatman, 8x10 inch Quartz Microfibre Filters, CAT No. 1851-865) for detailed chemical characterization. Organic carbon (OC) and elemental carbon (EC) content was determined from the quartz filters using an OC: EC analyzer (Sunset Laboratory Inc., Model 4) that uses a thermo-optical transmittance method; the reported results were an average over at least 3 measurements. We also collected additional samples on nucleopore filters (100 nm pore, Whatman) and Transmission electron microscope (TEM) lacey formvar grids (300 mesh, Ted Pella, Inc.) using a custom made sequential sampler for microscopy analysis. Note that additional microscopy samples and samples from high-volume samplers were collected around same time and duration but from different sampling line. Table 1 reports the sampling times and conditions. 
Table 6-1: Sampling date, duration, plume age and mean particle concentrations (MPC) for two size-channels $\left(\mathrm{PM}_{0.3}\right.$ for particles between $0.3 \mu \mathrm{m}$ and $5 \mu \mathrm{m}$; and $\mathrm{PM}_{0.4}$ for particles between $0.4 \mu \mathrm{m}$ and $5 \mu \mathrm{m})$.

\begin{tabular}{ccccccc}
\hline Sample\# & $\begin{array}{c}\text { Sampling date } \\
(2013)\end{array}$ & $\begin{array}{c}\text { Sampling } \\
\text { times }\end{array}$ & $\begin{array}{c}\text { Sampling } \\
\text { duration }(\mathrm{hr})\end{array}$ & $\begin{array}{c}\text { Plume age } \\
(\text { day })\end{array}$ & \multicolumn{2}{c}{$\mathrm{MPC}\left(\# \mathrm{~cm}^{-3}\right)$} \\
\cline { 6 - 8 } & Aug 23 & $20: 49-22: 18$ & 1.5 & 11.6 & 13.2 & 1.4 \\
\hline S1 & Aug 27-28 & $19: 55-14: 15$ & 18.3 & 12.3 & 6.6 & 0.7 \\
\hline S2 & Sept 07-08 & $16: 25-15: 32$ & 23.1 & 12.0 & 1.1 & 0.2 \\
\hline S4 & Sept 19-20 & $16: 48-14: 00$ & 21.2 & 17.3 & 0.4 & 0.1 \\
\hline
\end{tabular}

\subsubsection{Retroplume analysis}

Retroplume analysis were conducted using the Lagrangian particle dispersion model FLEXPART (Stohl et al., 2005). Plots in Figure 6-1 show a total of 10 days of transport. The left panel shows a height vs. time plot. The dashed lines indicate the mean transport height and \pm 1 standard deviation. The right-hand plot exhibits the column-integrated horizontal transport from all height levels. The average location at each upwind time is indicated by the black numeral on this panel as well. We also computed average plume age using $\mathrm{CO}$ tracer concentration. The $\mathrm{CO}$ tracer concentration were computed using retroplumes and anthropogenic $\mathrm{CO}$ emission inventories. Total 20 day $\mathrm{CO}$ concentrations were divided into 80 age bins. Average plume age was estimated as total contribution of $\mathrm{CO}$ concentrations in each bin divided by total $\mathrm{CO}$ concentrations. The air mass that reached PMO during the collection of sample S1 originated in North America (mostly Canada). Sample S2 was also affected by North American air masses, but probably those air masses were mixed with marine air (see height vs.time plot) as the air reaching PMO spent a significant amount of time over the Atlantic Ocean. Airm asses for S2 were mostly from the Northern part of USA. The air masses correspondent to the collection peridod for sample S3 was also from North America, with contributions from the entire USA. S3 is also influenced by marine air. The air mass S4 
was collected from, is the most aged ( $\sim 17.3$ days) with evident air recirculation over the ocean. Table 6-1 reports the average estimated plume age for each sample.

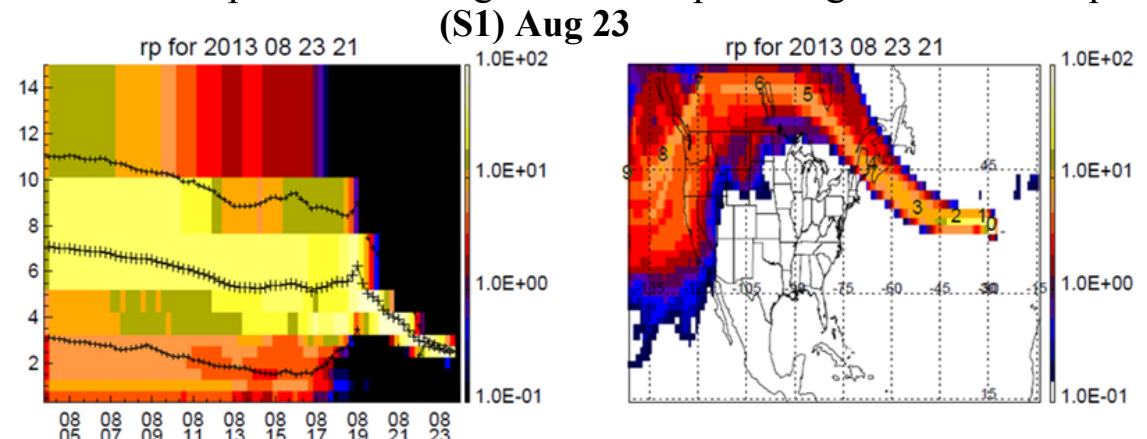

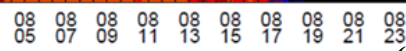

rp for 2013082806

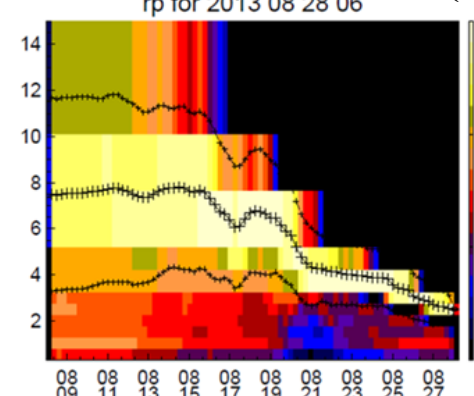

Aug 27-28

$1.0 \mathrm{E}+02$

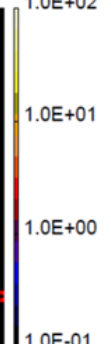

(S3) Sept 07-08

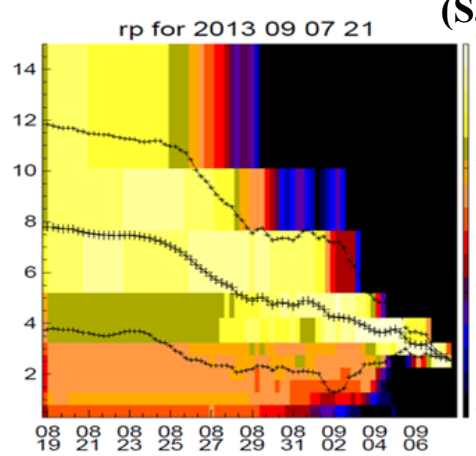

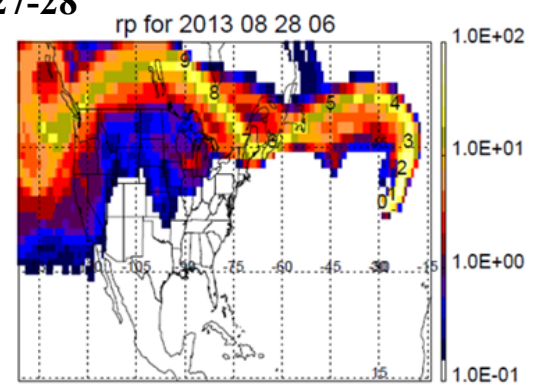

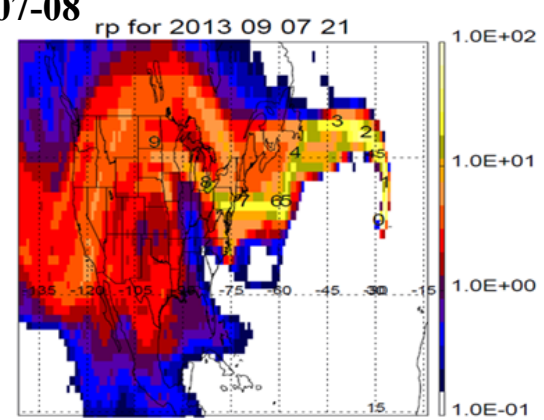

(S4) Sept 19-20
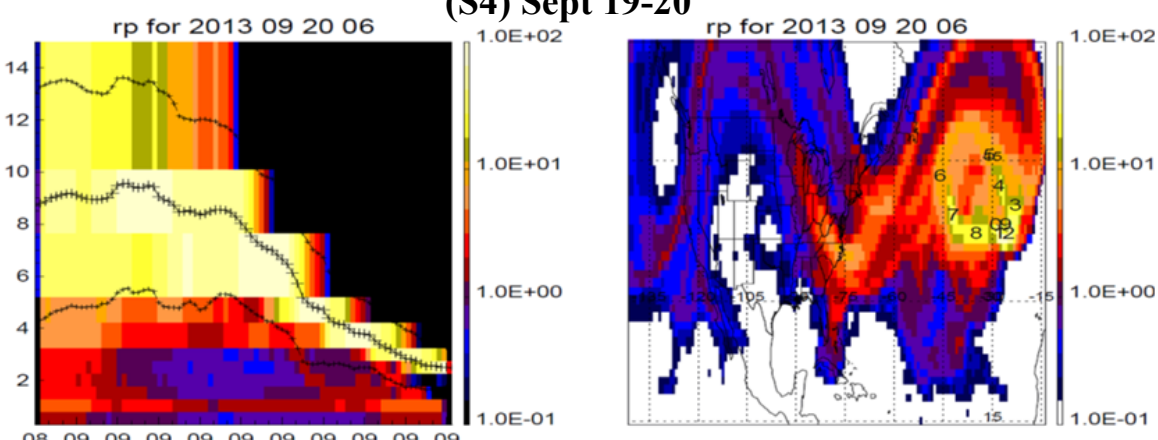

$\begin{array}{llllllllllll}088 & 09 & 09 & 09 & 09 & 09 & 09 & 09 & 09 & 09 & 09 & 1 \\ 31 & 02 & 04 & 06 & 08 & 10 & 12 & 14 & 16 & 18 & 20\end{array}$

Figure 6-1: Retroplumes from FLEXPART for the time periods of collection of the four samples discussed in this paper. 


\subsubsection{Single particle analysis}

Single particle analysis was carried out using scanning electron microscopy (SEM) on the same silicon nitride substrates, but only after having concluded the ice nucleation experiments. This sequence was chosen to avoid affecting the IN findings by potential modifications of the particles by the microscope vacuum and/or the electron beam energy. Particles were imaged using a field emission SEM (FE-SEM) (Hitachi S-4700). Later SEM images were processed to determine the particle morphology (shape and size) and the mixing state. In this study, the diameter of each particle is expressed in terms of the projected area equivalent diameter $\left(D_{A e q}\right)$ that is defined as the diameter of a spherical particle of the same projected area. Energy dispersive X-Ray spectroscopy (EDS) analysis was conducted on selected particles to analyze the elemental composition and assess the particle mixing. In addition to silicon nitride substrates TEM grids were also examined to investigate particle morphology and mixing state.

\subsubsection{Ice nucleation apparatus}

Ice nucleation and water uptake experiments were conducted using a custom built apparatus developed at Stony Brook University. The apparatus consists of an ice nucleation cell (INC) and an optical microscope. The experimental set up and methods have been discussed in previous studies in details (Knopf et al., 2010; Wang and Knopf, 2011). Here we provide a brief description. The optical microscope was operated in reflected light mode and was coupled with a digital camera and imaging software that monitors the entire sample area and any change in particle size and phase. The cell is $<0.8 \mathrm{~cm}^{3}$ in volume and $1 \mathrm{~mm}$ in diameter. Once the substrate was placed onto the cooling stage of the INC, particles were exposed to humidified nitrogen gas $\left(\mathrm{N}_{2}\right.$, ultrahigh purity) flowing at 1 standard liter per minute. Humidified $\mathrm{N}_{2}$ flow was generated by passing $\mathrm{N}_{2}$ gas through a temperature controlled water reservoir. The partial pressure of water within the humidified $\mathrm{N}_{2}$ gas was adjusted by changing the temperature of the water reservoir and mixing the humidified flow with another $\mathrm{N}_{2}$ dry flow. The 
temperature of the cooling stage was controlled by a heating foil while a constant flow of liquid nitrogen was supplied. The temperature of the cooling stage was measured by a temperature sensor (Pt100). The particle temperature $\left(T_{p}\right)$ as low as $200 \mathrm{~K}$ and $R H_{\text {ice }}$ up to water saturation can be achieved inside the INC. The dew point $\left(T_{d}\right)$ was measured by a chilled mirror hygrometer (GE Sensing) at the outlet of the INC in a range between 203 and $293 \mathrm{~K}$ with an uncertainty better than $\pm 0.15 \mathrm{~K}$ (Knopf et al., 2010). The $T_{p}$ and $T_{d}$ values were used to calculate the relative humidity with respect to water $(R H)$ and the relative humidity with respect to ice $\left(R H_{i c e}\right)$ using the following equations

$$
\begin{aligned}
& R H=\frac{p_{H_{2} O}^{0}\left(T_{d}\right)}{p_{H_{2}}^{0} O^{\left(T_{p}\right)}} \\
& R H_{\text {ice }}=\frac{\left.p_{\mathrm{H}_{2} O}^{0} \mathrm{O}_{d}\right)}{p_{\mathrm{H}_{2} \mathrm{O}}^{\mathrm{O} O}\left(T_{p}\right)}
\end{aligned}
$$

Where $p_{H_{2} O}^{0}\left(T_{d}\right)$ is the saturation vapor pressure at $T_{d}$ and $p_{H_{2} O}^{i c e}\left(T_{p}\right)$ and $p_{H_{2} O}^{0} O\left(T_{p}\right)$ represent the saturation vapor pressure over ice and water, respectively at $T_{p} . p_{H_{2} O}^{i c e}\left(T_{p}\right)$, $p_{\mathrm{H}_{2} \mathrm{O}}^{0}\left(T_{p}\right)$ and $p_{\mathrm{H}_{2} \mathrm{O}}^{0}\left(T_{d}\right)$ were calculated using the parameterizations by Murphy and Koop (2005).

\subsubsection{Ice nucleation and water uptake experiments}

First, $T_{d}$ was set to a desired temperature by adjusting the dry and humidified $\mathrm{N}_{2}$ gas flow; then the ice nucleation experiments started, at least after 30 minutes of stable $T_{d}$. Once $T_{d}$ was stable, $R H_{\text {ice }}$ was increased by cooling $T_{p}$ at a rate of $0.1 \mathrm{~K} / \mathrm{min}$. Four $T_{d}$ (223, 238, 248 and $258 \mathrm{~K}$ ) were selected for this study to cover typical temperature ranges of cirrus and mixed phase clouds. The $R H_{\text {ice }}$ was continuously increased until ice formation or water uptake was observed (Dymarska et al., 2006; Wang and Knopf, 2011; Wang et al., 2012).

Optical images of the sample, as well as $T_{d}$ and $T_{p}$ were simultaneously recorded every $0.02 \mathrm{~K}$ (i.e. every $\sim 12 \mathrm{~s}$ ). The optical microscope allows the visual identification of 
water uptake and ice nucleation by monitoring the particle size and phase for particles larger than 0.2 and $1 \mu \mathrm{m}$ when using a magnification of 1130x and 230x, respectively. We counted a freezing event as an immersion freezing if water uptake by the particle was observed prior to formation of ice, while we counted the event as deposition nucleation if no water uptake was observed before the ice formation. We report the onset conditions (first particle observed to nucleate ice) of $R H_{\text {ice }}$ and $T_{p}$. Note that in some cases, more than one particle nucleated ice simultaneously. In those cases, one ice nucleation event was considered and we report the first observed ice formation, but all the ice nuclei were counted.

After each ice nucleation event, the microscope objective was focused on to the ice crystal and a calibration experiment was conducted. $T_{p}$ was calibrated against $T_{d}$ (measured by the hygrometer) by measuring the projected surface area (SA) of the ice crystal. At the beginning of the calibration experiment, $R H_{\text {ice }}$ was set to below $100 \%$, $\left(T_{p}>T_{d}\right)$ so initially the ice crystal would shrink (decrease in SA of ice crystal). Subsequently, $T_{p}$ was set to decrease at $0.1 \mathrm{~K} / \mathrm{min}$ to increase $R H_{i c e}$. Constant SA of ice crystal represents $100 \% R H_{\text {ice }}$, indicating that $T_{d}$ is equal to the temperature of the substrate. After $R H_{\text {ice }}$ exceeds $100 \%$, the ice crystal starts growing (increase in SA of ice crystal). The difference between $T_{p}$ and $T_{d}$ at $100 \% R H_{\text {ice }}$ (constant SA of ice crystal) represents the temperature offset for which $T_{p}$ has to be calibrated. Experimental uncertainties were calculated from the uncertainties of $\Delta T_{d}< \pm 0.15 \mathrm{~K}$ and $\Delta T_{p}< \pm 0.0 .3 \mathrm{~K}$, resulting in $\Delta R H_{\text {ice }}< \pm 9 \%$ for $223 \mathrm{~K}$ and $\Delta R H_{\text {ice }}< \pm 3 \%$ for $260 \mathrm{~K}$ (Knopf et al., 2010; Wang and Knopf, 2011). Error bars presented in the plots are the standard deviation of the observed $R H_{\text {ice }}$ or experimental uncertainties, whichever is larger. 


\subsection{Results and Discussions}

\subsubsection{Particle concentrations}

Figure 6-2 shows particle concentrations time series of 5-minute averaged data during the times of collection of the aerosol samples used for the ice nucleation experiments. Particle concentrations were higher during S1 and S2 compared to S3 and S4. The highest number concentration was found during S1, on average $\# 13.2 / \mathrm{cm}^{3}$ and $\# 1.4 / \mathrm{cm}^{3}$ in channel 1 and channel 2 respectively. Note that the sampling duration for S1 was only $1.5 \mathrm{hrs}$, while the other samples were collected for 18-23 hrs. Sampling duration and mean particle concentration are reported in Table 6-1. Relatively smaller particles were present during the time that S1 was collected, while larger particles dominated at least half of the time period in which S4 was collected.
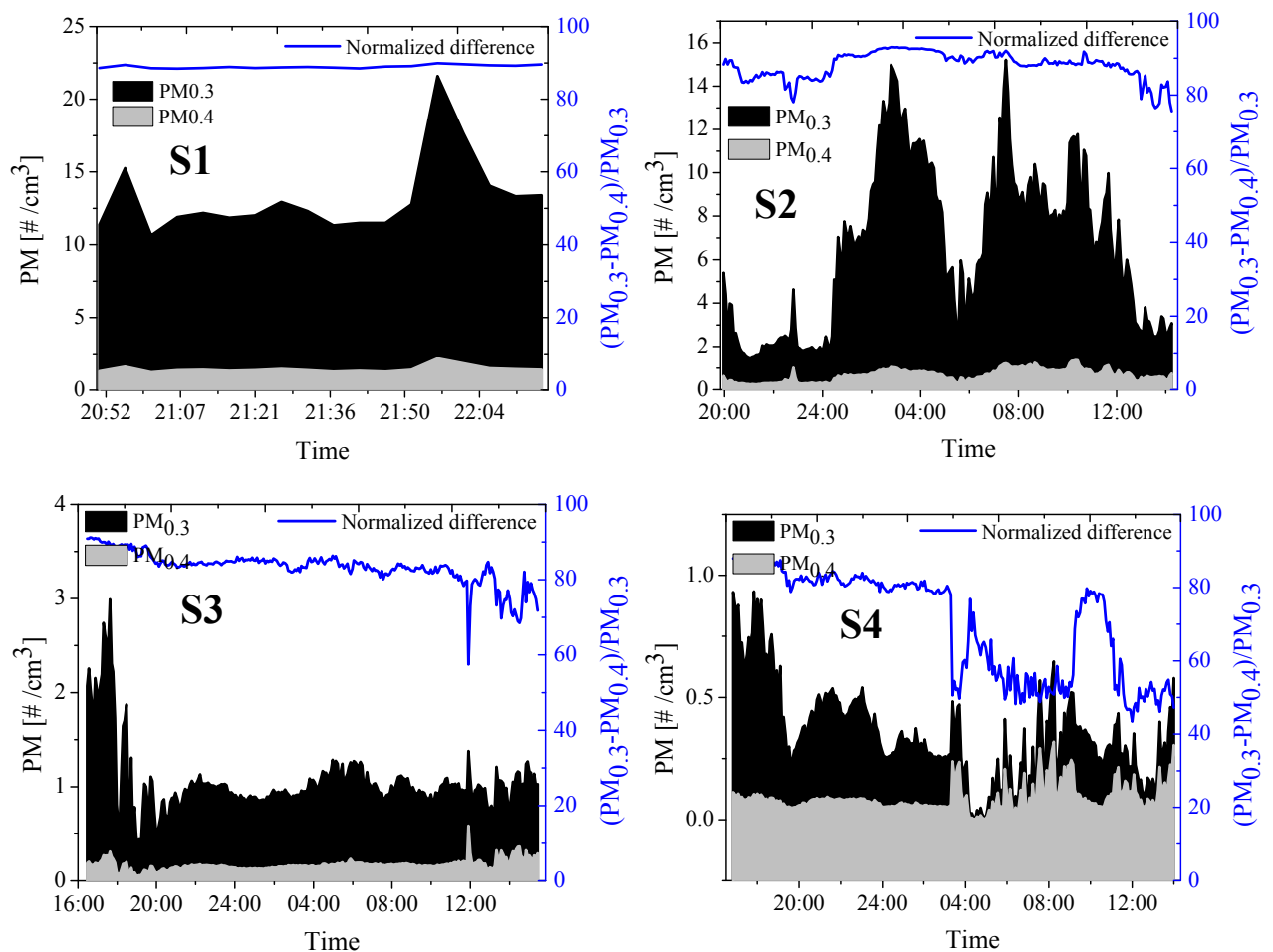

Figure 6-2: Particle concentrations from a 2-channel $(0.3-5 \mu \mathrm{m} ; 0.4-5 \mu \mathrm{m})$ optical particle counter. 


\subsubsection{Particle morphology and mixing state}

The mean $D_{\text {Aeq }}$ ranged from $0.56 \mu \mathrm{m}$ to $1.15 \mu \mathrm{m}$. The average number density of particles $\left(N_{d}\right)$ repoted in Table 6-2, was calculated using low magnification SEM images obtained from different portions (15 locations) of the substrate. The mean $N_{d}$ ranged from $1.2 \times 10^{5} \mathrm{~mm}^{-2}$ to $5.4 \times 10^{5} \mathrm{~mm}^{-2}$. The surface area $\left(N_{s}\right)$ avilable for ice nucleation expeiments on the substrate was calculated from $N_{d}, D_{A e q}$ and the sample area observed in the ice nucleation experiments. The value of $N_{s}$ ranged from 0.06 to $0.23 \mathrm{~mm}^{2}$.

Table 6-2: Sample ID, number of single particles analyzed at the electron microscope $(n)$, mean area equivalent diameter $\left(D_{\text {eeq }}\right)$, mean particle number density $\left(N_{d}\right)$ on the substrate exposed during the ice nucleation experiments and total surface area of the particles $\left(N_{s}\right)$ available for ice nucleation. The numbers in parentheses represent the standard deviations for $D_{A e q}$ and $N_{d}$ and uncertainties for $N_{s}$ propagated from $D_{A e q}$ and $N_{d}$.

\begin{tabular}{ccccc}
\hline Sample\# & $n$ & $D_{\text {Aeq }}[\mu \mathrm{m}]$ & $N_{d}\left[\times 10^{5} \mathrm{~mm}^{-2}\right]$ & $N_{s}\left[\mathrm{~mm}^{2}\right]$ \\
\hline S1 & 324 & $0.56(0.63)$ & $3.0(3.3)$ & $0.06(0.03)$ \\
\hline S2 & 1315 & $0.68(1.13)$ & $5.4(1.8)$ & $0.15(0.02)$ \\
\hline S3 & 431 & $0.98(1.29)$ & $3.9(2.6)$ & $0.23(0.06)$ \\
\hline S4 & 464 & $1.15(1.48)$ & $1.2(1.8)$ & $0.10(0.05)$ \\
\hline
\end{tabular}

Figure 6-3 shows typical SEM images of the four samples. S1 was dominated by smaller particles (mostly soot). However, soot particles were substantially coated with other material. S2 was dominated by salt particles and dust mixed with salt particles. In S3 we observed various internally mixed particles of mineral dust, salt, soot and sulfate. S4 was dominated by dust and soot particles and we observed internally mixed soot and dust particles here as well. In general, most of the particles in all the samples were coated and most of the particles were internally mixed. For example, TEM images (Figure 6-4 ) of S3 shows coated dust, organic particles, and soot and sulfate paticles embedded within organic particles. 

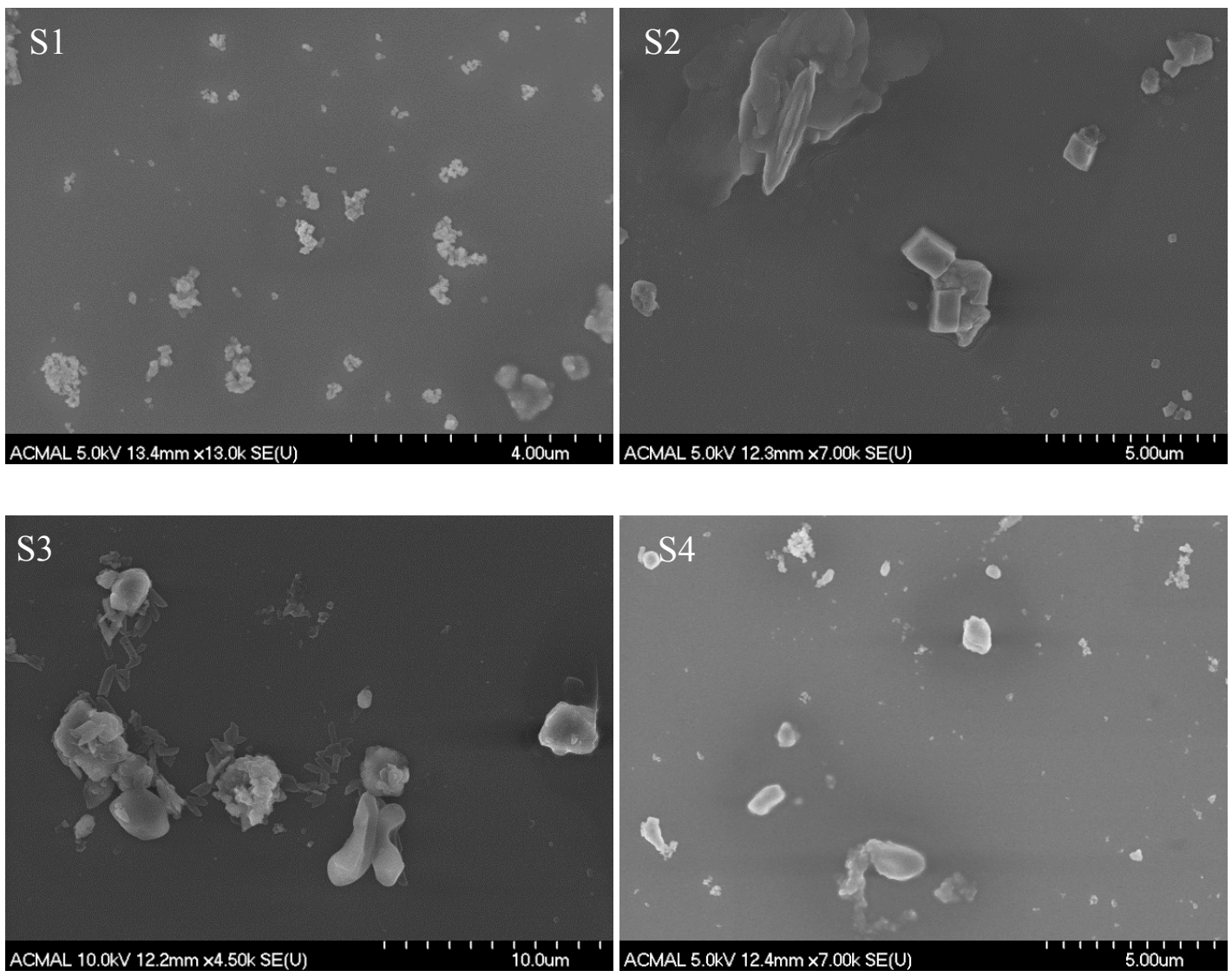

Figure 6-3: Typical SEM images of the four samples.

Table 6-3: Organic carbon (OC), elemental carbon (EC) and estimated organic mass $(\mathrm{OM})$ from aerosol samples collceted over periods partially overlapping with the collection times of the samples used in the ice nucelation analysis.

\begin{tabular}{cccc}
\hline Sample\# & $\mathrm{OC}\left[\mu \mathrm{g} \mathrm{m}^{-3}\right]$ & $\mathrm{EC}\left[\mu \mathrm{g} \mathrm{m}^{-3}\right]$ & $\mathrm{OM}\left[\mu \mathrm{g} \mathrm{m}^{-3}\right]$ \\
\hline \hline $\mathrm{S} 1$ & $2.48(0.13)$ & $0.041(0.003)$ & $4.47(0.24)$ \\
\hline $\mathrm{S} 2$ & $1.30(0.09)$ & $0.049(0.002)$ & $2.35(0.16)$ \\
\hline $\mathrm{S} 3$ & $0.43(0.04)$ & $0.067(0.004)$ & $0.77(0.08)$ \\
\hline $\mathrm{S} 4$ & $0.20(0.03)$ & $0.011(0.003)$ & $0.36(0.06)$ \\
\hline
\end{tabular}



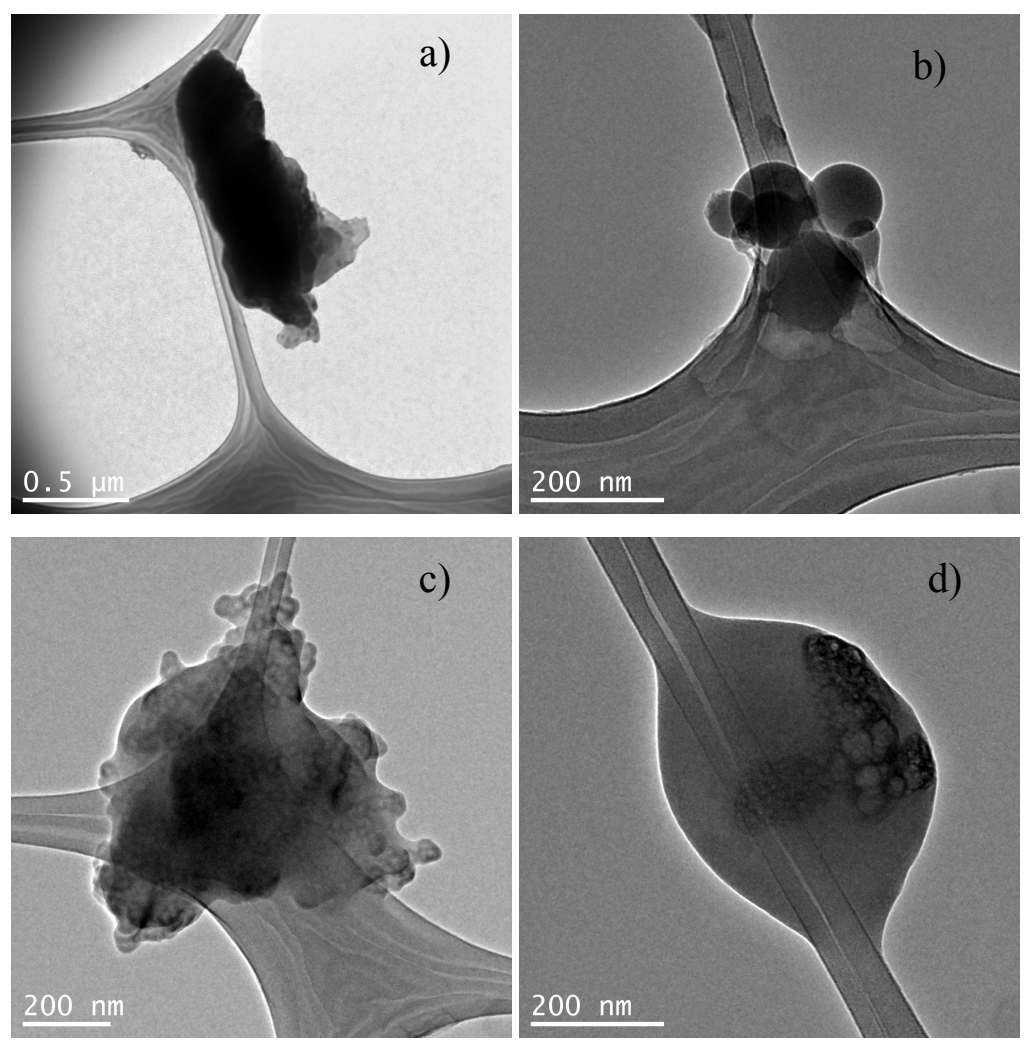

Figure 6-4: TEM images of S3. a) mineral dust coated with organic material b) organic particle c) soot coated with organic material and d) sulfate particle trapped inside organic particle.

Table 6-3 shows the measured organic carbon (OC) and elemntar carbon (EC) concentrations. The mean EC concentraion was in the range of $0.011 \mu \mathrm{g} \mathrm{m}^{-3}$ to $0.067 \mu \mathrm{g}$ $\mathrm{m}^{-3}$. From OC, we estimated the organic mass (OM) assuming and OM:OC ratio of 1.8 (Pitchford et al., 2007). The estimated OM ranged from $0.36 \mu \mathrm{g} \mathrm{m}^{-3}$ to $4.47 \mu \mathrm{g} \mathrm{m}^{-3}$ with the highest concentration found during S1 and the lowest concentration found during S4 that was dominated by dust particles. Note that concentration of OM in IN samples may not completely represent the concentration measured by EC/OC analyzer as quartz filters were collected over different time duration with partial overlap with IN sample collection times. 


\subsubsection{Onset conditions for deposition ice nucleation}

The mean onset conditions of the deposition nucleation experiments were determined as a function of $T_{p}$ and $R H_{\text {ice }}$ as shown in Figure 6-5. Each data point is the mean of at least three onset condition values. At $223 \mathrm{~K}$, particles nucleated via deposition mode at mean $R H_{\text {ice }}$ values of $112 \%-128 \%$, lower than water saturation and the homogeneous freezing limits (Koop et al., 2000). S1 exhibited higher $R H_{\text {ice }}$ of $128 \%$, whereas all the other samples nucleated within a very close range of $R H_{\text {ice }}$ values $(112 \%-116 \%)$.

The SEM analysis shows that S1 was mostly dominated by a higher abundance of soot particles (which typically is co-emitted during combustion processes together with organic compounds) compared to other samples which were dominated by dust and salt particles. In addition, particles in S1 were smaller in size than for all the other samples. These might be possible reasons for the slightly higher mean $R H_{\text {ice }}$ observed for $\mathrm{S} 1$ with respect to the other samples. Wang et al. (2012) suggested that marine influenced samples have higher propensity to initiate ice nucleation via deposition mode compared to samples containing anthropogenic organics. However, the differences of $R H_{\text {ice }}$ between the samples are not significant and lie within the experimental uncertainties. SEM and TEM images provided evidences that the majority of the particles were coated with organics in S3 (Figure 6-4). SEM images for other samples show substantial coating on particles but TEM analysis is required to verify presence of organic coating. It is possible that most of the organic coatings or pure organic particles turned into glassy state at the low temperatures used in our experiment. This might have resulted in the small range of $R H_{i c e}$ values observed for the different samples, even when the relative abundance of particle types and their sizes showed significant variability from sample to sample. 


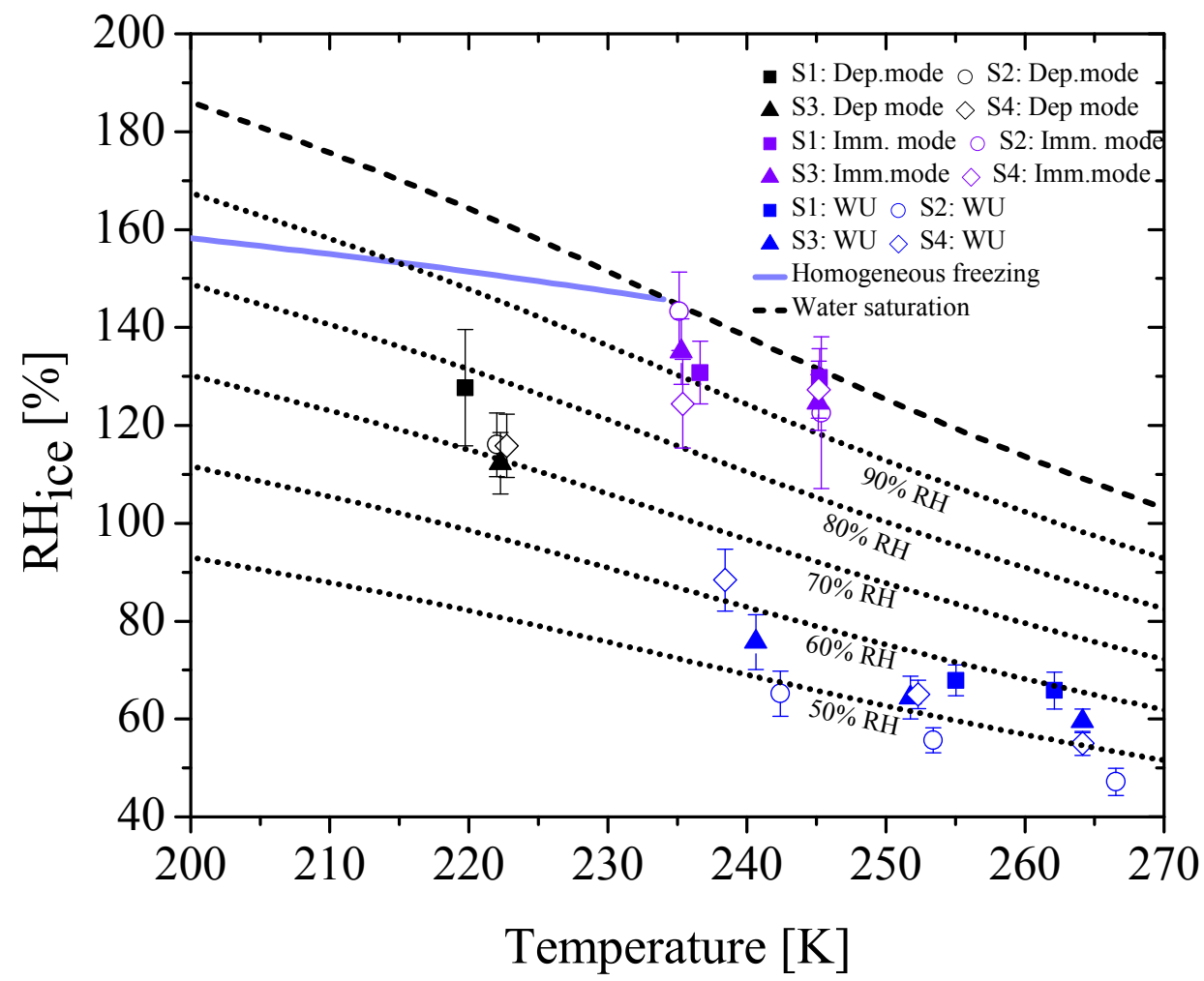

Figure 6-5: Mean onset conditions for ice nucleation via deposition mode (Dep.Mode), immersion mode (Imm.mode) and water uptake (WU). Total 54 ice nucleation events (25 deposition mode and 29 in immersion mode). Error bars are the standard deviation of the observed $\mathrm{RH}_{\text {ice }}$ or experimental uncertainties, whichever is larger. (Note that WU for $\mathrm{S} 1$ at $238 \mathrm{~K}$ is not available).

\subsubsection{Onset conditions for water uptake and immersion nucleation}

The mean onset conditions of immersion freezing and water uptake by particles on the four samples are also presented in Figure 6-5. The dotted lines show saturation (100\%), $90 \%, 80 \%, 70 \%, 60 \%$ and $50 \% R H$. The solid line indicates the $R H_{\text {ice }}$ thresholds for homogeneous ice nucleation. Water uptake by four samples occurred between $42 \%$ and $66 \% R H$ for temperatures between $238 \mathrm{~K}$ and $267 \mathrm{~K}$. On average, S2 is consistently the most effective in up-taking water in the entire temperature range. Sample S2 took up water at lower RH values in the range of $42-47 \%$ compared to $\mathrm{S} 1$ at $\mathrm{RH}$ of $57-61 \%$ at warmest temperature investigated $(267 \mathrm{~K})$ here. S3 and S4 typically took up water at 
intermediate RH values $53-56 \%$ and $49-53 \%$ respectively. This suggests that particles of S2 were more hydrophilic compared to the ones of S1. This may be due to the presence of a higher number of carboxylic groups on particles from the S2 than particles from the S1 samples (Wang et al., 2012). The mean onsets of water uptake by S2 samples increased by $\sim 4 \%$ from $\sim 44 \%$ to $48 \%$ within $24 \mathrm{~K}$ range, when $T_{p}$ decreased from $267 \mathrm{~K}$ to $242 \mathrm{~K}$.

Water uptake was observed at $258 \mathrm{~K}$ but no ice formation was observed before reaching water saturation for all four samples. Ice nucleation occurred via immersion freezing at $238 \mathrm{~K}$ and $248 \mathrm{~K}$. Overall, ice nucleation occurred below water saturation. Results showed no significant differences in $R H_{\text {ice }}$ between the samples in the immersion freezing mode.

\subsubsection{Identification of ice nuclei}

Out of four samples, we were able to identify a total of 20 ice nuclei from 2 samples (S2 and S4). Precisely, we identified 11 and 9 ice nuclei from S4 and S2 samples, but we were not able to identify ice nuclei from the other 2 samples (S1 and S3) in part due to the fact that the middle portion of the substrate of S1 was damaged after the ice nucleation experiment while taking it out from INC. Some of the ice nuclei identified nucleated multiple times, in those cases, one ice nucleation event was considered, but all the ice nuclei were counted. Table 6-4 explains the pattern of ice nucleation for the identified particles, meaning how many particles nucleated ice at different temperatures and if same particle nucleated multiple times as well as different temperatures. It is interesting to note that in some cases one particle nucleated multiple times at two different temperatures ( $238 \mathrm{~K}$ and $248 \mathrm{~K}$ ) in immersion mode. However, not a single particle that nucleated at $223 \mathrm{~K}$ by deposition mode was observed to initiate nucleation either at $238 \mathrm{~K}$ or $248 \mathrm{~K}$ by immersion freezing. 
Table 6-4: Pattern of ice nucleation for identified particles. In parenthesis is the number of nucleation events. $P$ represents particle.

\begin{tabular}{cccc}
\hline Sample & 223 K (dep. mode) & 238 K (imm. mode) & 248 K (imm. mode) \\
\hline S1 & All different (7) & 1 P 3 times (3) & 1 P same as $-35^{\circ} \mathrm{C} 2$ times (3) \\
\hline S2 & $\begin{array}{c}\text { 1 P } 4 \text { times; } \\
\text { 2 Ps 3 times (6) }\end{array}$ & All different (4) & 1 P same as $-35^{\circ} \mathrm{C} 2$ times (3) \\
\hline S3 & $\begin{array}{c}\text { 1 P } 5 \text { times; } \\
\text { 1 P times; }\end{array}$ & 1 P 2 times (4) & $\begin{array}{c}\text { 2 Ps same as }-35^{\circ} \mathrm{C} \\
\text { and } 1 \text { of them nucleated } 2 \text { times } \\
\text { (4) }\end{array}$ \\
\hline S4 2 times (7) & 2 Ps 2 times (5) & 1 P 2 times (5) & 1 P same as $-35^{\circ} \mathrm{C} \mathrm{(3)}$ \\
\hline
\end{tabular}

Examples of ice nuclei observed in S2 are exhibited in Figure 6-6. The diameter $\left(D_{\text {Aeq }}\right)$ of the ice nuclei were in the range of $0.84 \mu \mathrm{m}$ to $5.54 \mu \mathrm{m}$ with a mean of $2.88 \mu \mathrm{m}$. The mean aspect ratio and roundness of the ice nuclei were 1.36 and 0.67 respectively. Figure 6-7 shows some example of ice nuclei from sample $\mathrm{S} 4$. The $D_{A e q}$ of the ice nuclei of S4 sample were in the range of $1.94 \mu \mathrm{m}$ to $6.32 \mu \mathrm{m}$ with a mean of $3.52 \mu \mathrm{m}$. The mean aspect ratio and roundness of the ice nuclei observed at S4 were 1.56 and 0.56 respectively.

Particles were mostly composed of $\mathrm{Si}, \mathrm{Al}, \mathrm{O}$ and in some case, $\mathrm{Na}, \mathrm{S}$ and $\mathrm{K}, \mathrm{C}, \mathrm{Fe}, \mathrm{Cl}$. The elemental compositions are shown in Figure 6-6 and 6-7 for the particles identified as ice nuclei.
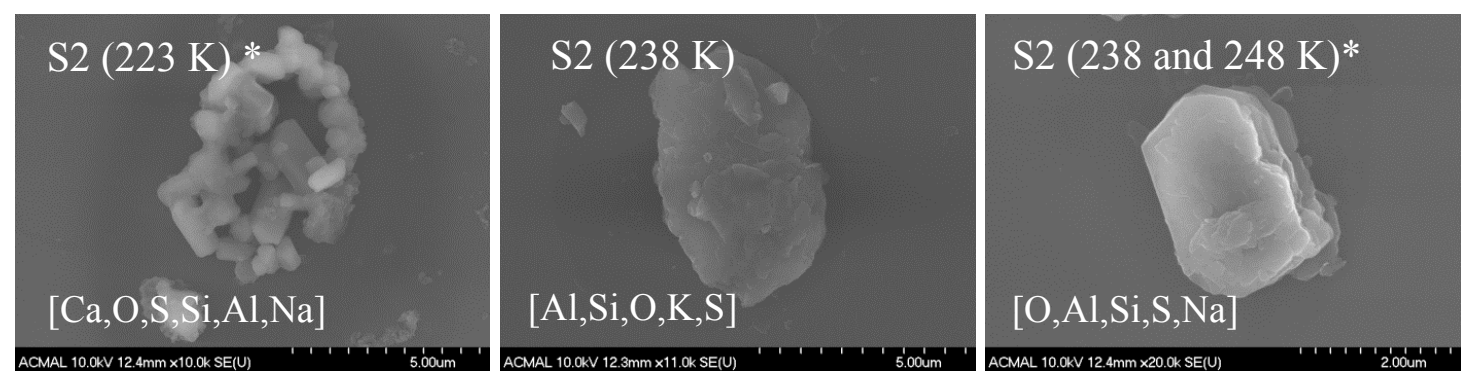

Figure 6-6: Examples of identified ice nuclei from S2 sample. The asterisk (*) indicates particles that nucleated more than once. 


\section{S4 $(238$ and $248 \mathrm{~K}) *$}

3

\&

$[\mathrm{O}, \mathrm{Si}, \mathrm{Al}, \mathrm{S}, \mathrm{Ca}, \mathrm{Mg}, \mathrm{Fe}, \mathrm{N}, \mathrm{C}$

[O, Si, Al,
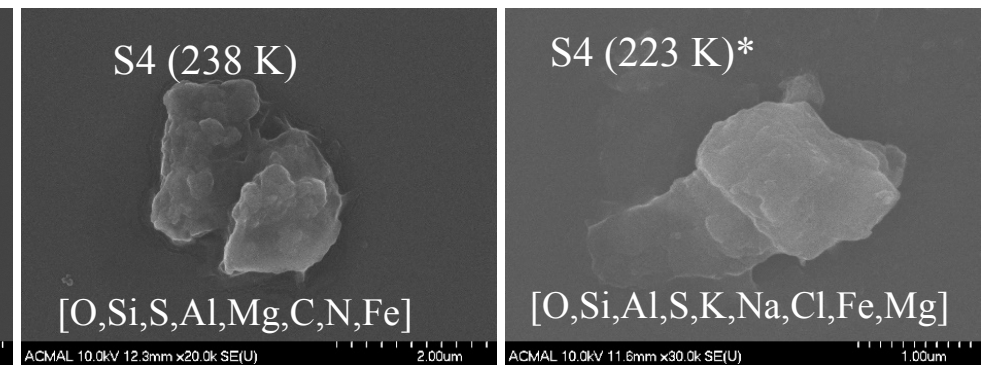

Figure 6-7: Examples of identified ice nuclei from S4 sample. The asterisk (*) indicates particles that nucleated more than once.

\subsection{Conclusions}

This study reports on the ice nucleation and water uptake by aged free tropospheric paticles and discusses their onset conditions in terms of relative humidity with respect to ice and tempeature. Almost all the particles in the investigated samples were internally mixed with both organic and inorganic material. Results suggested that aged particles sampled at Pico mountain were possibily more hydrophilic, and thus very efficient in water uptake at low relative humidity. Our results suggest that in the specific case of our sample conditions free tropospheric aged particles are efficient ice nuclei in deposition mode at $223 \mathrm{~K}$ and can serve as efficient ice nuclei for cirrus formation.

\subsection{Future work}

The results presented in this chapter are preliminary at this time. So far we investigated the elemental composition of a limited number of particles on the substrates collected and analyzed for IN and water uptake. We plan to investigate a significantly higher number of particles and to classify them based on their elemental composition. Detailted chemical analyses are needed to better understand the chemical characteristics of the particles such as quantification of inorganic and organic anions as well cations in terms of bulk properties from high volume quartz samples that were collected around same time. Future work will develop further this analysis, and include an in depth interpretation of the results and a discussion of their implications. 
For this study (2013 samples), particles were collected on silicon nitride coated discs. Future studies will be conducted at the PMO site by collecting samples on thin silicon nitride window, this will facilitate the TEM analysis aimed at identifying the ice nuclei. A significant advantage of using TEM instead of SEM is that TEM can provide valuable information about organic coatings and the particle internal structure. In addition, using silicon nitride windows will allow our colleagues at Lawrence Berkeley National Labolatory to investigate the samples using scanning transmission X-ray microscopy with near edge X-ray absorption fine structure spectroscopy (STXM/NEXAFS). STXM/NEXAFS can provide a spatial mapping of soot, organic carbon and inorganic components with chemical bonding information within inividual particles.

In this study, we investigated ice nucleation by particles in the size range of $0.5-2.0 \mu \mathrm{m}$ (aerodynamic diamter) for four temperatures (223, 238, 248 and $258 \mathrm{~K}$ ). Future study will also investigate ice nucleation by relatively smaller particles $(0.5-0.15 \mu \mathrm{m})$ and also at a larger number of temperatures (possibly 6 additional temperatures); this will allow to expand the investigation to conditions relevant to the upper troposphere and ice cloud formation.

\subsection{References}

Avramov, A. and Harrington, J. Y.: Influence of parameterized ice habit on simulated mixed phase Arctic clouds, Journal of Geophysical Research: Atmospheres, 115, D03205, 2010.

Cantrell, W. and Heymsfield, A.: Production of ice in tropospheric clouds - A review, Bulletin of the American Meteorological Society, 86, 795-807, 2005.

Chen, Y., Kreidenweis, S. M., McInnes, L. M., Rogers, D. C., and DeMott, P. J.: Single particle analyses of ice nucleating aerosols in the upper troposphere and lower stratosphere, Geophys. Res. Lett., 25, 1391-1394, 1998. 
Cziczo, D. J. and Froyd, K. D.: Sampling the composition of cirrus ice residuals, Atmospheric Research, 142, 15-31, 2014.

Cziczo, D. J., Froyd, K. D., Gallavardin, S. J., Moehler, O., Benz, S., Saathoff, H., and Murphy, D. M.: Deactivation of ice nuclei due to atmospherically relevant surface coatings, Environmental Research Letters, 4, 2009.

DeMott, P. J., Cziczo, D. J., Prenni, A. J., Murphy, D. M., Kreidenweis, S. M., Thomson, D. S., Borys, R., and Rogers, D. C.: Measurements of the concentration and composition of nuclei for cirrus formation, Proceedings of the National Academy of Sciences, 100, 14655-14660, 2003a.

DeMott, P. J., Sassen, K., Poellot, M. R., Baumgardner, D., Rogers, D. C., Brooks, S. D., Prenni, A. J., and Kreidenweis, S. M.: African dust aerosols as atmospheric ice nuclei, Geophys. Res. Lett., 30, 1732, 2003 b.

Dymarska, M., Murray, B. J., Sun, L., Eastwood, M. L., Knopf, D. A., and Bertram, A. K.: Deposition ice nucleation on soot at temperatures relevant for the lower troposphere, Journal of Geophysical Research: Atmospheres, 111, D04204, 2006.

Ebert, M., Worringen, A., Benker, N., Mertes, S., Weingartner, E., and Weinbruch, S.: Chemical composition and mixing-state of ice residuals sampled within mixed phase clouds, Atmos. Chem. Phys., 11, 2805-2816, 2011.

Froyd, K. D., Murphy, D. M., Lawson, P., Baumgardner, D., and Herman, R. L.: Aerosols that form subvisible cirrus at the tropical tropopause, Atmos. Chem. Phys., 10, 209-218, 2010.

George, I. J. and Abbatt, J. P. D.: Heterogeneous oxidation of atmospheric aerosol particles by gas-phase radicals, Nature Chemistry, 2, 713-722, 2010.

Kärcher, B. and Ström, J.: The roles of dynamical variability and aerosols in cirrus cloud formation, Atmos. Chem. Phys., 3, 823-838, 2003.

Knopf, D. A., Wang, B., Laskin, A., Moffet, R. C., and Gilles, M. K.: Heterogeneous nucleation of ice on anthropogenic organic particles collected in Mexico City, Geophysical Research Letters, 37, L11803, 2010. 
Koop, T., Luo, B., Tsias, A., and Peter, T.: Water activity as the determinant for homogeneous ice nucleation in aqueous solutions, Nature, 406, 611-614, 2000.

Lau, K. M. and $\mathrm{Wu}, \mathrm{H}$. T.: Warm rain processes over tropical oceans and climate implications, Geophysical Research Letters, 30, 2003.

Liu, Fan, S., Horowitz, L. W., and Levy, H.: Evaluation of factors controlling longrange transport of black carbon to the Arctic, Journal of Geophysical Research: Atmospheres, 116, D04307, 2011.

McFarquhar, G. M., Zhang, G., Poellot, M. R., Kok, G. L., McCoy, R., Tooman, T., Fridlind, A., and Heymsfield, A. J.: Ice properties of single-layer stratocumulus during the Mixed-Phase Arctic Cloud Experiment: 1. Observations, Journal of Geophysical Research: Atmospheres, 112, D24201, 2007.

Morrison, H., de Boer, G., Feingold, G., Harrington, J., Shupe, M. D., and Sulia, K.: Resilience of persistent Arctic mixed-phase clouds, Nature Geoscience, 5, 11$17,2012$.

Murphy, D. M. and Koop, T.: Review of the vapour pressures of ice and supercooled water for atmospheric applications, Quarterly Journal of the Royal Meteorological Society, 131, 1539-1565, 2005.

Murray, B. J.: Inhibition of ice crystallisation in highly viscous aqueous organic acid droplets, Atmos. Chem. Phys., 8, 5423-5433, 2008.

Petzold, A., Ström, J., Ohlsson, S., and Schröder, F. P.: Elemental composition and morphology of ice-crystal residual particles in cirrus clouds and contrails, Atmospheric Research, 49, 21-34, 1998.

Pitchford, M., Malm, W., Schichtel, B., Kumar, N., Lowenthal, D., and Hand, J.: Revised Algorithm for Estimating Light Extinction from IMPROVE Particle Speciation Data, Journal of the Air \& Waste Management Association, 57, 1326-1336, 2007.

Pratt, K. A., DeMott, P. J., French, J. R., Wang, Z., Westphal, D. L., Heymsfield, A. J., Twohy, C. H., Prenni, A. J., and Prather, K. A.: In situ detection of biological particles in cloud ice-crystals, Nature Geoscience, 2, 398-401, 2009. 
Pruppacher, H. R. and Klett, J. D.: Microphysics of clouds and precipitation, Kluwer Academic Publishers, Dordrecht, Netherlands, 1997.

Sassen, K.: Meteorology: Dusty ice clouds over Alaska, Nature, 434, 456-456, 2005.

Seinfeld, J. H. and Pandis, S. N.: Atmospheric chemistry and physics: from air pollution to climate change, John Wiley \& Sons, Hoboken, New Jersey, 2006.

Stohl, A., Forster, C., Frank, A., Seibert, P., and Wotawa, G.: Technical note: The Lagrangian particle dispersion model FLEXPART version 6.2, Atmos. Chem. Phys., 5, 2461-2474, 2005.

Twohy, C. H. and Poellot, M. R.: Chemical characteristics of ice residual nuclei in anvil cirrus clouds: evidence for homogeneous and heterogeneous ice formation, Atmos. Chem. Phys., 5, 2289-2297, 2005.

Vali, G.: NUCLEATION TERMINOLOGY, Bulletin of the American Meteorological Society, 66, 1426-1427, 1985.

Virtanen, A., Joutsensaari, J., Koop, T., Kannosto, J., Yli-Pirilä, P., Leskinen, J., Mäkelä, J. M., Holopainen, J. K., Pöschl, U., and Kulmala, M.: An amorphous solid state of biogenic secondary organic aerosol particles, Nature, 467, 824$827,2010$.

Wang, B. and Knopf, D. A.: Heterogeneous ice nucleation on particles composed of humic-like substances impacted by O3, Journal of Geophysical Research: Atmospheres, 116, D03205, 2011.

Wang, B., Laskin, A., Roedel, T., Gilles, M. K., Moffet, R. C., Tivanski, A. V., and Knopf, D. A.: Heterogeneous ice nucleation and water uptake by field-collected atmospheric particles below $273 \mathrm{~K}$, Journal of Geophysical Research: Atmospheres, 117, D00V19, 2012.

Wang, S.-H., Tsay, S.-C., Lin, N.-H., Hsu, N. C., Bell, S. W., Li, C., Ji, Q., Jeong, M.J., Hansell, R. A., Welton, E. J., Holben, B. N., Sheu, G.-R., Chu, Y.-C., Chang, S.-C., Liu, J.-J., and Chiang, W.-L.: First detailed observations of long-range transported dust over the northern South China Sea, Atmospheric Environment, 45, 4804-4808, 2011. 


\section{Appendix}

\section{A.1 Permission for Chapter 2}

Permission to use copyrighted material from the Environmental Science \& Technology journal.

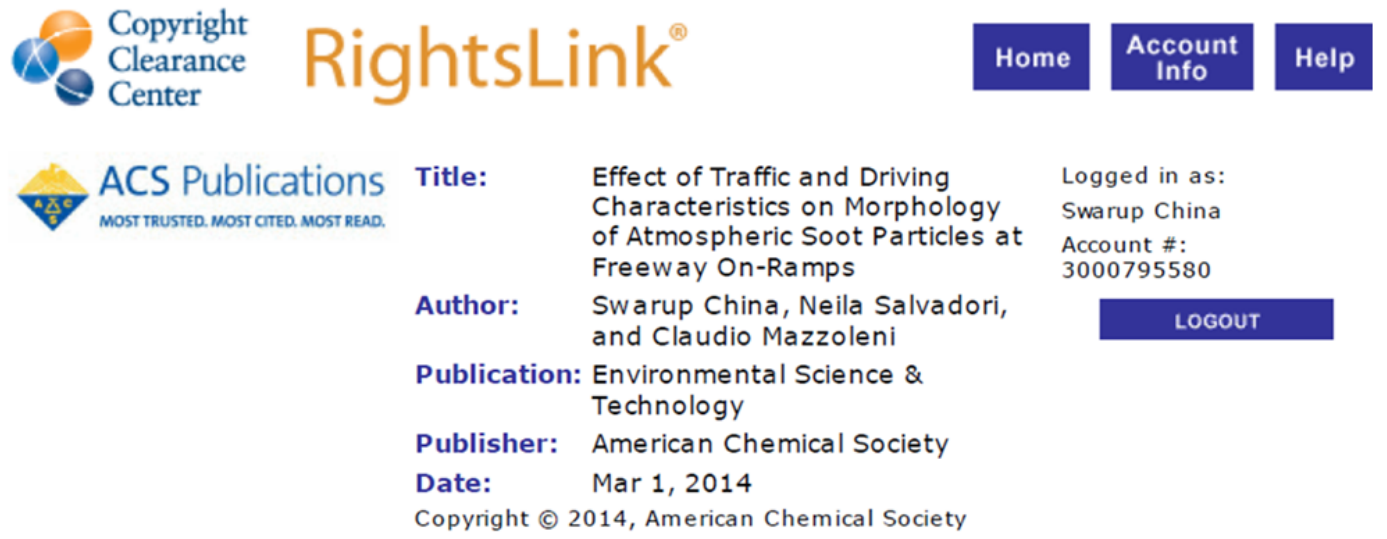

PERMISSION/LICENSE IS GRANTED FOR YOUR ORDER AT NO CHARGE

This type of permission/license, instead of the standard Terms \& Conditions, is sent to you because no fee is being charged for your order. Please note the following:

- Permission is granted for your request in both print and electronic formats, and translations.

- If figures and/or tables were requested, they may be adapted or used in part.

- Please print this page for your records and send a copy of it to your publisher/graduate school.

- Appropriate credit for the requested material should be given as follows: "Reprinted (adapted) with permission from (COMPLETE REFERENCE CITATION). Copyright (YEAR) American Chemical Society." Insert appropriate information in place of the capitalized words.

- One-time permission is granted only for the use specified in your request. No additional uses are granted (such as derivative works or other editions). For any other uses, please submit a new request. 


\section{A.2 Permission for Chapter 3}

Permission to use copyrighted material from the Nature Communications journal.

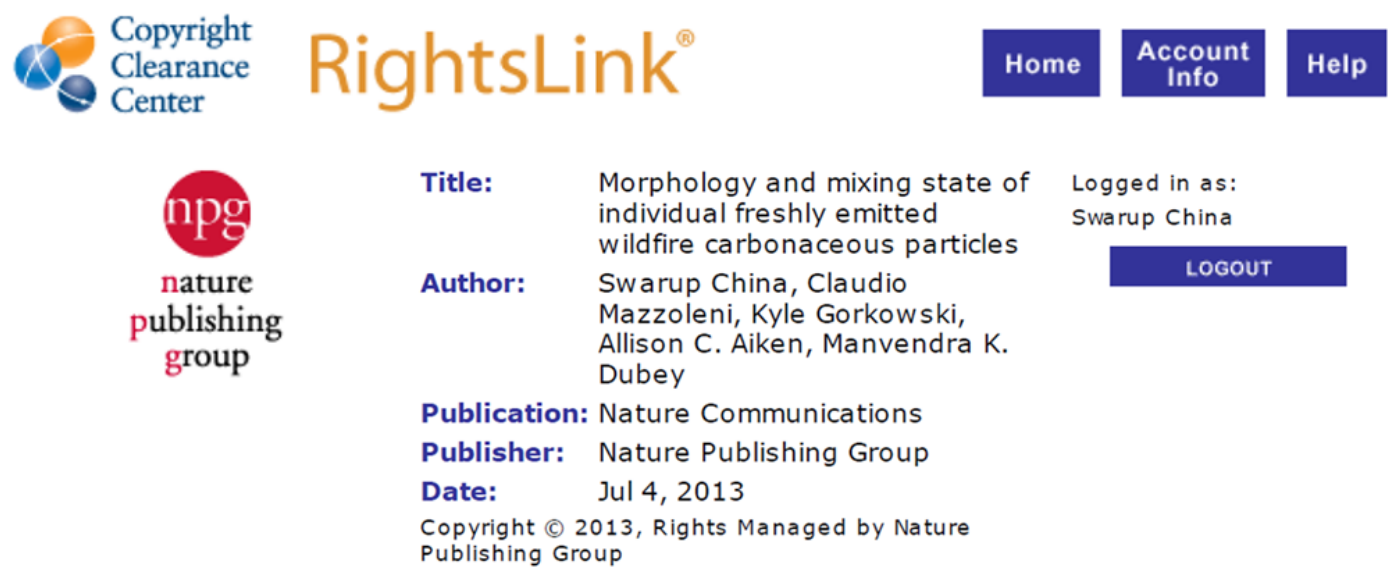

\section{Creative Commons}

The request you have made is considered to be non-commercial/educational. As the article you have requested has been distributed under a Creative Commons license (AttributionNoncommercial 2.5), you may reuse this material for non-commercial/educational purposes without obtaining additional permission from Nature Publishing Group, providing that the author and the original source of publication are fully acknowledged.

For full terms and conditions of the Creative Commons license, please see the attached link http://creativecommons.org/licenses/by-nc/2.5 